\title{
Food security and food production systems
}

Porter, John Roy; Xie, Liyong; Challinor, Andrew J. ; Cochrane, Kevern; Howden, S. Mark ; lqbal, Muhammed Mohsin; Lobell, David B.; Travasso, Maria Isabel

Published in:

Climate Change 2014

Publication date:

2014

Document version

Early version, also known as pre-print

Citation for published version (APA):

Porter, J. R., Xie, L., Challinor, A. J., Cochrane, K., Howden, S. M., Iqbal, M. M., Lobell, D. B., \& Travasso, M. I. (2014). Food security and food production systems. In Climate Change 2014: Impacts, Adaptation, and Vulnerability (pp. 485-533). Cambridge University Press. 


\section{Food Security and Food Production Systems}

Coordinating Lead Authors:

John R. Porter (Denmark/UK), Liyong Xie (China)

Lead Authors:

Andrew J. Challinor (UK), Kevern Cochrane (South Africa), S. Mark Howden (Australia), Muhammad Mohsin Iqbal (Pakistan), David B. Lobell (USA), Maria Isabel Travasso (Argentina)

Contributing Authors:

Netra Chhetri (USA/Nepal), Karen Garrett (USA), John Ingram (UK), Leslie Lipper (Italy), Nancy McCarthy (USA), Justin McGrath (USA), Daniel Smith (UK), Philip Thornton (UK), James Watson (UK), Lewis Ziska (USA)

Review Editors:

Pramod Aggarwal (India), Kaija Hakala (Finland)

Volunteer Chapter Scientist:

Joanne Jordan (UK)

This chapter should be cited as:

Porter, J.R., L. Xie, A.J. Challinor, K. Cochrane, S.M. Howden, M.M. Iqbal, D.B. Lobell, and M.I. Travasso, 2014: Food security and food production systems. In: Climate Change 2014: Impacts, Adaptation, and Vulnerability. Part A: Global and Sectoral Aspects. Contribution of Working Group II to the Fifth Assessment Report of the Intergovernmental Panel on Climate Change [Field, C.B., V.R. Barros, D.J. Dokken, K.J. Mach, M.D. Mastrandrea, T.E. Bilir, M. Chatterjee, K.L. Ebi, Y.O. Estrada, R.C. Genova, B. Girma, E.S. Kissel, A.N. Levy, S. MacCracken, P.R. Mastrandrea, and L.L. White (eds.)]. Cambridge University Press, Cambridge, United Kingdom and New York, NY, USA, pp. 485-533. 


\section{Table of Contents}

Executive Summary

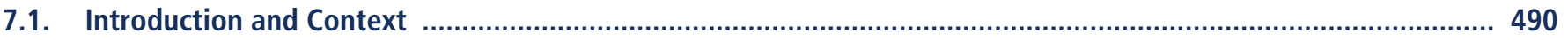

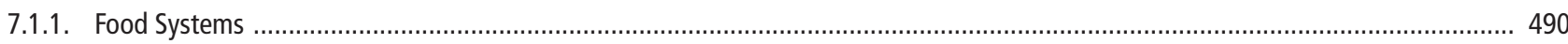

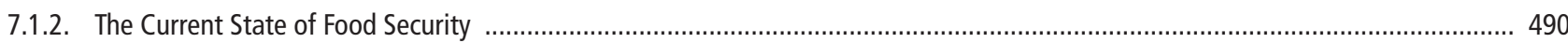

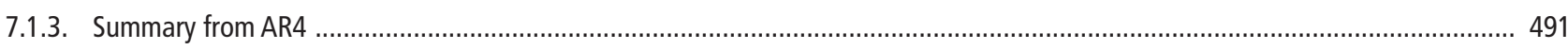

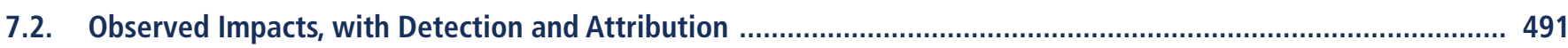

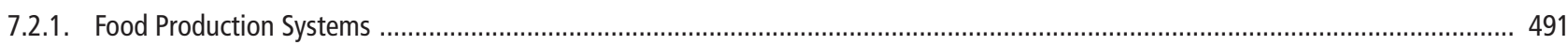

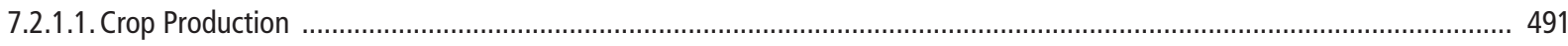

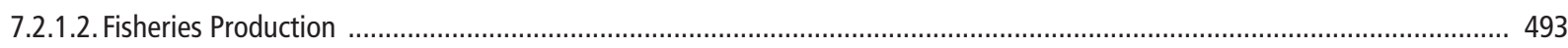

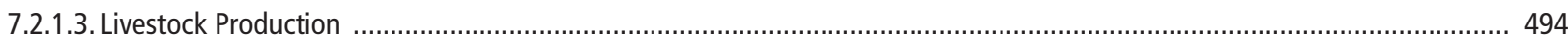

7.2.2. Food Security and Food Prices ............................................................................................................................... 494

\subsection{Assessing Impacts, Vulnerabilities, and Risks}

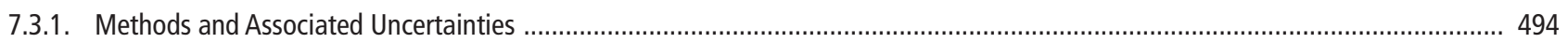

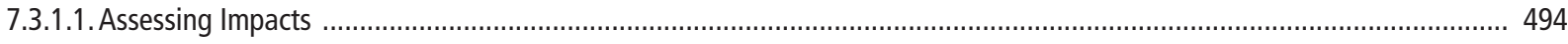

7.3.1.2. Treatment of Adaptation in Impacts Studies ............................................................................................. 497

7.3.2. Sensitivity of Food Production to Weather and Climate ................................................................................................. 497

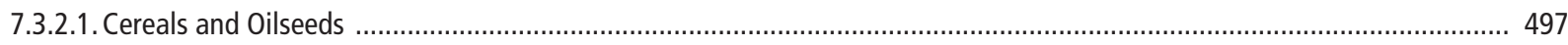

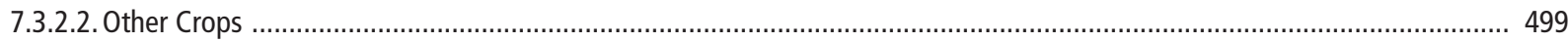

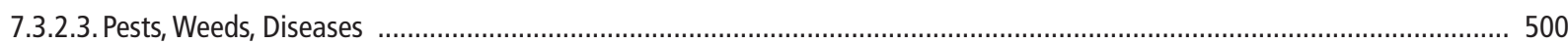

7.3.2.4. Fisheries and Aquaculture ................................................................................................................... 500

7.3.2.5. Food and Fodder Quality and Human Health .................................................................................................... 501

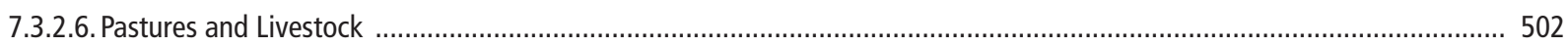

7.3.3. Sensitivity of Food Security to Weather and Climate …................................................................................................. 502

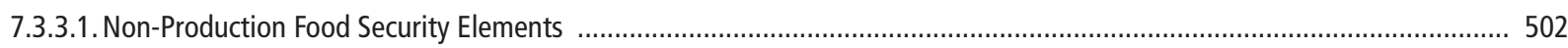

7.3.3.2. Accessibility, Utilization, and Stability .............................................................................................................. 502

7.3.4. Sensitivity of Land Use to Weather and Climate ..................................................................................................... 504

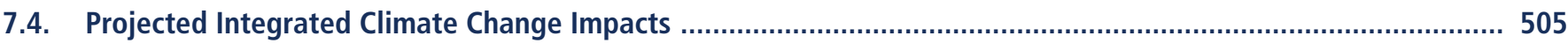

7.4.1. Projected Impacts on Cropping Systems .............................................................................................................. 505

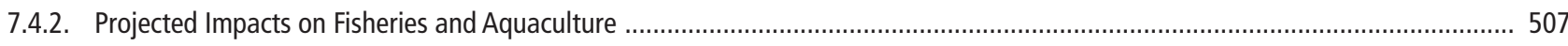

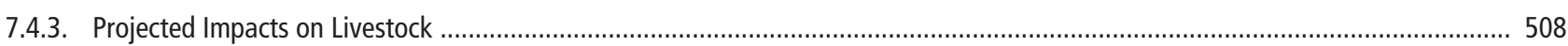

Box 7-1. Projected Impacts for Crops and Livestock in Global Regions and Sub-Regions under Future Scenarios ................. 509

7.4.4. Projected Impacts on Food Prices and Food Security ……….......................................................................................... 512 
7.5. Adaptation and Managing Risks in Agriculture and Other Food System Activities ........................................ 513

7.5.1. Adaptation Needs and Gaps Based on Assessed Impacts and Vulnerabilities .................................................................... 513

7.5.1.1. Methods of Treating Impacts in Adaptation Studies_-Incremental to Transformational .............................................. 513

7.5.1.2. Practical Regional Experiences of Adaptation, Including Lessons Learned ................................................................... 518

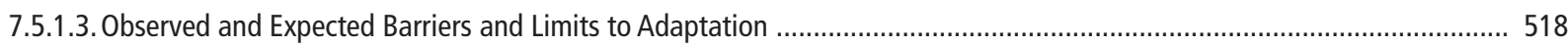

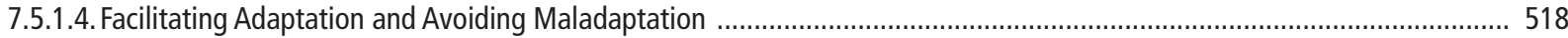

7.5.2. Food System Case Studies of Adaptation—Examples of Successful and Unsuccessful Adaptation ........................................... 518

7.5.3. Key Findings from Adaptations_Confidence Limits, Agreement, and Level of Evidence ...................................................... 519

7.6. Research and Data Gaps_Food Security as a Cross-Sectoral Activity ...................................................... 520

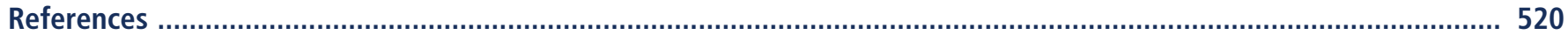

\section{Frequently Asked Questions}

7.1: $\quad$ What factors determine food security and does low food production necessarily lead to food insecurity? ................................ 494

7.2: How could climate change interact with change in fish stocks and ocean acidification? .......................................................... 507

7.3: How could adaptation actions enhance food security and nutrition? ............................................................................... 514 


\section{Executive Summary}

The effects of climate change on crop and terrestrial food production are evident in several regions of the world (high confidence). Negative impacts of climate trends have been more common than positive ones. \{Figures 7-2, 7-7\} Positive trends are evident in some highlatitude regions (high confidence). Since AR4, there have been several periods of rapid food and cereal price increases following climate extremes in key producing regions, indicating a sensitivity of current markets to climate extremes, among other factors. \{Figure 7-3, Table 18-3\} Several of these climate extremes were made more likely as the result of anthropogenic emissions (medium confidence). \{Table 18-3\}

Climate trends are affecting the abundance and distribution of harvested aquatic species, both freshwater and marine, and aquaculture production systems in different parts of the world. $\{7.2 .1 .2,7.3 .2 .4,7.4 .2\}$ These are expected to continue with negative impacts on nutrition and food security for especially vulnerable people, particularly in some tropical developing countries $\{7.3 .3 .2\}$, but with benefits in other regions that become more favorable for aquatic food production (medium confidence). \{7.5.1.1.2\}

Studies have documented a large negative sensitivity of crop yields to extreme daytime temperatures around $30^{\circ} \mathrm{C}$. \{WGII AR4 Chapter 5, 7.3.2.1\} These sensitivities have been identified for several crops and regions and exist throughout the growing season (high confidence). Several studies report that temperature trends are important for determining both past and future impacts of climate change on crop yields at sub-continental to global scales (medium confidence). $\{7.3 .2$, Box 7-1\} At scales of individual countries or smaller, precipitation projections remain important but uncertain factors for assessing future impacts (high confidence). $\{7.3 .2$, Box 7-1\}

Evidence since AR4 confirms the stimulatory effects of carbon dioxide $\left(\mathrm{CO}_{2}\right)$ in most cases and the damaging effects of elevated tropospheric ozone $\left(\mathrm{O}_{3}\right)$ on crop yields (high confidence). Experimental and modeling evidence indicates that interactions between $\mathrm{CO}_{2}$ and $\mathrm{O}_{3}$, mean temperature and extremes, water, and nitrogen are nonlinear and difficult to predict (medium confidence). \{7.3.2.1, Figure 7-2\}

Changes in climate and $\mathrm{CO}_{2}$ concentration will enhance the distribution and increase the competitiveness of agronomically important and invasive weeds (medium confidence). Rising $\mathrm{CO}_{2}$ may reduce the effectiveness of some herbicides (low confidence). The effects of climate change on disease pressure on food crops are uncertain, with evidence pointing to changed geographical ranges of pests and diseases but less certain changes in disease intensity (low confidence). \{7.3.2.3\}

All aspects of food security are potentially affected by climate change, including food access, utilization, and price stability (high confidence). \{7.3.3.1, Table 7-1\} There remains limited quantitative understanding of how non-production elements of food security will be affected, and of the adaptation possibilities in these domains. Nutritional quality of food and fodder, including protein and micronutrients, is negatively affected by elevated $\mathrm{CO}_{2}$, but these effects may be counteracted by effects of other aspects of climate change (medium confidence). $\{7.3 .2 .5\}$

For the major crops (wheat, rice, and maize) in tropical and temperate regions, climate change without adaptation will negatively impact production for local temperature increases of $2^{\circ} \mathrm{C}$ or more above late-20th-century levels, although individual locations may benefit (medium confidence). \{7.4, Figure 7-4\} Projected impacts vary across crops and regions and adaptation scenarios, with about $10 \%$ of projections for the period 2030-2049 showing yield gains of more than $10 \%$ and about $10 \%$ of projections showing yield losses of more than $25 \%$, compared to the late 20th century. \{Figure 7-5\} After 2050, the risk of more severe impacts increases. \{Figure 7-5\} Regional Chapters 22 (Africa), 23 (Europe), 24 (Asia), 27 (Central and South America), and Box 7-1 show crop production to be consistently and negatively affected by climate change in the future in low-latitude countries, while climate change may have positive or negative effects in northern latitudes (high confidence). Climate change will increase progressively the inter-annual variability of crop yields in many regions (medium confidence). \{Figure 7-6\} 
On average, agronomic adaptation improves yields by the equivalent of $\sim 15-18 \%$ of current yields $\{$ Figure $7-8$, Table $7-2\}$, but the effectiveness of adaptation is highly variable (medium confidence) ranging from potential dis-benefits to negligible to very substantial (medium confidence). \{7.5.1.1.1\} Projected benefits of adaptation are greater for crops in temperate, rather than tropical, regions (medium confidence) $\{7.5 .1 .1 .1$, Figures 7-4, 7-7\}, with wheat- and rice-based systems more adaptable than those of maize (low confidence). \{Figure 7-4\} Some adaptation options are more effective than others (medium confidence). \{Table 7-2\}

Global temperature increases of $\sim 4^{\circ} \mathrm{C}$ or more above late-20th-century levels, combined with increasing food demand, would pose large risks to food security globally and regionally (high confidence). Risks to food security are generally greater in lowlatitude areas. \{Box 7-1, Table 7-3, Figures 7-4, 7-5, 7-7\}

Changes in temperature and precipitation, without considering effects of $\mathrm{CO}_{2}$, will contribute to increased global food prices by 2050, with estimated increases ranging from 3 to $84 \%$ (medium confidence). Projections that include the effects of $\mathrm{CO}_{2}$ changes, but ignore $\mathrm{O}_{3}$ and pest and disease impacts, indicate that global price increases are about as likely as not, with a range of projected impacts from $-30 \%$ to $+45 \%$ by 2050 . $\{7.4 .4\}$

Adaptation in fisheries, aquaculture, and livestock production will potentially be strengthened by adoption of multi-level adaptive strategies to minimize negative impacts. Key adaptations for fisheries and aquaculture include policy and management to maintain ecosystems in a state that is resilient to change, enabling occupational flexibility, and development of early warning systems for extreme events (medium confidence). \{7.5.1.1.2\} Adaptations for livestock systems center on adjusting management to the available resources, using breeds better adapted to the prevailing climate and removing barriers to adaptation such as improving credit access (medium confidence). $\{7.5 .1 .1 .3\}$

A range of potential adaptation options exist across all food system activities, not just in food production, but benefits from potential innovations in food processing, packaging, transport, storage, and trade are insufficiently researched. \{7.1, 7.5, 7.6, Figures 7-1, 7-7, 7-8\} More observational evidence is needed on the effectiveness of adaptations at all levels of the food system. $\{7.6\}$ 


\subsection{Introduction and Context}

Many definitions of food security exist, and these have been the subject of much debate. As early as 1992, Maxwell and Smith (1992) reviewed more than 180 items discussing concepts and definitions, and more definitions have been formulated since (DEFRA, 2006). Whereas many earlier definitions centered on food production, more recent definitions highlight access to food, in keeping with the 1996 World Food Summit definition (FAO, 1996) that food security is met when "all people, at all times, have physical and economic access to sufficient, safe, and nutritious food to meet their dietary needs and food preferences for an active and healthy life." Worldwide attention on food access was given impetus by the food "price spike" in 2007-2008, triggered by a complex set of long- and short-term factors (FAO, 2009b; von Braun and Torero, 2009). FAO concluded, "provisional estimates show that, in 2007, 75 million more people were added to the total number of undernourished relative to 2003-05" (FAO, 2008); this is arguably a low-end estimate (Headey and Fan, 2010). More than enough food is currently produced per capita to feed the global population, yet about 870 million people remained hungry in the period from 2010 to 2012 (FAO et al., 2012). The questions for this chapter are how far climate and its change affect current food production systems and food security and the extent to which they will do so in the future (Figure 7-1).

\subsubsection{Food Systems}

A food system is all processes and infrastructure involved in satisfying a population's food security, that is, the gathering/catching, growing, harvesting (production aspects), storing, processing, packaging, transporting, marketing, and consuming of food, and disposing of food waste (non-production aspects). It includes food security outcomes of these activities related to availability and utilization of, and access to, food as well as other socioeconomic and environmental factors (Ericksen, 2008; Ericksen et al., 2010; Ingram, 2011). This chapter synthesizes and evaluates evidence for the impacts of climate on both production and non-production elements and their adaptation to climate change (Figure 7-1).
The impacts of climate change on food systems are expected to be widespread, complex, geographically and temporally variable, and profoundly influenced by socioeconomic conditions (Vermeulen et al., 2012). Changes in food system drivers give rise to changes in food security outcomes (medium evidence, high agreement), but often researchers consider only the impacts on the food production element of food security (Figure 7-1). Efforts to increase food production are nevertheless increasingly important as $60 \%$ more food will be needed by 2050 given current food consumption trends and assuming no significant reduction in food waste (FAO et al., 2012).

\subsubsection{The Current State of Food Security}

Most people on the planet currently have enough food to eat. The vast majority of undernourished people live in developing countries (medium evidence, medium agreement), when estimated based on aggregate national calorie availability and assumptions about food distribution and nutritional requirements. More precise estimates are possible with detailed household surveys, which often show a higher incidence of food insecurity than estimated by FAO. Using food energy deficit as the measure of food insecurity, Smith et al. (2006) estimated average rates of food insecurity of $59 \%$ for 12 African countries, compared to a $39 \%$ estimate from FAO for the same period (Smith et al., 2006). While there is medium evidence, medium agreement on absolute numbers, there is robust evidence, high agreement that sub-Saharan Africa has the highest proportion of food-insecure people, with an estimated regional average of $26.8 \%$ of the population undernourished in 2010-2012, and where rates higher than $50 \%$ can be found (FAO et al., 2012). The largest numbers of food-insecure persons are found in South Asia, which has roughly 300 million undernourished (FAO et al., 2012). In addition to common measures of calorie availability, food security can be broadened to include nutritional aspects based on the diversity of diet including not only staple foods but also vegetables, fruits, meat, milk, eggs, and fortified foods (FAO, 2011). There is robust evidence and high agreement that lack of essential micronutrients such as zinc and vitamin A affect hundreds of millions of additional people (Lopez et al., 2006; PinstrupAndersen, 2009).
Drivers

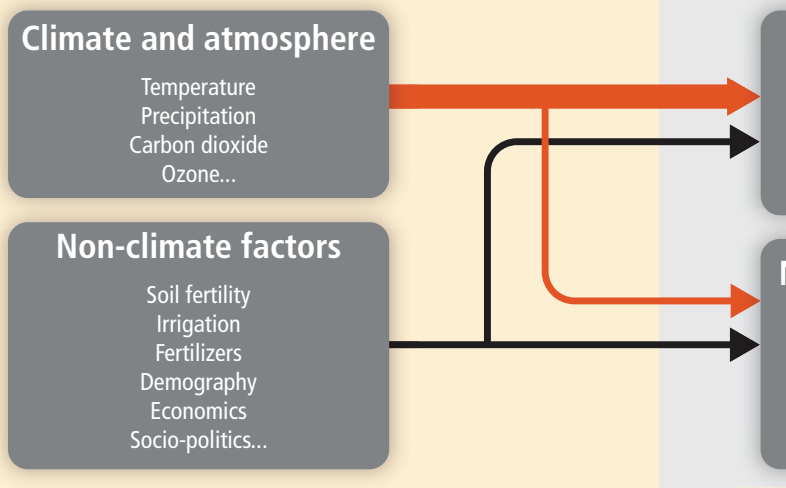

Responses

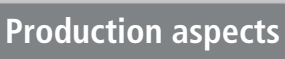

Crops

Livestock

Fish...

Food security

Food systems adapted to

ensure availability, access, utilization, and stability

Figure 7-1 | Main issues of the chapter. Drivers are divided into climate and non-climate elements, affecting production and non-production elements of food systems, thereafter combining to provide food security. The thickness of the red lines is indicative of the relative availability of refereed publications on the two elements. 
Food insecurity is closely tied to poverty; globally about 25 to $30 \%$ of poor people, measured using a US\$1 to US\$2 per day standard, live in urban areas (Ravallion et al., 2007; IFAD, 2010). Most poor countries have a larger fraction of people living in rural areas and poverty rates tend to be higher in rural settings (by slight margins in South Asia and Africa, and by large margins in China). In Latin America, poverty is more skewed to urban areas, with roughly two-thirds of the poor in urban areas, a proportion that has been growing in the past decade (medium evidence, medium agreement). Rural areas will continue to have the majority of poor people for at least the next few decades, even as population growth is higher in urban areas (medium evidence, medium agreement) (Ravallion et al., 2007; IFAD, 2010).

The effects of price volatility are distinct from the effects of gradual price rises, for two main reasons. First, rapid shifts make it difficult for the poor to adjust their activities to favor producing higher value items. Second, increased volatility leads to greater uncertainty about the future and can dampen willingness to invest scarce resources into productivity enhancing assets, such as fertilizer purchases in the case of farmers or rural infrastructure in the case of governments. Several factors have been found to contribute to increased price volatility: poorly articulated local markets, increased incidence of adverse weather events, and greater reliance on production areas with high exposure to such risks, biofuel mandates, and increased links between energy and agricultural markets (World Bank, 2012). Vulnerability to food price volatility depends on the degree to which households and countries are net food purchasers; the level of integration into global, regional, and local markets; and their relative degree of volatility, which in turn is conditional on their respective governance (robust evidence, medium agreement) (HLPE, 2011; World Bank, 2012).

\subsubsection{Summary from AR4}

Food systems as integrated drivers, activities, and outcomes for food security did not feature strongly in AR4. Summary points from AR4 were that, with medium confidence, in mid- to high-latitude regions moderate warming will raise crop and pasture yields. Sight warming will decrease yields in low-latitude regions. Extreme climate and weather events will, with high confidence, reduce food production. The benefits of adaptation vary with crops and across regions and temperature changes; however, on average, they provide approximately a $10 \%$ yield benefit when compared with yields when no adaptation is used (WGII AR4 Section 5.5.1). Adaptive capacity is projected to be exceeded in low-latitude areas with temperature increases of more than $3^{\circ} \mathrm{C}$. Local extinctions of particular fish species are expected at the edges of their ranges (high confidence) and have serious negative impacts on fisheries (medium confidence).

\subsection{Observed Impacts, with Detection and Attribution}

\subsubsection{Food Production Systems}

Formal detection of impacts requires that observed changes be compared to a clearly specified baseline that characterizes behavior in the absence of climate change (Chapter 18). For food production systems, the number and strength of non-climate drivers, such as cultivar improvement or increased use of irrigation and fertilizers in the case of crops, make defining a clear baseline extremely difficult. Most non-climatic factors are not very well characterized in terms of spatial and temporal distributions, and the relationships between these factors and specific outcomes of interest (e.g., crop or fish production) are often difficult to quantify.

Attribution of any observed changes to climate trends are further complicated by the fact that models linking climate and agriculture must, implicitly or explicitly, make assumptions about farmer behavior. In most cases, models implicitly assume that farming practices or technologies did not adjust in response to climate over the period of interest. This assumption can be defended in some cases based on ancillary data on practices, or based on small differences between using models with and without adaptation (Schlenker and Roberts, 2009). However, in some instances the relationship between climate conditions and crop production has been shown to change over time because of management changes, such as introduction of irrigation or changes in crop varieties (Zhang et al, 2008; Liu et al., 2009; Sakurai et al., 2012).

\subsubsection{Crop Production}

Many studies of cropping systems have estimated impacts of observed climate changes on crop yields over the past half century, although they typically do not attempt to compare observed yields to a counterfactual baseline, and thus are not formal detection and attribution studies. These studies employ both mechanistic and statistical approaches (Section 7.3.1), and estimate impacts by running the models with observed historical climate and then computing trends in modeled outcomes. Based on these studies, there is medium confidence that climate trends have negatively affected wheat and maize production for many regions (Figure 7-2) (medium evidence, high agreement). Because many of these regional studies are for major producers, and a global study (Lobell et al., 2011a) estimated negative impacts on these crops, there is also medium confidence for negative impacts on global aggregate production of wheat and maize. Effects on rice and soybean yields have been small in major production regions and globally (Figure 7-2) (medium evidence, high agreement). There is also high confidence that warming has benefitted crop production in some high-latitude regions, such as northeast China or the UK (Jaggard et al., 2007; Chen et al., 2010; Supit et al., 2010; Gregory and Marshall, 2012).

More difficult to quantify with models is the impact of very extreme events on cropping systems, as by definition these occur very rarely and models cannot be adequately calibrated and tested. Table 18-3 lists some notable extremes over the past decade, and the impacts on cropping systems. Despite the difficulty of modeling the impacts of these events, they clearly have sizable impacts (Sanchez et al. 2014) that are apparent immediately or soon after the event, and therefore not easily confused with effects of more slowly moving factors. For a subset of these events, climate research has evaluated whether anthropogenic activity has increased or decreased their likelihood (Table 18-3).

A sizable fraction of crop modeling studies were concerned with production for individual sites or provinces, spatial scales below which 
(a)

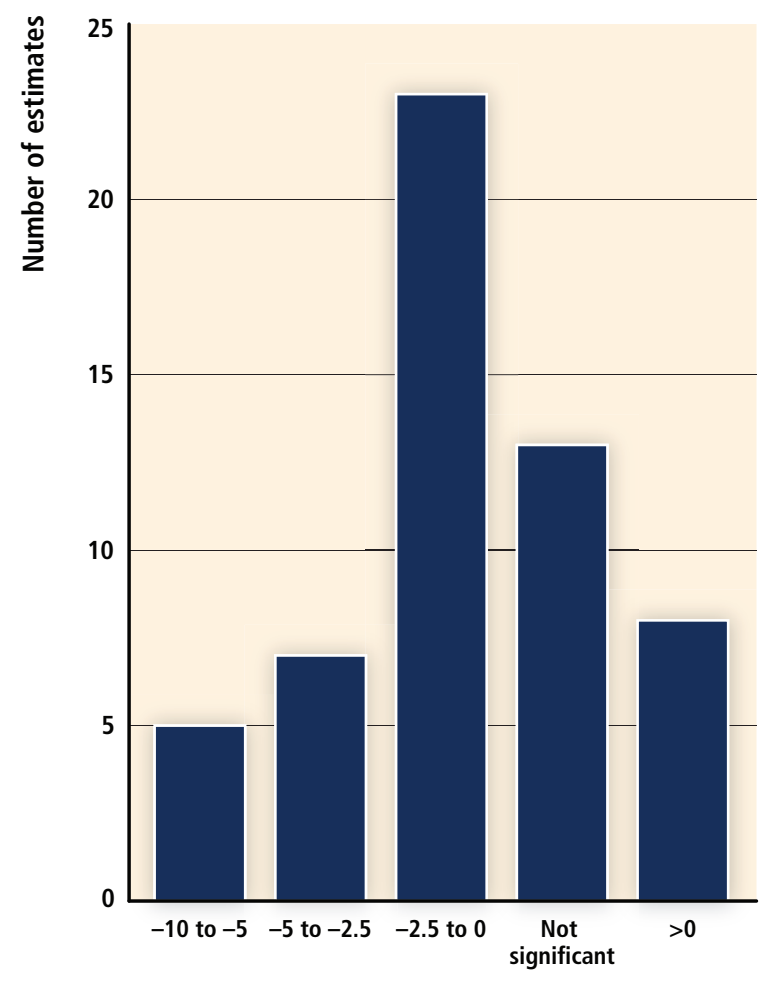

Yield impact of climate trend (\% per decade) (b)

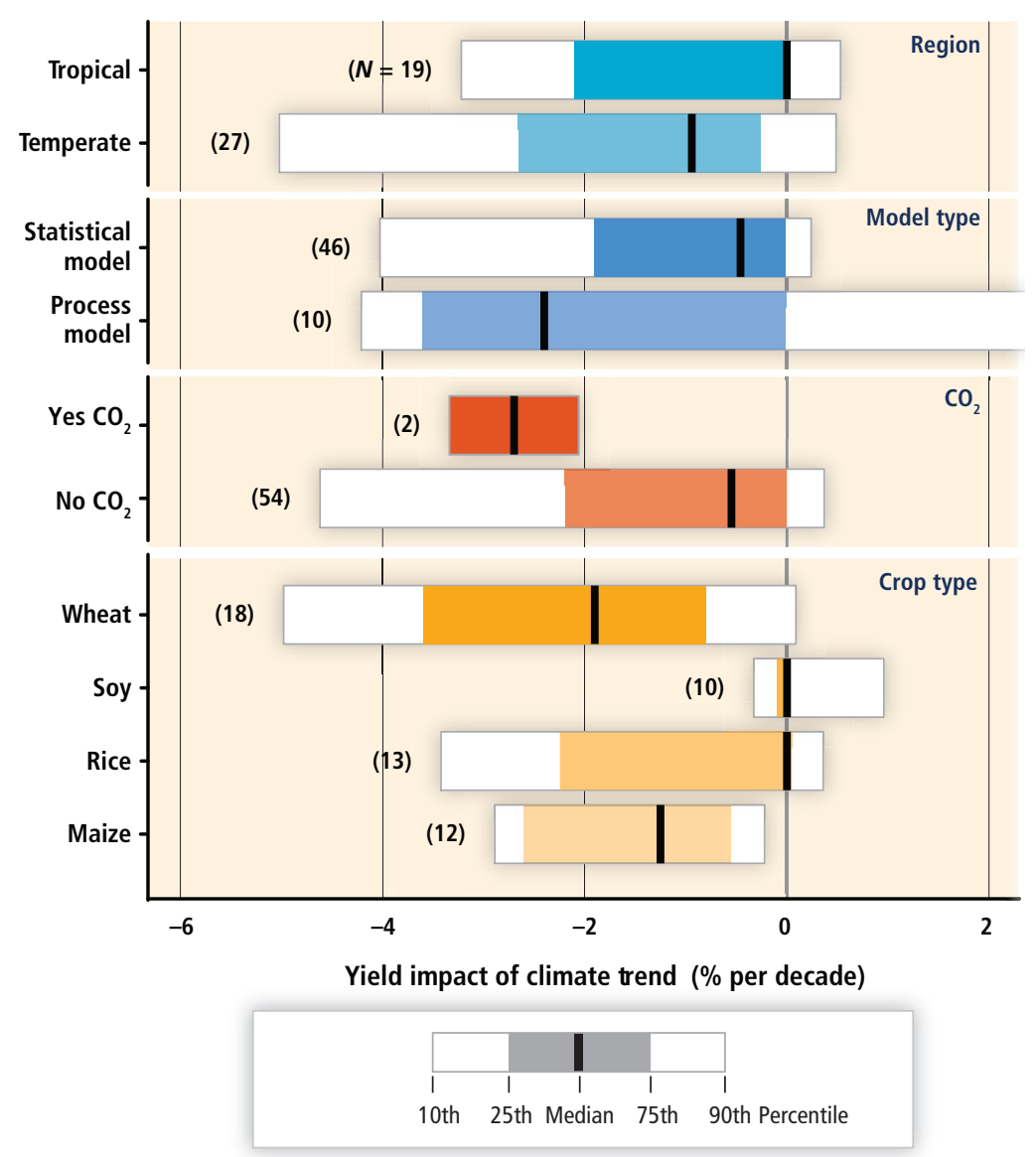

Figure 7-2 | Summary of estimates of the impact of recent climate trends on yields for four major crops. Studies were taken from the peer-reviewed literature and used different methods (i.e., physiological process-based crop models or statistical models), spatial scales (stations, provinces, countries, or global), and time periods (median length of 29 years). Some included effects of positive carbon dioxide $\left(\mathrm{CO}_{2}\right)$ trends (Section 7.3.2.1.2) but most did not. (a) Number of estimates with different level of impact (\% yield per decade). (b) Boxplot of estimates separated by temperate vs. tropical regions, modeling approach (process-based vs. statistical), whether $\mathrm{CO}_{2}$ effects were included, and crop. Boxplots indicate the median (vertical line), 25th to 75th percentiles (colored box), and 10th to 90th percentiles (white box) for estimated impacts in each category, and numbers in parentheses indicate the number of estimates. Studies were for China (Tao et al., 2006, 2008a, 2012; Wang et al., 2008; You et al., 2009; Chen et al., 2010), India (Pathak et al., 2003; Auffhammer et al., 2012), USA (Kucharik and Serbin, 2008), Mexico (Lobell et al., 2005), France (Brisson et al., 2010; Licker et al., 2013), Scotland (Gregory and Marshall, 2012), Australia (Ludwig et al., 2009), Russia (Licker et al., 2013), and some studies for multiple countries or global aggregates (Lobell and Field, 2007; Welch et al., 2010; Lobell et al., 2011a). Values from all studies were converted to percentage yield change per decade. Each study received equal weighting as insufficient information was available to judge the uncertainties of each estimate.

the changes in climate conditions are attributable to anthropogenic activity (WGI AR5 Chapter 10). Similarly, most crop studies have focused on the past few decades, a time scale shorter than most attribution studies for climate. However, some focused on continental or global scales (Lobell and Field, 2007; You et al., 2009; Lobell et al., 2011a), at which trends in several climatic variables, including average summer temperatures, have been attributed to anthropogenic activity. In particular, global temperature trends over the past few decades are attributable to human activity (WGI AR5 Chapter 10), and the studies discussed above indicate that this warming has had significant impacts on global yield trends of some crops.

In general, little work in food production or food security research has focused on determining whether climate trends affecting agriculture can be attributed to anthropogenic influence on the climate system. However, as the field of climate detection and attribution proceeds to finer spatial and temporal scales, and as agricultural modeling studies expand to broader scales, there should be many opportunities to link climate and crop studies in the next few years. Importantly, climate attribution is increasingly documented not only for measures of average conditions over growing seasons, but also for extremes. For instance, Min et al. (2011) attributed changes in rainfall extremes for 1951-1999 to anthropogenic activity, and these are widely acknowledged as important to cropping systems (Rosenzweig et al., 2002). Frost damage is an important constraint on crop growth in many crops, including for various high-value crops, and significant reductions in frost occurrence since 1961 have been observed and attributed to greenhouse gas (GHG) emissions in nearly every region of the world (Zwiers et al., 2011; IPCC, 2012).

Increased frequency of unusually hot nights since 1961 are also attributable to human activity in most regions (WGI AR5 Chapter 10). These events are damaging to most crops, an effect that has been observed most commonly for rice yields (Peng et al., 2004; Wassmann 
et al., 2009; Welch et al., 2010) as well as rice quality (Okada et al., 2011). Extremely high daytime temperatures are also damaging and occasionally lethal to crops (Porter and Gawith, 1999; Schlenker and Roberts, 2009), and trends at the global scale in annual maximum daytime temperatures since 1961 have been attributed to GHG emissions (Zwiers et al., 2011). At regional and local scales, however, trends in daytime maximum are harder to attribute to GHG emissions because of the prominent role of soil moisture and clouds in driving these trends (Christidis et al., 2005; Zwiers et al., 2011).

In addition to effects of changes in climatic conditions, there are clear effects of changes in atmospheric composition on crops. Increase of atmospheric $\mathrm{CO}_{2}$ by greater than $100 \mathrm{ppm}$ since preindustrial times has virtually certainly enhanced water use efficiency and yields, especially for $C_{3}$ crops such as wheat and rice, although these benefits played a minor role in driving overall yield trends (Amthor, 2001; McGrath and Lobell, 2011).

Emissions of $\mathrm{CO}_{2}$ often are accompanied by ozone $\left(\mathrm{O}_{3}\right)$ precursors that have driven a rise in tropospheric $\mathrm{O}_{3}$ that harms crop yields (Morgan et al., 2006; Mills et al., 2007; Section 7.3.2.1.2). Elevated $O_{3}$ since preindustrial times has very likely suppressed global production of major crops compared to what they would have been without $\mathrm{O}_{3}$ increases, with estimated losses of roughly $10 \%$ for wheat and soybean and 3 to $5 \%$ for maize and rice (Van Dingenen et al., 2009). Impacts are most severe over India and China (Van Dingenen et al., 2009; Avnery et al. 2011a,b), but are also evident for soybean and maize in the USA (Fishman et al., 2010).

\subsubsection{Fisheries Production}

The global average consumption of fish and other products from fisheries and aquaculture in 2010 was $18.6 \mathrm{~kg}$ per person per year, derived from a total production of 148.5 million tonnes, of which $86 \%$ was used for direct human consumption. The total production arose from contributions of 77.4 and 11.2 million tonnes respectively from marine and inland capture fisheries, and 18.1 and 41.7 million tonnes respectively from marine and freshwater aquaculture (FA0, 2012). Fisheries make particular contributions to food security and more than $90 \%$ of the people engaged in the sector are employed in small-scale fisheries, many of whom are found in the poorer countries of the world (Cochrane et al., 2011). The detection and attribution of impacts are as confounded in inland and marine fisheries as in terrestrial food production systems. Overfishing, habitat modification, pollution, and interannual to decadal climate variability can all have impacts that are difficult to separate from those directly attributable to climate change.

One of the best studied areas is the Northeast Atlantic, where the temperature has increased rapidly in recent decades, associated with a poleward shift in distribution of fish (Perry et al., 2005; Brander, 2007; Cheung et al., 2010, 2013). There is high confidence in observations of increasing abundance of fish species in the northern extent of their ranges while decreases in abundance have occurred in the southern part (Section 30.5.1.1.1). These trends will have mixed implications for fisheries and aquaculture with some commercial species negatively and others positively affected (Cook and Heath, 2005). There is a similar well-documented example in the oceans off southeast Australia with large warming trends associated with more southward incursion of the Eastern Australian Current, resulting in southward migration of marine species into the oceans around eastern Tasmania (robust evidence, high agreement; Last et al., 2011).

As a further example, coral reef ecosystems provide food and other resources to more than 500 million people and with an annual value of US\$5 billion or more (Munday et al., 2008; Hoegh-Guldberg, 2011). More than $60 \%$ of coral reefs are considered to be under immediate threat of damage from a range of local threats, of which overfishing is the most serious (Burke et al., 2011; see also Box CC-CR) and the percentage under threat rises to approximately $75 \%$ when the effect of rising ocean temperatures is added to these local impacts (Burke et al., 2011). Wilson et al. (2006) demonstrated that declines in coral reef cover typically led to declines in abundance of the majority of fish species associated with coral reefs. There is high confidence that the availability of fish and invertebrate species associated with coral reefs that are important in many tropical coastal fisheries is very likely to be reduced (Section 30.6.2.1.2). Other examples around the world are described in Section 30.5.1.1.1.

These changes are impacting marine fisheries: a recent study that examined the composition of global fisheries catches according to the inferred temperature preferences of the species caught in fisheries found that there had been changes in the species composition of marine capture fisheries catches and that these were significantly related to changes in ocean temperatures (Cheung et al. 2013; Section 6.4.1.1). These authors noted that the relative contribution to catches by warmer water species had increased at higher latitudes while the contributions of subtropical species had decreased in the tropics. These changes have negative implications for coastal fisheries in tropical developing countries, which tend to be particularly vulnerable to climate change (Cheung et al., 2013; Sections 6.4.3, 7.5.1.1.2).

There is considerably less information available on climate change impacts on fisheries and fishery resources in freshwater systems and aquaculture. Considerable attention has been given to the impacts of climate change in some African lakes but with mixed interpretations (Section 22.3.3.1.4). There is evidence that increasing temperature has reduced the primary productivity of Lake Tanganyika in East Africa and a study by O'Reilly et al. (2003) estimated that this would have led to a decrease of approximately $30 \%$ in fish yields. However, Sarvala et al. (2006) disagreed and concluded that observed decreases in the fish catches could be explained by changed fishery practices. There has been a similar difference of opinion for Lake Kariba, where Ndebele-Murisa et al. (2011) argued that a reduction in fisheries productivity had been caused by climate change while Marshall (2012) argued that the declines in fish catches can only have been caused by fishing. There is medium confidence that, in India, changes in a number of climate variables including an increase in air temperature, regional monsoon variation, and a regional increase in incidence of severe storms have led to changes in species composition in the River Ganga and to have reduced the availability of fish spawn for aquaculture in the river Ganga while having positive impacts on aquaculture on the plains through bringing forward and extending the breeding period of the majors carps (Vass et al., 2009). 
Frequently Asked Questions

\title{
FAQ 7.1 | What factors determine food security and does low food production necessarily lead to food insecurity?
}

\begin{abstract}
Observed data and many studies indicate that a warming climate has a negative effect on crop production and generally reduces yields of staple cereals such as wheat, rice, and maize, which, however, differ between regions and latitudes. Elevated $\mathrm{CO}_{2}$ could benefit crops yields in the short term by increasing photosynthesis rates; however, there is big uncertainty in the magnitude of the $\mathrm{CO}_{2}$ effect and the significance of interactions with other factors. Climate change will affect fisheries and aquaculture through gradual warming, ocean acidification, and changes in the frequency, intensity, and location of extreme events. Other aspects of the food chain are also sensitive to climate but such impacts are much less well known. Climate-related disasters are among the main drivers of food insecurity, both in the aftermath of a disaster and in the long run. Drought is a major driver of food insecurity, and contributes to a negative impact on nutrition. Floods and tropical storms also affect food security by destroying livelihood assets. The relationship between climate change and food production depends to a large degree on when and which adaptation actions are taken. Other links in the food chain from production to consumption are sensitive to climate but such impacts are much less well known.
\end{abstract}

\subsubsection{Livestock Production}

In comparison to crop and fish production, considerably less work has been published on observed impacts for other food production systems, such as livestock or aquaculture, and to our knowledge nothing has been published for hunting or collection of wild foods other than for capture fisheries. The relative lack of evidence reflects a lack of study in this topic, but not necessarily a lack of real-world impacts of observed climate trends. A study of blue-tongue virus, an important ruminant disease, evaluated the effects of past and future climate trends on transmission risk, and concluded that climate changes have facilitated the recent and rapid spread of the virus into Europe (Guis et al., 2012). Ticks that carry zoonotic diseases have also likely changed distribution as a consequence of past climate trends (Section 23.4.2).

\subsubsection{Food Security and Food Prices}

Food production is an important aspect of food security (Section 7.1), and the evidence that climate change has affected food production implies some effect on food security. Yet quantifying this effect is an extremely difficult task, requiring assumptions about the many nonclimate factors that interact with climate to determine food security. There is thus limited direct evidence that unambiguously links climate change to impacts on food security.

One important aspect of food security is the prices of internationally traded food commodities (Section 7.1.3). These prices reflect the overall balance of supply and demand, and the accessibility of food for consumers integrated with regional to global markets. Although food prices gradually declined for most of the 20th century (FAO, 2009b) since AR4 there have been several periods of rapid increases in international food prices (Figure 7-3). A major factor in recent price changes has been increased crop demand, notably via increased use in biofuel production related both to energy policy mandates and oil price fluctuations (Roberts and Schlenker, 2010; Mueller et al., 2011; Wright, 2011). Yet fluctuations and trends in food production are also widely believed to have played a role in recent price changes, with recent price spikes often following climate extremes in major producers (Figure 7-3). Moreover, some of these extreme events have become more likely as a result of climate trends (Table 18-3). Domestic policy reactions can also amplify international price responses to weather events, as was the case with export bans announced by several countries since 2007 (FAO, 2008). In a study of global production responses to climate trends (Lobell et al., 2011a) estimated a price increase of $19 \%$ due to the impacts of temperature and precipitation trends on supply, or an increase of $6 \%$ once the beneficial yield effects of increased $\mathrm{CO}_{2}$ over the study period were considered. Because the price models were developed for a period ending in 2003, these estimates do not account for the policy responses witnessed in recent years which have amplified the price responses to weather.

\subsection{Assessing Impacts, Vulnerabilities, and Risks}

\subsubsection{Methods and Associated Uncertainties}

\subsubsection{Assessing Impacts}

Methods developed or extended since AR4 have resulted in more robust statements on climate impacts, both in the literature and in Section 7.3.2. Two particular areas, which are explored below, are improved quantification and presentation of uncertainty; and greater use of historical empirical evidence of the relationship between climate and food production.

The methods used for field and controlled environment experiments remain similar to those at the time of AR4. There has been a greater use of remote sensing and geographic information systems for assessing temporal and spatial changes in land use, particularly in agricultural land use for assessment of food security status (Thenkabail et al., 2009; 


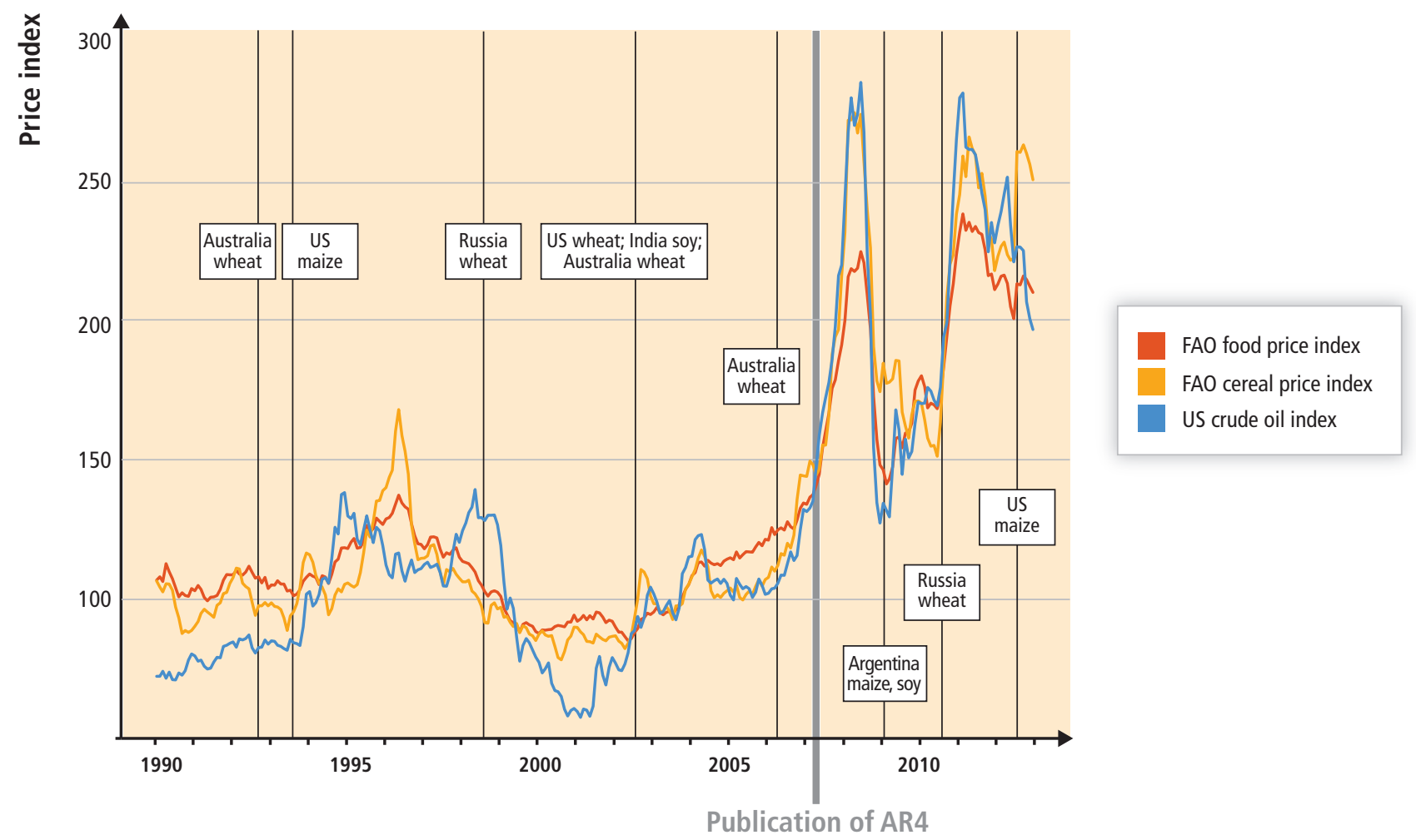

Figure 7-3 | Since the AR4, international food prices have reversed historical downward trend. The plot shows the history of FAO food and cereal price indices (composite measures of food prices), with vertical lines indicating events when a top five producer of a crop had yields $25 \%$ below trend line (indicative of a seasonal climate extreme). Australia is included despite not being a top five producer, because it is an important exporter and the drops were $40 \%$ or more below trend line. Prices may have become more sensitive to weather-related supply shortfalls in recent years. At the same time, food prices are increasingly associated with the price of crude oil (blue line), making attribution of price changes to climate difficult. Thus, there is clear evidence since AR4 that prices can rise rapidly, but the role of weather in these increases remains unclear. All indices are expressed as percentage of 2002-2004 averages. Food price and crop yield data from FAO (http://www.fao.org/worldfoodsituation/foodpricesindex and http://faostat.fao.org/) and oil price data from http://www.eia.gov.

Fishman et al., 2010; Goswami et al., 2012). There has also been an increase in the number of Free Air Concentration Enrichment (FACE) studies that examine $\mathrm{O}_{3}$ instead of, or in addition to, $\mathrm{CO}_{2}$. In agriculture, FACE experiments have been used for assessing impacts of atmospheric $\mathrm{CO}_{2}$ on grain yield, quality characteristics of important crops (Erbs et al., 2010), elemental composition (Fernando et al., 2012), and diseases (Chakraborty et al., 2011; Eastburn et al., 2011). A number of metaanalyses of experimental studies, in particular FACE studies, have been made since AR4. However, debate continues on the disparities between results from FACE experiments and non-FACE experiments, such as in open-top chambers or greenhouses. As reported in AR4, FACE studies tend to show lower elevated $\mathrm{CO}_{2}$ responses than non-FACE studies. Although some authors have claimed that the results of the two are statistically indistinct, others have argued that the results are similar only when the FACE experiments are grown under considerably more water stress than non-FACE experiments (Ainsworth et al., 2008; Kimball, 2010). Hence comparisons between different methodologies must take care to control for differences in water availability and microclimate. Another reason for differences between experiments may be differences in the temporal variance of $\mathrm{CO}_{2}$, that is, whether concentrations are fluctuating or constant (Bunce, 2012). Unfortunately, the FACE experiments are carried out mostly in the USA and in China, and thus limited to specific environmental conditions, which do not fully reflect tropical or subtropical conditions, where $\mathrm{CO}_{2}$ and soil nutrient interactions could lead to large differences in photosynthesis rate, water use, and yield.
Also, the number of FACE studies is still quite low, which limits statistical power when evaluating the average yield effects of elevated $\mathrm{CO}_{2}$ or interactions with temperature and moisture (Section 7.3.2).

Numerical simulation models can be used to investigate a larger number of possible environmental and management conditions than possible via physical experiments. This, in turn, enables a broader range of statements regarding the possible response of food production systems to climate variability and change. Previous assessment reports have documented new knowledge resulting from numerical simulation of the response of food production to climate change. AR4 noted the increasing number of regional studies, which is a trend that has continued to date (Craufurd et al., 2013; Zhu et al., 2013). Since AR4, crop models have been used to examine a large number of management and environmental conditions, such as interactions among various components of food production systems (Lenz-Wiedemann et al., 2010), determination of optimum crop management practices (Soltani and Hoogenboom, 2007), vulnerability and adaptability assessments (Sultana et al., 2009), evaluation of water consumption and water use efficiency (Kang et al., 2009; Mo et al., 2009), and fostering communication among scientists, managers, policymakers, and planners.

The trend toward quantification of uncertainty in both climate and its impacts has continued since AR4. Novel developments include methodologies to assess the impact of climate model error on projected 
agricultural output, particularly for crops (Ramirez-Villegas et al., 2013, Watson and Challinor, 2013). Models that integrate crop growth models as part of broader land surface and earth systems models (Bondeau et al., 2007; Osborne et al., 2007) are also increasingly common. Ensemble techniques for climate impacts, which were in their infancy at AR4, now include the use of Bayesian methods to constrain crop model parameters (Tao et al., 2008b, 2009a; lizumi et al., 2009). It is also increasingly common to assess both biophysical and socioeconomic drivers of crop productivity within the same study (Fraser et al., 2008; Reidsma et al., 2009; Challinor et al., 2010; Tao et al., 2011b). Finally, an important recent development is the systematic comparison of results from different modeling and experimental approaches for providing insights into model uncertainties as well as to develop risk management (Challinor and Wheeler, 2008; Kang et al., 2009; Schlenker and Lobell, 2010; Rosenzweig et al., 2013, 2014).

Increased quantification of uncertainty can lead to clear statements regarding climate impacts. Studies with different methods have been shown to produce convergent results for some crops and locations (Challinor et al., 2009; medium evidence, medium agreement). The methods used to describe uncertainty have also improved since AR4. The projected range of global and local temperature changes can be described by quantifying uncertainty in the temporal dimension, rather than that in temperature itself (Joshi et al., 2011), and a similar approach can be used for crop yield (Figure 7-5). Descriptions of uncertainty that present key processes and trade-offs, rather than ranges of outcome variables, have also proved to be useful tools for understanding future impacts (Thornton et al., 2009a; Hawkins et al., 2012; Ruane et al., 2013). Section 7.3.2 reviews the results of such studies.

A considerable body of work since AR4 has used extensive data sets of country-, regional-, and farm-level crop yield together with observed and/or simulated weather time series to assess the sensitivity of food production to weather and climate (Tao et al., 2009a, 2011). Statistical models offer a complement to more process-based model approaches, some of which require many assumptions about soil and management practices. Process-based models, which extrapolate based on measured interactions and mechanisms, can be used to develop a causal understanding of the empirically determined relationships in statistical models (cf. Schlenker and Roberts, 2009; Lobell et al., 2013a). Although statistical models forfeit some of the process knowledge embedded in other approaches, they can often reproduce the behavior of other models (Iglesias et al., 2000; Lobell and Burke, 2010) and can leverage within one study a growing availability of crop and weather data (Welch et al., 2010; Lobell et al., 2011b). However, statistical models usually exclude the direct impact of elevated $\mathrm{CO}_{2}$, making multi-decadal prediction problematic. In determining future trends, crop models of all types can extrapolate only based on historically determined relationships. Agro-climatic indices provide an alternative to crop models that avoid various assumptions by developing metrics, rather than providing yield predictions per se (Trnka et al., 2011). However, correlations between climate or associated indices and yield are not always statistically significant.

The robustness of crop model results depends on data quality, model skill prediction, and model complexity (Bellocchi et al., 2010). Modeling and experiments are each subject to their own uncertainties. Measurement uncertainty is a feature of field and controlled environment experiments. For example, interactions among $\mathrm{CO}_{2}$ fertilization, temperature, soil nutrients, $\mathrm{O}_{3}$, pests, and weeds are not well understood (Soussana et al., 2010) and therefore most crop models do not include all of these effects, or broader issues of water availability, such as competition for water between industry and households (Piao et al., 2010). There are also uncertainties associated with generalizing the results of field experiments, as each one has been conducted relatively few times under a relatively small range of environmental and management conditions, and for a limited number of genotypes. This limits breadth of applicability both through limited sample size and limited representation of the diversity of genotypic responses to environment (Craufurd et al., 2013). For example, yield increases normalized by increase in $\mathrm{CO}_{2}$ have been found to vary between zero and more than $30 \%$ among crop varieties (Tausz et al., 2011).

Uncertainty in climate simulation is generally larger than, or sometimes comparable to, the uncertainty in crop simulation using a single crop model (lizumi et al., 2011), although temperature-driven processes in crop models have been shown to dominate the causes of uncertainty (Koehler et al., 2013). There is significant uncertainty in agricultural simulation arising from climate model error. Since AR4 the choice of method for General Circulation Model (GCM) bias correction has been identified as a significant source of uncertainty (Hawkins et al., 2012). There is also a contribution to uncertainty in crop model output from yield measurement error, through the calibration procedure. Yield measurements rarely have associated error bars to give an indication of accuracy. Greater access to accurate regional-scale crop yield data can lead to decreased uncertainty in projected yields (Watson and Challinor, 2013).

The use of multiple crop models in impacts studies is relatively rare. Field-scale historical model intercomparisons have shown variations in the simulation of mean yield and above-ground biomass of more than $60 \%$ (Palosuo et al., 2011). Early results from impacts studies with multiple crop models suggest that the crop model uncertainty can be larger than that caused by GCMs, due in particular to high temperature and temperature-by- $\mathrm{CO}_{2}$ interactions (Asseng et al., 2013). However, in contrast to absolute values, yield changes can be consistent across crop models (Olesen et al., 2007). Given these different strengths and weaknesses, and associated dependencies, it is critical that both experimental and modeling lines of evidence, and their uncertainties, are examined carefully when drawing conclusions regarding impacts, vulnerabilities, and risks. This approach to assessment is applied to each of the topics described in the rest of the chapter.

The methods used for assessing impacts, vulnerabilities, and risks in fisheries and aquaculture face the constraint that meaningful controlled experiments are usually not practical for fisheries in large rivers, lakes, and marine environments because of the typical open and connected nature of these ecosystems. Experimentation has been used to examine responses to impacts at the scale of individual species, for example, to demonstrate the impacts of high atmospheric $\mathrm{CO}_{2}$ in reducing coral calcification and growth (Hoegh-Guldberg et al., 2007) and to study the temperature tolerances of different cultured species (Ficke et al., 2007; De Silva and Soto, 2009). The far more common approach, however, is the empirical analysis of data collected in the field. This has been used 
to examine the effect of climate-related factors on recruitment to a population, growth, and population production of specific species, for example (Brander, 2010; see also Chapters 6 and 30). Different modeling approaches have also been used to integrate available information and assess the impacts of climate change on ecosystems and fish production at scales from national to global (Cheung et al., 2010; Fulton, 2011; Merino et al., 2012; see also Section 6.5). Efforts to assess the vulnerability of those dependent on fisheries and aquaculture have increased in recent years and range from studies that use available information on exposure, sensitivity, and adaptive capacity to provide an index of vulnerability (Allison et al., 2009; Cinner at al., 2012) to more detailed social and economic studies focused on particular communities or localities (Daw et al., 2009).

\subsubsection{Treatment of Adaptation in Impacts Studies}

Adaptation occurs on a range of time scales and by a range of actors. Incremental adaptation, such as a change in crop management, can occur relatively autonomously within farming systems. It is the type of adaptation most commonly assessed in the impacts literature, and it is the only form of adaptation discussed in Sections 7.3 and 7.4. Systemic and transformational adaptations are discussed in Section 7.5. Methods exist to examine impacts and adaptation together in the context of nonclimatic drivers (Mandryk et al., 2012), but conclusions are difficult to generalize.

\subsubsection{Sensitivity of Food Production to Weather and Climate}

\subsubsection{Cereals and Oilseeds}

\subsection{Mean and extremes of temperature and precipitation}

Both statistical and process-based models have been used widely since AR4 to assess the response of crop yield to temperature. Model results confirm the importance of known key physiological processes, such as the shortening of the time to maturity of a crop with increasing mean temperature (Iqbal et al., 2009), decline in grain set when high temperatures occur during flowering (Moriondo et al., 2011), and increased water stress at high temperatures throughout the growing cycle (Lobell et al., 2013a). Temperature responses are generally well understood for temperatures up to the optimum temperature for crop development. The impacts of prolonged periods of temperatures beyond the optimum for development are not as well understood (Craufurd and Wheeler, 2009). For example, temperatures above $32-34^{\circ} \mathrm{C}$ after flowering appear to speed senescence rapidly in wheat (Asseng et al., 2011; Lobell et al., 2012), but many crop models do not represent this process (Sanchez et al., 2014). Crop models can be used to quantify abiotic stresses such as these, although only by hypothesizing that the functional responses to weather derived from experiments are valid at regional scales. Thus, although many fundamental biophysical processes are understood at the plant or field scale, it remains difficult to quantify the extent to which these mechanisms are responsible for the observed regional-scale relationships between crop yield and weather. Despite these particular areas where specific understanding is lacking, the evidence from regional- scale statistical analyses (Schlenker and Roberts, 2009) and process-based models shows clear negative impacts of temperatures above $30^{\circ} \mathrm{C}$ to $34^{\circ} \mathrm{C}$ on crop yields (depending on the crop and region) (high evidence, high agreement).

The overall relationship between weather and yields is often crop and region specific, depending on differences in baseline climate, management and soil, and the duration and timing of crop exposure to various conditions. For example, rice yields in China have been found to be positively correlated with temperature in some regions and negatively correlated in others (Zhang et al., 2008, 2010). The trade-offs that occur in determining yield are therefore region-specific. This difference may be due to positive correlation between temperature and solar radiation in the former case, and negative correlation between temperature and water stress in the latter case. Similarly, although studies consistently show spikelet sterility in rice for daytime temperatures exceeding $33^{\circ} \mathrm{C}$ (Jadadish et al., 2007; Wassmann et al., 2009), some statistical studies find a positive effect of daytime warming on yields because these extremes are not reached frequently enough to affect yields (Welch et al., 2010). Responses to temperature may vary according whether yields are limited by low or high temperatures. However, there is evidence that high temperatures will limit future yields even in cool environments (Semenov et al., 2012; Teixeira et al., 2013).

The relative importance of temperature and water stress for crop productivity can be assessed using models, and can vary according to the criteria used for assessment (Challinor et al., 2010). There are also some cases where the sign of a correlation depends on the direction of the change. For example, Thornton et al. (2009b) found that the response of crop yields to climate change in the drylands of East Africa is insensitive to increases in rainfall, as wetter climates are associated with warmer temperatures that act to reduce yields. Because precipitation exhibits more spatial variability than temperature, temporal variations in the spatial average of precipitation tend to diminish as the spatial domain widens. As a result, precipitation becomes less important as a predictor of crop yields at broad scales (Lobell and Field, 2007; Li et al., 2010). Similarly, projected changes in precipitation from climate models tend to be more spatially variable than temperature, leading to the greater importance of projected temperatures as the spatial scale of analysis grows wider (Lobell and Burke, 2008). There is also evidence that where irrigation increases over time the influence of temperature on yields starts to dominate over that of precipitation (Hawkins et al., 2012). The impact of drought on crop yield is a more common topic of research than the impact of floods.

Analysis of 66 yield impact studies for major cereals, including both preand post-AR4 contributions, gives broadly similar results to AR4 (Figure 7-4). Figure 7-4 shows that yields of maize and wheat begin to decline with $1^{\circ} \mathrm{C}$ to $2^{\circ} \mathrm{C}$ of local warming in the tropics. Temperate maize and tropical rice yields are less clearly affected at these temperatures, but significantly affected with warming of $3^{\circ} \mathrm{C}$ to $5^{\circ} \mathrm{C}$. These data confirm AR4 findings that even slight warming will decrease yields in low-latitude regions (medium evidence, high agreement). However, although AR4 had few indications of yield reductions at less than $2^{\circ} \mathrm{C}$ of local warming, the new analysis has, in the absence of incremental adaptation, more yield decreases than increases at all temperatures. Hence, although AR4 concluded with medium confidence that in mid- to high-latitude 

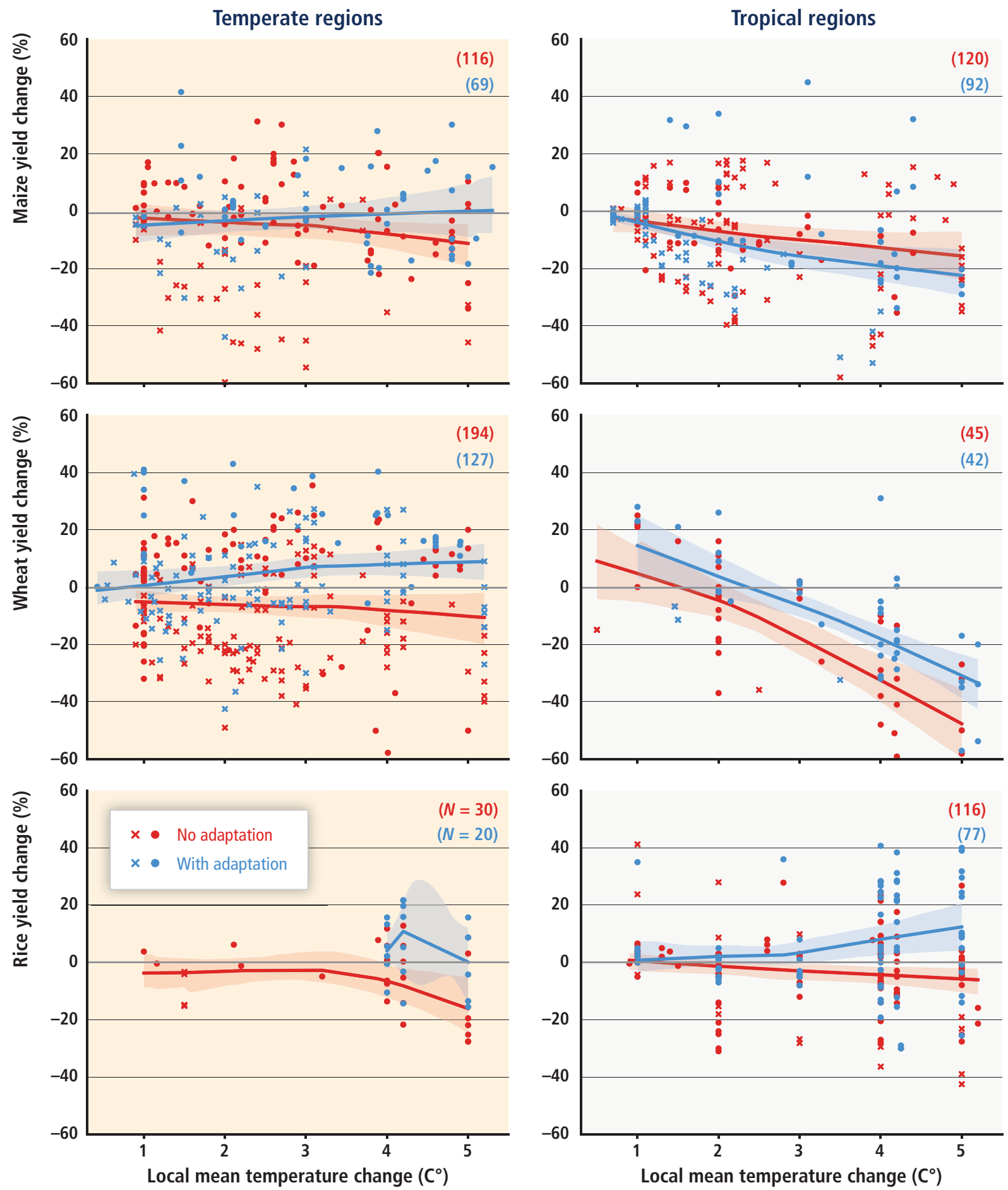

Figure 7-4 | Percentage simulated yield change as a function of local temperature change for the three major crops and for temperate and tropical regions. Dots indicate where a known change in atmospheric $\mathrm{CO}_{2}$ was used in the study; remaining data are indicated by $\mathrm{x}$. Note that differences in yield value between these symbols do not measure the $\mathrm{CO}_{2}$ fertilization effect, as changes in other factors such as precipitation may be different between studies. Non-parametric regressions (LOESS, span $=1$ and degree $=1$ ) of subsets of these data were made 500 times. These bootstrap samples are indicated by shaded bands at the $95 \%$ confidence interval. Regressions are separated according to the presence (blue) or absence (red) of simple agronomic adaptation (Table 7-2). In the case of tropical maize, the central regression for absence of adaptation is slightly higher than that with adaptation. This is due to asymmetry in the data — not all studies compare adaptated and non-adapted crops. Figure 7-8 presents a pairwise adaptation comparison. Note that four of the 1048 data points across all six panels are outside the yield change range shown. These were omitted for clarity. Some of the studies have associated temporal baselines, with center points typically between 1970 and 2005. Note that local warming in cropping regions generally exceeds global mean warming (Figure 21-4). Data are taken from a review of literature: Rosenzweig and Parry, 1994; Karim et al., 1996; El-Shaher et al., 1997; Kapetanaki and Rosenzweig, 1997; Lal et al., 1998; Moya et al., 1998; Winters et al., 1998; Yates and Strzepek, 1998; Alexandrov, 1999; Kaiser, 1999; Reyenga et al., 1999; Alexandrov and Hoogenboom, 2000; Southworth et al., 2000; Tubiello et al., 2000; DeJong et al., 2001; Izaurralde et al., 2001; Aggarwal and Mall, 2002; Abou-Hadid, 2006; Alexandrov et al., 2002; Corobov, 2002; Chipanshi et al., 2003; Easterling et al., 2003; Jones and Thornton, 2003; Luo et al., 2003; Matthews and Wassmann, 2003; Droogers, 2004; Howden and Jones, 2004; Butt et al., 2005; Erda et al., 2005; Ewert et al., 2005; Gbetibouo and Hassan, 2005; Izaurralde et al., 2005; Porter and Semenov, 2005; Sands and Edmonds, 2005; Thomson et al., 2005; Xiao et al., 2005; Zhang and Liu, 2005; Zhao et al., 2005; Abraha and Savage, 2006; Brassard and Singh, 2007, 2008; Krishnan et al., 2007; Lobell and Ortiz-Monasterio, 2007; Xiong et al., 2007; Tingem et al., 2008; Walker and Schulze, 2008; El Maayar et al., 2009; Schlenker and Roberts, 2009; Thornton et al., 2009a, 2010, 2011; Tingem and Rivington, 2009; Byjesh et al., 2010; Chhetri et al., 2010; Liu et al., 2010; Piao et al., 2010; Tan et al., 2010; Tao and Zhang, 2010, 2011a,b; Arndt et al., 2011; Deryng et al., 2011; lqbal et al., 2011; Lal, 2011; Li et al., 2011; Rowhanji et al., 2011; Shuang-He et al., 2011; Osborne et al., 2013. 
regions moderate warming will raise crop yields, new knowledge suggests that temperate wheat yield decreases are about as likely as not for moderate warming. A recent global crop model intercomparison for rice, wheat, and maize shows similar results to those presented here, although with less impacts on temperate rice yields (Rosenzweig et al., 2013 , 2014). That study also showed that crop models without explicit nitrogen stress fail to capture the expected response.

Quantitative assessments of yield changes can be found in Section 7.4. Across the globe, regional variability, which has not been summarized in meta-analyses except in contributing to the spread of data (Figure 7-4), will be important in determining how climate change affects particular agricultural systems.

\subsection{Impact of carbon dioxide and ozone}

There is further observational evidence since AR4 that response to a change in $\mathrm{CO}_{2}$ depends on plant type: $\mathrm{C}_{3}$ or $\mathrm{C}_{4}$ (DaMatta et al., 2010). The effect of increase in $\mathrm{CO}_{2}$ concentration tends to be higher in $\mathrm{C}_{3}$ plants (wheat, rice, cotton, soybean, sugar beets, and potatoes) than in $\mathrm{C}_{4}$ plants (corn, sorghum, sugarcane), because photosynthesis rates in $\mathrm{C}_{4}$ crops are less responsive to increases in ambient $\mathrm{CO}_{2}$ (Leakey, 2009). The highest fertilization responses have been observed in tuber crops, which have large capacity to store extra carbohydrates in belowground organs (Fleisher et al., 2008; Högy and Fangmeier, 2009). There is observational evidence, new since AR4, that the response of crops to $\mathrm{CO}_{2}$ is genotype specific (Ziska et al., 2012). For example, yield enhancement at $200 \mathrm{ppm}$ additional $\mathrm{CO}_{2}$ ranged from 3 to $36 \%$ among rice cultivars (Hasegawa et al., 2013).

FACE studies have shown that the impact of elevated $\mathrm{CO}_{2}$ varies according to temperature and availability of water and nutrients, although the strong geographical bias of FACE studies toward temperate zones limits the strength of this evidence. FACE studies have shown that yield enhancement by elevated $\mathrm{CO}_{2}$ is limited under both low (Shimono et al., 2008; Hasegawa et al., 2013) and high temperature. Theory suggests that water-stressed crops will respond more strongly to elevated $\mathrm{CO}_{2}$ than well-watered crops, because of $\mathrm{CO}_{2}$-induced increases in stomatal resistance. This suggests that rain-fed cropping systems will benefit more from elevated $\mathrm{CO}_{2}$ than irrigated systems.

Both the Third Assessment Report (TAR) and AR4 cited the expectation that rain-fed systems benefit more from elevated $\mathrm{CO}_{2}$ than systems under wetter conditions. New evidence based on historical observations supports this notion by demonstrating that the rate of yield gains in rain-fed systems is higher in dry years than in wet years (McGrath and Lobell, 2011). However, this response is not seen consistently across models and FACE meta-analyses, and there is some suggestion that the relationship between water stress and assimilation may vary with spatial scale, with canopy analyses showing a reversal of the expected leaf-level dry versus wet signal (Challinor and Wheeler, 2008).

$\mathrm{O}_{3}$ in the stratosphere provides protection from lethal short-wave solar ultraviolet radiation, but in the troposphere it is a phytotoxic air pollutant. The global background concentration of $\mathrm{O}_{3}$ has increased since the preindustrial era due to anthropogenic emission of its precursors (carbon monoxide, volatile organic compounds, and oxides of nitrogen), by vehicles, power plants, biomass burning, and other sources of combustion. Like $\mathrm{CO}_{2}, \mathrm{O}_{3}$ is taken up by green leaves through stomata during photosynthesis but, unlike $\mathrm{CO}_{2}$, its concentration is significantly variable depending on geographic location, elevation, and extent of anthropogenic sources. Being a powerful oxidant, $\mathrm{O}_{3}$ and its secondary by-products damage vegetation by reducing photosynthesis and other important physiological functions (Mills et al., 2009; Ainsworth and McGrath, 2010). This results in stunted crop plants, inferior crop quality, and decreased yields (Booker et al., 2009; Fuhrer, 2009; Vandermeiren et al., 2009; Pleijel and Uddling, 2012) and poses a growing threat to global food security (robust evidence, high agreement).

The literature published since AR4 further corroborates the negative impacts of increasing concentrations of surface $\mathrm{O}_{3}$ on yield at global (Van Dingenen et al., 2009; Avnery et al., 2011 a,b; Teixeira et al., 2011) and regional scales (Northern Hemisphere: Hollaway et al., 2011; USA: Emberson et al., 2009; Fuhrer, 2009; Fishman et al., 2010; India: Roy et al., 2009; Rai et al., 2010; Sarkar and Agrawal, 2010; China:Wang et al., 2007, 2011; Piao et al., 2010; Bangladesh: Akhtar et al., 2010; Europe: Hayes et al., 2007; Fuhrer, 2009; Vandermeiren et al., 2009). Global estimates of yield losses due to increased $\mathrm{O}_{3}$ in soybean, wheat, and maize in 2000 ranged from 8.5 to $14 \%, 3.9$ to $15 \%$, and 2.2 to $5.5 \%$ respectively, amounting to economic losses of US\$11 to 18 billion (Avnery et al., 2011a). $\mathrm{O}_{3}$ may have a direct effect on reproductive process, leading to reduced seed and fruit development and abortion of developing fruit (robust evidence, high agreement; Royal Society, 2008).

The interactive effects of $\mathrm{O}_{3}$ with other environmental factors such as $\mathrm{CO}_{2}$, temperature, moisture, and light, are important but not well understood. Generally, the ambient and increasing concentrations of $\mathrm{O}_{3}$ and $\mathrm{CO}_{2}$ individually exert counteractive effects on $\mathrm{C}_{3}$ plants (Tianhong et al., 2005; Ainsworth et al., 2008; Gillespie et al., 2012), but their interactive effect may compensate for each other (Ainsworth et al., 2008; Taub et al., 2008; Gillespie et al., 2012). However, the losses might be greater when elevated $\mathrm{O}_{3}$ combines with high temperature (Long, 2012) particularly during grain filling of wheat, when elevated $\mathrm{O}_{3}$ causes premature leaf senescence (Feng et al., 2008b, 2011). Periods of abundant radiation and adequate water supply are favorable for both agricultural production and the formation of surface $\mathrm{O}_{3}$; thus, the effects of $\mathrm{O}_{3}$ on crops can be difficult to detect (Long, 2012).

\subsubsection{Other Crops}

Earlier flowering and maturity have been observed (robust evidence, high agreement) worldwide in grapes (Duchêne et al., 2010; GarcíaMozo et al., 2010; Jorquera-Fontena and Orrego-Verdugo, 2010; Sadras and Petrie, 2011; Webb et al., 2011), apples (Fujisawa and Koyabashi, 2010; Grab and Craparo, 2011), and other perennial horticultural crops (Glenn et al., 2013). Cassava (also known as manioc) is an important source of food for many people in Africa and Latin America and recent studies suggest (medium evidence, medium agreement) that future climate should benefit its productivity as this crop is characterized by elevated optimum temperature for photosynthesis and growth, and a positive response to $\mathrm{CO}_{2}$ increases (El-Sharkawy, 2012; Jarvis et al., 2012; Rosenthal and Ort, 2012). 


\subsubsection{Pests, Weeds, Diseases}

As a worldwide average, yield loss in major crop species due to animal pests and (non-virus) pathogens, in the absence of any physical, biological, or chemical crop protection, has been estimated at $18 \%$ and $16 \%$, respectively (Oerke, 2006), but weeds produce the highest potential loss $(34 \%)$. Climate change will alter potential losses to many pests and diseases. Changes in temperature can result in geographic shifts through changes in seasonal extremes, and thus, for example, overwintering and summer survival. $\mathrm{CO}_{2}$ and $\mathrm{O}_{3}$ can either increase or decrease plant disease, and can exhibit important interactions (Chakraborty and Newton, 2011; Garrett et al., 2011), suggesting the need for system-specific risk assessment (Chakraborty et al., 2008; Eastburn et al., 2011). Interactions with landscape effects may be particularly important in forests and grasslands (Pautasso et al., 2010).

The rarity of long-term studies of plant diseases and pests is a problem for the evaluation of climate change effects, but there are some examples of the potential for such analyses. Ongoing wheat experiments at Rothamsted Research Station UK, maintained for more than 160 years, have revealed shifts in foliar wheat pathogens linked to rainfall, temperature, and sulfur dioxide $\left(\mathrm{SO}_{2}\right)$ emissions (Bearchell et al., 2005; Shaw et al., 2008). Wheat rust risk has been observed to respond to $\mathrm{El}$ Niño-Southern Oscillation (ENSO; Scherm and Yang, 1995). Over almost 7 decades, earlier and more frequent epidemics of potato late blight, and more frequent pesticide use, were observed in Finland, associated with changing climate conditions and lack of crop rotation (Hannukkala et al., 2007).

Changes in climate are expected to affect the geographic range of specific species of insects and diseases for a given crop growing region. For example, Cannon (1998) has suggested that migratory insects could colonize crops over a larger range in response to temperature increases, with subsequent reductions in yield. Climate change may also be a factor in extending the northward migration of agronomic and invasive weeds in North America (Ziska et al., 2011). Weed species also possess characteristics that are associated with long-distance seed dispersal, and it has been suggested (Hellman et al., 2008) that they may migrate rapidly with increasing surface temperatures. Predator and insect herbivores respond differently to increasing temperature, leading to possible reductions in insect predation and thus greater insect numbers. However, ecosystems are complex and insect and disease occurrence can go down as well as up. Overall, our ability to predict $\mathrm{CO}_{2} /$ climate change impacts on pathogen biology and subsequent changes on yield is limited because, with few exceptions (Savary et al., 2011), experimental data are not available and analyses focus on individual diseases rather than the complete set of important diseases (medium evidence, medium agreement).

Elevated $\mathrm{CO}_{2}$ can reduce yield losses due to weeds for $\mathrm{C}_{3}$ crops (soybean, wheat, and rice), as many agricultural weeds are $C_{4}$ species; and the $C_{3}$ pathway, in general, shows a stronger response to rising $\mathrm{CO}_{2}$ levels. However, both $\mathrm{C}_{3}$ and $\mathrm{C}_{4}$ weed species occur in agriculture, and there is a wide range of responses among these species to recent and projected $\mathrm{CO}_{2}$ levels (Ziska, 2010). For example, in the USA, every crop, on average, competes with an assemblage of 8 to 10 weed species (Bridges, 1992). $\mathrm{CO}_{2}$ and climate can also affect weed demographics. For example, with field grown soybean, elevated $\mathrm{CO}_{2}$ per se appeared to be a factor in increasing the relative proportion of $C_{3}$ to $C_{4}$ weedy species with subsequent reductions in soybean yields (Ziska and Goins, 2006). For rice and barnyard grass $\left(\mathrm{C}_{4}\right)$, increasing $\mathrm{CO}_{2}$ favored rice, but if both temperature and $\mathrm{CO}_{2}$ increased simultaneously, the $\mathrm{C}_{4}$ weed was favored, primarily because higher temperatures resulted in increased seed yield loss for rice. For weeds that share physiological, morphological, or phenological traits with the crop, including those weeds that are wild relatives of the domesticated crop species (often among the "worst" weeds in agronomic situations, e.g., rice and red rice), the decrease in seed yield from weeds may be greater under elevated $\mathrm{CO}_{2}$ (Ziska, 2010).

With respect to control, a number of studies have, to date, indicated a decline in herbicide efficacy in response to elevated $\mathrm{CO}_{2}$ and/or temperature for some weed species, both $\mathrm{C}_{3}$ and $\mathrm{C}_{4}$ (Archambault, 2007; Manea et al., 2011). Some of the mechanisms for this are understood, for example, for the invasive plant species Canada thistle (Cirsium arvense), elevated $\mathrm{CO}_{2}$ results in a greater root biomass, thus diluting the active ingredient of the herbicide used and reducing chemical control (Ziska, 2010). To date, studies on physical, cultural, or biological weed control are lacking.

\subsubsection{Fisheries and Aquaculture}

The natural and human processes in fisheries and aquaculture differ from mainstream agriculture and are particularly vulnerable to impacts and interactions related to climate change. Capture fisheries in particular, comprising the largest remaining example of harvesting natural, wild resources, are strongly influenced by global ecosystem processes. The social, economic, and nutritional requirements of the growing human population are already driving heavy exploitation of capture fisheries and rapid development of aquaculture (Section 6.4.1.1). This trend will continue over the next 20 to 30 years at least: Merino et al. (2012) forecast that in addition to a predicted small increase in marine fisheries production, between 71 and 117 million tonnes of fish will need to be produced by aquaculture to maintain current average per capita consumption of fish. The impacts of climate change add to and compound these threats to the sustainability of capture fisheries and aquaculture development (FAO, 2009a). Expected changes in the intensity, frequency, and seasonality of climate patterns and extreme events, sea level rise, glacier melting, ocean acidification, and changes in precipitation with associated changes in groundwater and river flows are expected to result in significant changes across a wide range of aquatic ecosystem types and regions with consequences for fisheries and aquaculture in many places (FAO, 2009a; see also Section 30.5.1.1). Ocean acidification will also have negative impacts on the culture of calcifying organisms (Section 30.6.2.1.4), including mollusc species of which 14.2 million tonnes were produced by aquaculture in 2010, equivalent to $23.6 \%$ of global aquaculture production (FAO, 2012). There are also concerns that climate change could lead to the spread of pathogens with impacts on wild and cultured aquatic resources (De Silva and Soto, 2009).

Given the proximity of fishing and aquaculture sites to oceans, seas, and riparian environments, extreme events can be expected to have impacts on fisheries and aquaculture with those located in low-lying 
areas at particular risk. The consequences of sea level rise and the expected increased frequency and intensity of storms include increased risks of loss of homes and infrastructure, increased safety risks while fishing, and the loss of days at sea because of bad weather (Daw et al., 2009). In areas that experience water stress and competition for water resources, aquaculture operations and inland fisheries production will be at risk.

Food production from fisheries and aquaculture will be affected by the sensitivity of the caught and cultured species to climate change and both positive and negative outcomes can be expected. Changes in marine and freshwater mean temperatures, ocean acidification, hypoxia, and other climate-related changes will influence the distribution and productivity of fished and farmed aquatic species (Sections 6.4.3, 7.2.1.2, 30.6.2). Changes in temperature extremes are also likely to have impacts. Many aquatic species are routinely subjected to large daily and seasonal fluctuations in temperature and are able to cope with them: for example, temperatures in shallow coastal habitats in the tropical Pacific can vary by more than $14^{\circ} \mathrm{C}$ diurnally (Pratchett et al., 2011). Nevertheless, distribution and productivity of aquatic species and communities are sensitive to changes in temperature extremes. A study on salmon populations in Washington State, USA (Mantua et al., 2010), demonstrated important impacts of seasonal variations and extremes. The study concluded that warming in winter and spring would have some positive impacts while increased summertime stream temperatures, seasonal low flows, and changes in the peak and base flows would have negative impacts on the populations. Coral reefs are particularly susceptible to extremes in temperature: temperatures $1^{\circ} \mathrm{C}$ or $2^{\circ} \mathrm{C}$ in excess of normal maximums for 3 to 4 weeks are sufficient to disrupt the essential relationship between endosymbiotic dinoflagellates and their coral hosts, leading to coral bleaching. Large-scale bleaching of coral reefs has increased in recent decades both in intensity and frequency (HoeghGuldberg et al., 2007).

The impacts of climate change on the fisheries and aquaculture sector will have implications for the four dimensions of food security, that is, availability of aquatic foods, stability of supply, access to aquatic foods, and utilization of aquatic products (FAO, 2009a). Where climate-driven ecological changes are significant, countries and communities will need to adapt through, for example, changes in fishing and aquaculture practices and operations (Section 7.5.1.1.2).

\subsubsection{Food and Fodder Quality and Human Health}

Food quality is any characteristic other than yield that is valuable to the producer or consumer. Examples include wheat protein and starch concentrations, which affect dough quality; amylose content in rice, which affects taste; and mineral concentrations, which affects nutrient intake of consumers. Climate change will have some adverse impacts on food quality through both biotic and abiotic stresses (Ceccarelli et al., 2010). These changes may affect crop quality by altering carbon and nutrient uptake and biochemical processes that produce secondary compounds or redistribute and store compounds during grain development and maturation. This in turn could impact human and livestock health by altering nutritional intake and/or affect economic value by altering traits valuable to processers or the consumers.
Change in nitrogen concentration, a proxy for protein concentration, is the most examined quality trait and since AR4 studies have been extended to almost all the major food crops. Cereals grown in elevated $\mathrm{CO}_{2}$ show a decrease in protein (Pikki et al., 2007; Högy et al., 2009; Erbs et al., 2010; Ainsworth and McGrath, 2010; DaMatta et al., 2010; Fernando et al., 2012). Meta-analysis of 228 experimental observations finds decreases between 10 and $14 \%$ in edible portions of wheat, rice, barley, and potato, but only $1.5 \%$ in soybeans, a nitrogen-fixing legume, when grown in elevated $\mathrm{CO}_{2}$ (Taub et al., 2008).

Mineral concentration of edible plant tissues are affected by growth in elevated $\mathrm{CO}_{2}$ in a similar manner to nitrogen. Although there are numerous studies measuring mineral concentration, there are relatively few measurements for any given mineral relevant to human health. Although there were several studies published before the release of AR4, this topic was not covered in any depth in AR4. Meta-analysis of studies prior to 2002 finds that phosphorus, calcium, sulfur, magnesium, iron, zinc, manganese, and copper decline by 2.5 to $20 \%$ in wheat grain and leaves of numerous species in elevated $\mathrm{CO}_{2}$, but potassium increases insignificantly in wheat grain (Loladze, 2002; Högy et al., 2009; Fernando et al., 2012). Since 2002, studies generally find decreases in zinc, sulfur, phosphorus, magnesium, and iron in wheat and barley grain; increase in copper, molybdenum, and lead (from a limited number of studies); and mixed results for calcium and potassium (Högy et al., 2009; Erbs et al., 2010; Fernando et al., 2012). Changes in mineral concentration due to elevated $\mathrm{CO}_{2}$ are determined by several factors including crop species, soil type, tissue (tubers, leaves, or grain) and water status.

Elevated $\mathrm{CO}_{2}$ can lower the nutritional quality of flour produced from grain cereals (Högy et al., 2009; Erbs et al., 2010) and of cassava (Gleadow et al., 2009). When coupled with increased crop and pathogen biomass, elevated $\mathrm{CO}_{2}$ can result in increased severity of the Fusarium pseudograminearum pathogen, leading to shriveled grains with low market value (Melloy et al., 2010).

Extreme temperatures and elevated $\mathrm{CO}_{2}$ concentrations reduce milling quality of rice by increasing chalkiness, but can improve taste, through, for example, reduced amylase concentration (Yang et al., 2007). Cultivars vary in their susceptibility to these processes (Ambardekar et al., 2011; Lanning et al., 2011). Overall, there is robust evidence and high agreement that elevated $\mathrm{CO}_{2}$ on its own likely results in decreased nitrogen concentrations. Combining knowledge of nitrogen and mineral studies, there is medium evidence and medium agreement that mineral concentrations will decline. The majority of these data are from wheat, with comparatively little information from key crops such as maize, rice, potato, and cassava; thus magnitudes are uncertain for these species.

Elevated $\mathrm{O}_{3}$ concentrations appear to have the opposite effect as elevated $\mathrm{CO}_{2}$. Meta-analysis of about 50 wheat experiments found that elevated $\mathrm{O}_{3}$ increased grain protein concentration by decreasing yield (Pleijel and Uddling, 2012). For other species, studies find both increases and decreases of $\mathrm{N}$ and several minerals (Taub et al., 2008), and as such no firm conclusions can be drawn, but they mostly respond similarly. Likewise, experiments examining the effect of drought on mineral concentrations find both decreases and increases (Ghorbanian et al., 2011; Sun et al., 2011). 
Confidence in the impact of climate, $\mathrm{CO}_{2}$, and $\mathrm{O}_{3}$ on food quality does not imply confidence in changes regarding human health for several reasons. Processing of food affects nutrient concentrations, when the nutrient-rich outer layers of rice are removed, leaving the starch dense endosperm. Also, elevated $\mathrm{CO}_{2}$ can increase crop yield, thus increasing the overall yield of minerals (Duval et al., 2011) and permitting greater mineral consumption. Furthermore, since calorie intake is the primary concern in many food-insecure populations, even if intake of minerals is decreased, those negative effects could be outweighed by increased calorie intake. In assessing impacts on health, current diets must be considered. Decreased mineral intake will matter for those who currently do not meet, or just barely meet, requirements, but will not affect those who already exceed requirements. Little is known about combined effects of climate change factors on food quality or the economic and behavioral changes that will occur. Thus, there is little confidence regarding effects of climate change on human health through changes in nutrient composition.

\subsubsection{Pastures and Livestock}

Pastures response to climate change is complex because, in addition to the direct major atmospheric and climatic drivers $\left(\mathrm{CO}_{2}\right.$ concentration, temperature, and precipitation), there are important indirect interactions such as plant competition, perennial growth habits, seasonal productivity, and plant-animal interactions. Projected increases in temperature and the lengthening of the growing season should extend forage production into late fall and early spring, thereby decreasing the need for accumulation of forage reserves during the winter season in USA (Izaurralde et al., 2011). In addition, water availability may play a major role in the response of pasturelands to climate change although there are differences in species response (Izaurralde et al., 2011). There is general consensus that increases in $\mathrm{CO}_{2}$ will benefit $\mathrm{C}_{3}$ species; however, warmer temperatures and drier conditions will tend to favor $\mathrm{C}_{4}$ species (Hatfield et al., 2011; Izaurralde et al., 2011; Chapter 4). While elevated atmospheric $\mathrm{CO}_{2}$ concentrations reduce sensitivity to lower precipitation in grassland ecosystems and can reduce mortality and increase recovery during severe water stress events, it is still unclear how general this result is (Soussana et al., 2010).

Temperature is an important limiting factor for livestock. As productivity increases, be it increasing milk yield in dairy cattle or higher growth rates and leanness in pigs or poultry, so metabolic heat production increases and the capacity to tolerate elevated temperatures decreases (Zumbach et al., 2008; Dikmen and Hansen, 2009). Over the long term, single-trait selection for productivity will tend to result in animals with lower heat tolerance (Hoffmann, 2010). Recent work adds to previous understanding (WGII AR4 Chapter 5) and indicates that heat stress (medium evidence, high agreement) in dairy cows can be responsible for the increase in mortality and economic losses (Vitali et al., 2009); it affects a wide range of parameters in broilers (Feng et al., 2008a); it impairs embryonic development and reproductive efficiency in pigs (Barati et al., 2008); and affects ovarian follicle development and ovulation in horses (Mortensen et al., 2009). Water stress also limits livestock systems. Climate change will affect the water resources available for livestock via impacts on runoff and groundwater (Chapter 3). Populated river basins may experience changes in river discharge, and large human and livestock populations may experience water stress such that proactive or reactive management interventions will almost certainly be required (Palmer et al., 2008). Problems of water supply for increasing livestock populations will be exacerbated by climate change in many places in sub-Saharan Africa and South Asia.

\subsubsection{Sensitivity of Food Security to Weather and Climate}

\subsubsection{Non-Production Food Security Elements}

As indicated in the discussion in Section 7.1.1 and Figure 7-1, food security is dependent on access and consumption patterns, food utilization and nutrition, and overall stability of the system as much as food production and availability. The overall impact of climate change on food security is considerably more complex and potentially greater than projected impacts on agricultural productivity alone. Figure 7-1 indicates the main components of food security and their key elements. All of these will be affected by climate change to some extent. For example, climate change effects on water, sanitation, and energy availability have major implications for food access and utilization as well as availability. Likewise, changes in the frequency and severity of climate extremes can affect stability of food availability and prices, with consequent impacts on access to food.

\subsubsection{Accessibility, Utilization, and Stability}

\subsection{Climate change impacts on access}

As noted in the discussion in Section 7.1.3, change in the levels and volatility of food prices is a key determinant of food access. Given the hypothesis that climate change will be a contributing factor to food price increases, and hence its affordability, the vulnerability of households to reduced food access depends on their channel of food access (medium evidence, medium agreement). Table 7-1 divides households into five main categories of food access, indicating their relative impacts of food price increases.

Concern about the impact of increased food prices on poverty and food security arises due to the high share of income that poor consumers spend on food, thus generating a disproportionately negative effect of price increases on this group (FAO, 2011). A study by the World Bank estimated a net increase of 44 million people in extreme poverty in lowand middle-income countries as a result of food price increases since June 2010 (Ivanic et al., 2011).

The distribution of net food buyers and net food sellers varies considerably across countries and can be expected to change with the process of economic development (Zezza et al., 2008; Aksoy et al., 2010; FAO, 2011). Changing consumption patterns associated with dietary transitions that accompany income growth, urbanization, market development, and trade liberalization determine the rate and nature of food demand growth and nutritional levels, and thus is a key determinant of global and local food security (Kearney, 2010). However, the evidence base on potential climate change impacts on consumption patterns, or on other non-production elements of food security is thin, particularly when 
Table 7-1 | Households divided into five categories of food access, indicating the impacts of food price increases.

\begin{tabular}{l|l|l}
\hline Food access category & \multicolumn{1}{|c|}{ Characteristics } & \multicolumn{1}{c}{ Impacts of food price increase on food access } \\
\hline $\begin{array}{l}\text { Primarily subsistence } \\
\text { (autarkic) }\end{array}$ & $\begin{array}{l}\text { Subsistence farmers, herders, fishers, and forest-dependent populations; } \\
\text { generally low share of population (Karfakis et al., 2011) }\end{array}$ & Limited impact \\
\hline Food producers: net sellers & $\begin{array}{l}\text { Generally lower share of population compared with net buyers (Aksoy and } \\
\text { Sid-Dimelik, 2008; Zezza et al., 2008; FAO, 2011) }\end{array}$ & $\begin{array}{l}\text { Positive impact through increased income effect. Major beneficiaries are those } \\
\text { with greatest surplus (e.g., larger, more commercialized farms) (FAO, 2011) }\end{array}$ \\
\hline Food producers: net buyers & Majority of poor rural households (IFAD, 2010; FAO, 2011) & $\begin{array}{l}\text { Ambiguous: depends on relative size of income and price effects, but generally } \\
\text { expected to be negative due to high share of income spent on food (Ivanic and } \\
\text { Martin, 2008; FAO, 2011; Ivanic et al., 2011) }\end{array}$ \\
\hline $\begin{array}{l}\text { Rural non-farming } \\
\text { households }\end{array}$ & $\begin{array}{l}\text { Rural landless: characterized by high rates of food insecurity; average share of } \\
\text { population for 15 low-income countries was 22\% (Aksoy et al., 2010) }\end{array}$ & $\begin{array}{l}\text { Negative impact due to high share of income spent on food; however, some } \\
\text { limited evidence that wage increases may accompany price increases, in which } \\
\text { case overall effects are ambiguous (Aksoy and Sid-Dikmelik, 2008; FA0, 2011) }\end{array}$ \\
\hline Urban consumers & Growing share of population in most countries (IFAD, 2010) & $\begin{array}{l}\text { Negative impact by reducing food affordability. Especially vulnerable to } \\
\text { changes in global food prices, as they are more likely to consume staple foods } \\
\text { derived from tradable commodities (FAO, 2008; Ivanic et al., 2011) }\end{array}$ \\
\hline
\end{tabular}

compared with the literature on climate change impacts on food production and availability.

Current and future variation in the distribution and vulnerability to loss of food access across household types makes impacts assessment complex and difficult. Nonetheless, there are reasons for concern about food access due to the current high rates of food insecurity in many low income countries. Agricultural producers who are net food buyers are particularly vulnerable. Similarly, low-income agricultural dependent economies that are net food importers, which are those that already have high rates of food insecurity, could experience significant losses in food access through a double negative effect on reduced domestic agricultural production and increased food prices on global markets.

\subsection{Climate change impacts on stability}

There is increasing evidence of and confidence in the effect of climate change on increasing the incidence and frequency of some types of climate extreme events (IPCC, 2012), and this will have significant impacts on food security (medium evidence, medium agreement). Recent experience of global climate patterns affecting food security indicates the potential nature and magnitude of increased variability. An impact assessment of the 2010 Pakistan floods surveyed 1800 households 6 months after the floods and found that $88 \%$ of the households reported income losses of up to $50 \%$, with significantly higher rates in rural than urban areas (Kirsch et al., 2012). The same study indicated that loss of key services such as electricity, sanitation, and clean water resulted in lower standards of living even in the wake of significant relief attempts, again with significantly heavier effects on rural populations (Kirsch et al., 2012). The Russian heat wave of 2010 and subsequent export ban contributed to the more than doubling of global wheat prices by the end of the year. The degree to which these price increases affected domestic consumers and poverty depended on national responses in importing countries, although a significant net negative effect on poverty was found (Ivanic et al., 2011).

Increased incidence of climate extremes reduces incentives to invest in agricultural production, potentially offsetting positive impacts from increasing food price trends. This is particularly true for poor smallholders with limited or no access to credit and insurance. Greater exposure to climate risk, in the absence of well-functioning insurance markets, leads to (1) greater emphasis on low-return but low-risk subsistence crops (Roe and Graham-Tomasi, 1986; Fafchamps, 1992; Heltberg and Tarp, 2002), (2) a lower likelihood of applying purchased inputs such as fertilizer (Kassie et al., 2008; Dercon and Christiansen, 2011), (3) a lower likelihood of adopting new technologies (Feder et al., 1985; Antle and Crissman., 1990), and (4) lower investments (Skees et al., 1999). All of these responses generally lead to both lower current and future farm profits (robust evidence, high agreement) (Rosenzweig and Binswanger, 1993; Hurley, 2010).

It is also well documented that in many rural areas, smallholders in particular do not have the capacity to smooth consumption in the face of climate shocks, particularly generalized shocks that affect a majority of households in the same location (Dercon, 2004; Skoufias and Quisumbing, 2005; Dercon, 2006; Fafchamps, 2009; Prakash, 2011). Any increases in climate extremes will exacerbate the vulnerability of all food-insecure people, including smallholders (robust evidence, high agreement). Currently, smallholders rely to a large extent on increasing labor off-farm where possible (Fafchamps, 1999; Kazianga and Udry, 2006), but also by decreasing both food consumption and non-food expenditures, such as those on education and health care (medium evidence, high agreement; Skoufias and Quisumbing, 2005). Furthermore, some evidence also suggests that poorer households are more likely to reduce consumption, while wealthier households liquidate assets to cover current deficits (limited evidence, medium agreement; Kazianga and Udry, 2006; Carter and Lybbert, 2012). Reductions in food consumption, sales of productive assets, education, and health care can lead to long-term losses in terms of income generation and thus to future food security (limited evidence, medium agreement; Skoufias and Quisumbing, 2005; Hoddinot et al., 2008). Increased uncertainty of future climate conditions and increases in climate extremes will increase food insecurity unless these significant barriers to consumption and asset smoothing can be addressed (medium evidence, medium agreement).

\subsection{Climate change impacts on utilization}

Climate change impacts on utilization may come about through changes in consumption patterns in response to shocks, as well as changes in nutrient content of food as well as food safety (medium evidence, medium agreement). Rationing consumption to prioritize calorie-rich but nutrient-poor foods is another common response (Bloem et al., 
2010). The effects are a decrease in dietary quality as well as quantity, which are magnified by pre-existing vulnerabilities — and lead to longterm loss of health, productivity capacity, and low incomes (medium evidence, medium agreement) (Alderman, 2010; Bloem et al., 2010; Brinkman et al., 2010; Campbell et al., 2010; Sari et al., 2010). The biological effects of climate change on nutrient content of foods are one of the main pathways for effects on utilization. A summary of recent literature on the impacts of climate change on the composition of nutrients in food items is given in HLPE (2012). Research on grains generally shows lowering of protein content with elevated temperature and $\mathrm{CO}_{2}$ levels (Erda et al., 2005; Ainsworth and McGrath, 2010; Hatfield et al., 2011). There is good agreement that for plant-derived foods, mycotoxins are considered the key issue for food safety under climate change (Miraglia et al., 2009). The impacts of climate change on mycotoxins in the longer term are complex and region-specific; temperatures may increase sufficiently to eliminate certain mycotoxin-producing species from parts of the tropics but, in colder tropical regions and temperate zones, infections may increase (Cotty and Jaime-Garcia, 2007).

\subsubsection{Sensitivity of Land Use to Weather and Climate}

As noted in the AR4, changes in land use, for example, adjusting the location of crop production, are a potential adaptation response to climate change. Studies since the AR4 have confirmed that high-latitude locations will, in general, become more suitable for crops (Iqbal et al., 2009). Trnka et al. (2011), for example, examined projections of eleven agro-climatic indices across Europe, and found that declines in frost occurrence will lead to longer growing seasons, although temperature and moisture stress will often lead to greater interannual variability in crop suitability. The potential influence of pests and diseases is commonly beyond the scope of such studies (Gregory et al., 2009).

For tropical systems where moisture availability or extreme heat rather than frost limits the length of the growing season, there is a likelihood that the length of the growing season and overall suitability for crops will decline (medium evidence, medium agreement; Jones and Thornton, 2009; Zhang and Cai, 2011). For example, half of the wheat-growing area of the Indo-Gangetic Plains could become significantly heat stressed by the 2050s, while temperate wheat environments will expand northwards as climate changes (Ortiz et al., 2008). Similarly, by 2050, the majority of African countries will experience climates over at least half of their current crop area that lie outside the range currently experienced within the country (Burke et al., 2009). The majority of these novel climates have analogs in other African countries. In mountainous regions, where temperature varies significantly across topography, changes in crop suitability can be inferred from the variation of temperature across topography. The resulting vertical zones of increasing, decreasing, and unchanging suitability can be relatively robust in the face of uncertainty in future climate (Schroth et al., 2009).

The interaction between water resources and agriculture is expected to become increasingly important as climate changes. For example, whilst projected changes in crop productivity in China are uncertain, even within a single emissions scenario, irrigation has significant adaptation potential (Piao et al., 2010). However, limitations to availability of water will affect this potential. Changes in water use, including increased water diversion and development to meet increasing water demand,

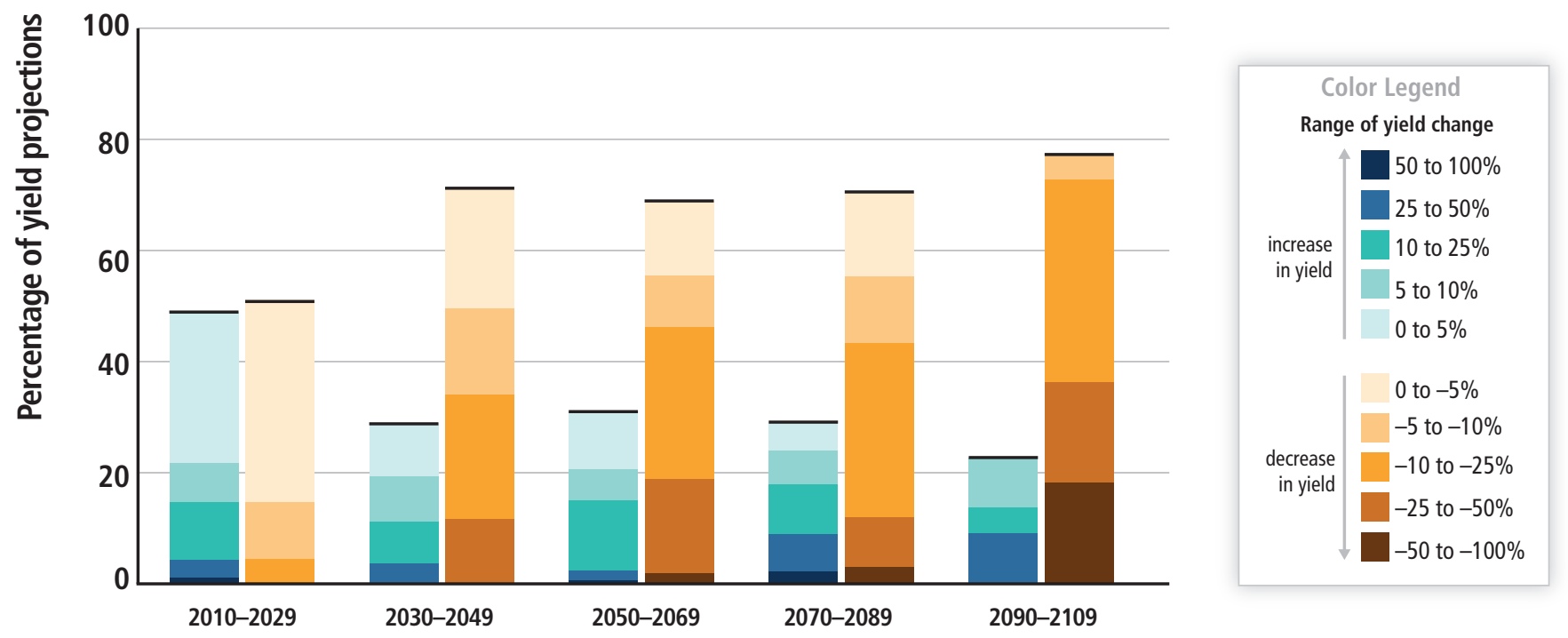

Figure 7-5 | Summary of projected changes in crop yields, due to climate change over the 21st century. The figure includes projections for different emission scenarios, for tropical and temperate regions, and for adaptation and no-adaptation cases combined. Relatively few studies have considered impacts on cropping systems for scenarios where global mean temperatures increase by $4^{\circ} \mathrm{C}$ or more. For five timeframes in the near-term and long-term, data $(n=1090)$ are plotted in the 20-year period on the horizontal axis that includes the midpoint of each future projection period. Changes in crop yields are relative to late-20th-century levels. Data for each timeframe sum to $100 \%$. Projections taken from Abraha and Savage, 2006; Alexandrov and Hoogenboom, 2000; Arndt et al., 2011; Berg et al., 2013; Brassard and Singh, 2008; Brassard and Singh, 2007; Butt et al., 2005; Calzadilla et al., 2009; Chhetri et al., 2010; Ciscar et al., 2011; Deryng et al., 2011; Giannakopoulos et al., 2009; Hermans et al., 2010; Iqbal et al., 2011; Izaurralde et al, 2005; Kim et al., 2010; Lal, 2011; Li et al., 2011; Lobell et al., 2008; Moriondo et al., 2010; Müller et al., 2010; Osborne et al., 2013; Peltonen-Sainio et al., 2011; Piao et al., 2010; Ringler et al., 2010; Rowhanji et al., 2011; Schlenker and Roberts, 2009; Shuang-He et al., 2011; Southworth et al., 2000; Tan et al., 2010; Tao \& Zhang, 2010; Tao and Zhang, 2011; Tao et al., 2009; Thornton et al., 2009; Thornton et al., 2010; Thornton et al., 2011; Tingem and Rivington, 2009; Tingem et al., 2008; Walker and Schulze, 2008; Wang et al., 2011; Xiong et al., 2007; Xiong et al., 2009. 
and increased dam building will also have implications for inland fisheries and aquaculture, and therefore for the people dependent on them (Ficke et al., 2007; FAO, 2009a). In the case of the Mekong River basin, a large proportion of the 60 million inhabitants are dependent in some way on fisheries and aquaculture that will be seriously impacted by human population growth, flood mitigation, increased offtake of water, changes in land use, and overfishing, as well as by climate change (Brander, 2007). Ficke et al. (2007) reported that at that time there were 46 large dams planned or already under construction in the Yangtze River basin, the completion of which would have detrimental effects on those dependent on fish for subsistence and recreation.

The models used in projections of land suitability and cropland expansion discussed above rely on assumptions about non-climatic constraints on crop productivity, such as soil quality and access to markets. These assumptions are increasingly amenable to testing as the climate system shifts, by comparing observed changes in cropland area with model predictions. The location of the margin between cropping land and extensive grazing in southern Australia has varied with decadal climate conditions and is projected to shift toward the coast with hotter and drier conditions, notwithstanding the positive impacts of elevated $\mathrm{CO}_{2}$ (Nidumolu et al., 2012). Recent trends in climate have seen reductions in cropping activity consistent with these projections (Nidumolu et al., 2012).

\subsection{Projected Integrated Climate Change Impacts}

\subsubsection{Projected Impacts on Cropping Systems}

Crop yields remain the most well studied aspect of food security impacts from climate change, with many projections published since AR4. These newer studies confirm many of the patterns identified in AR4, such as negative yield impacts for all crops past $3^{\circ} \mathrm{C}$ of local warming without adaptation, even with benefits of higher $\mathrm{CO}_{2}$ and rainfall (Figure 7-4).

Figure 7-5 shows projected impacts on mean crop yield in 20-year bins, including cases with no adaptation and a range of incremental adaptations. The data indicate that negative impacts on average yields become likely from the 2030s. Negative impacts of more than $5 \%$ are more likely than not beyond 2050 and likely by the end of the century. Some important differences by emission scenario and region are masked in Figure 7-5. From the 2080s onwards, negative yield impacts in the tropics are very likely, regardless of adaptation or emission scenario. This is consistent with the meta-analysis of Knox et al. (2012), and a recent model intercomparison of global gridded crop models (Rosenzweig et al., 2013, 2014).

A few studies have explicitly compared projections for different regions or crops to identify areas at most risk. Lobell et al. (2008) used a statistical crop model with 20 GCMs and identified South Asia and southern Africa as two regions that, in the absence of adaptation, would suffer the most negative impacts on several important crops. Yields changes have also been assessed by regional meta-analyses: Knox et al. (2012) synthesized projections from 52 studies and estimated an expected $8 \%$ negative yield impact in both regions by 2050 averaged over crops, with wheat, maize, sorghum, and millets more affected than rice, cassava, and sugarcane.

Changes in the interannual variability of yields could potentially affect stability of food availability and access. Figure 7-6 shows projected changes in the coefficient of variation (CV) of yield from some of the few studies that publish this information. The data shown are consistent with reports of CV elsewhere: Müller et al. (2014) conducted gridded simulations across the globe and reported an increase of more than $5 \%$ in CV in $64 \%$ of grid cells, and a decrease of more than $5 \%$ in $29 \%$ of cases. Increases in CV can be due to reductions in mean yields and/or increases in standard deviation of yields, and often simulated changes are a combination of the two. Overall, climate change will increase crop yield variability in many regions (medium evidence, medium agreement).

Estimated impacts of both historical and future climate changes on mean yields are summarized along with projected impacts on yield variability in Figure 7-7, with all impacts expressed as the average percentage impact per decade. This comparison illustrates that future impacts are expected to be consistent with the trajectory of past impacts, with the majority of locations experiencing negative impacts while some locations benefit. Each additional decade of climate change is expected to reduce mean yields by roughly $1 \%$, which is a small but nontrivial fraction of the anticipated roughly $14 \%$ increase in productivity per decade needed to keep pace with demand. For future projections, enough studies are available to assess differences by region and adaptation scenario, with significant adaptation effects apparent mainly in temperate systems (Section 7.5).

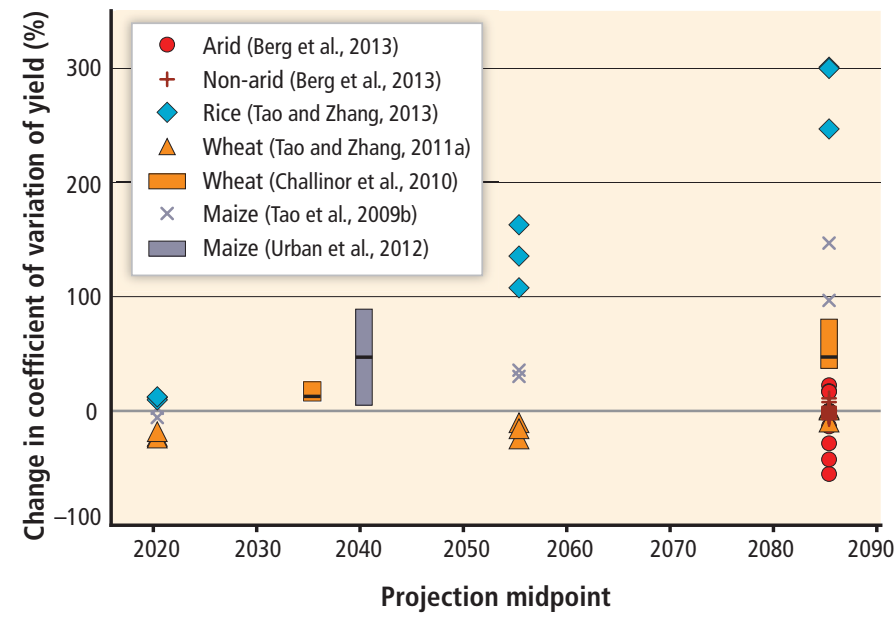

Figure 7-6 | Projected percentage change in coefficient of variation (CV) of yield for wheat (Tao and Zhang, 2011a; Challinor et al., 2010), maize (Tao et al., 2009b; Urban et al., 2012), rice (Tao and Zhang, 2013), and $C_{4}$ crops (arid and non-arid, Berg et al., 2013). The data from Urban et al. (2012) show the range (mean plus and minus one standard deviation) of percentage changes in CV. For the Challinor et al. (2010) data, paired CV changes were not available, so the box shows changes in the mean $C V$, the mean CV plus one standard deviation, and the mean CV minus one standard deviation. All other studies plot individual data points. A total of 81 data points are plotted in the figure, although the underlying data consist of many thousands of crop model simulations. The studies used a range of scenarios (Special Report on Emissions Scenarios (SRES) A1B, A2, A1FI, and B1). Berg et al. (2013) is a global study of the tropics, Urban et al. (2012) is for US maize, and the remaining data points are for China. 
(a) Impact of climate trend on mean crop yield

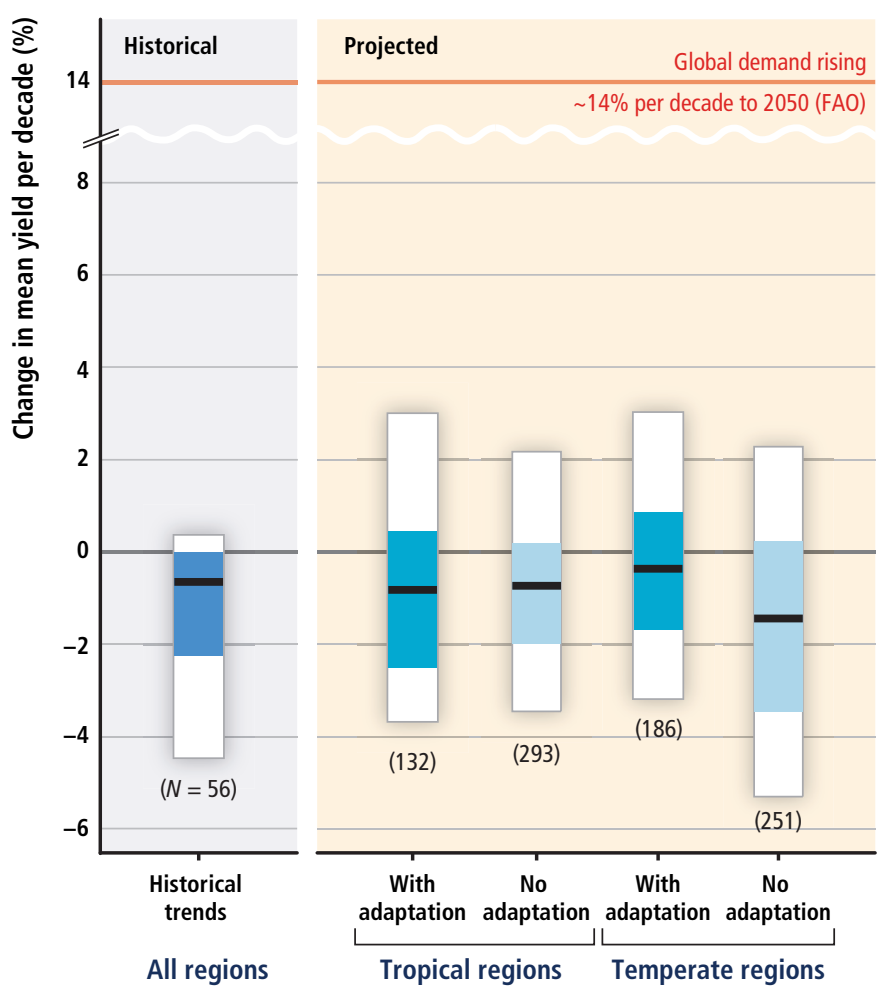

(b) Impact on year-to-year crop yield variability

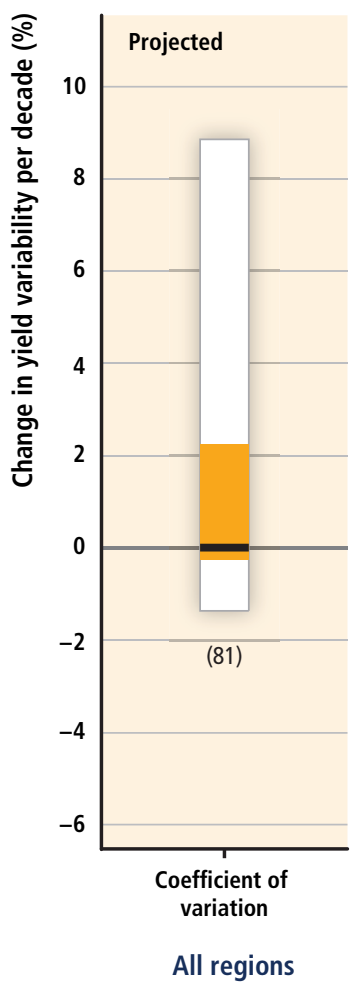

90th Percentile 75th Percentile Median 25th Percentile 10th Percentile -

Figure 7-7 | Boxplot summary of studies that quantify impact of climate and $\mathrm{CO}_{2}$ changes on crop yields, including historical and projected impacts, mean and variability of yields, and for all available crops in temperate and tropical regions. All impacts are expressed as average impact per decade (a 10\% total impact from a 50-year period of climate change would be represented as $2 \%$ per decade). References for historical impacts are given in Figure 7-2, for projected mean yields in Figure 7-5, and for yield variability in Figure 7-6. $N$ indicates the number of estimates, with some studies providing multiple estimates. In general, decreases in mean yields and increases in yield variability are considered negative outcomes for food security. Also indicated in the figure is the expected increase in crop demand of 14\% per decade (Alexandratos and Bruinsma, 2012), which represents a target for productivity improvements to keep pace with demand.

Relatively few studies have considered impacts on cropping systems for scenarios where global mean temperatures increase by $4^{\circ} \mathrm{C}$ or more. An analysis for sub-Saharan Africa predicted overall decreases of $19 \%$ for maize yields, $68 \%$ decrease for bean yields, and a small increase for fodder grass (Brachiaria decumbens) given $5^{\circ} \mathrm{C}$ global average warming (Thornton et al., 2011). Rötter et al. (2011) conclude that positive effects of modest warming and increased $\mathrm{CO}_{2}$ levels on crop yields in Finland will be reversed at global temperatures increases of $4^{\circ} \mathrm{C}$, leading to negative yield impacts in excess of $20 \%$ in relation to current conditions.

For perennial crops, winter chill accumulation that is important to many fruit and nut trees is projected to continue its decline, with, for instance, a 40 chill-hours per decade reduction projected for California for the period up to 2100 (Baldocchi and Wong, 2008). Averaging over three GCMs, annual winter chill loss by 2050 compared to 1970 would amount $17.7 \%$ to $22.6 \%$ in Egypt (Farag et al., 2010). Several studies have projected negative yield impacts of climate trends for perennial trees, including apples in eastern Washington (Stöckle et al., 2010) and cherries in California (Lobell and Field, 2011), although $\mathrm{CO}_{2}$ increases may offset some or all of these losses. Reductions in suitability for grapevine are expected in most of the wine-producing regions (Hall and Jones, 2009; White et al., 2009; Jones et al., 2010). Wine grape production and quality will be affected in Europe, USA, Australia (Jones et al., 2005; Wolfe et al., 2008; Cozzolino et al., 2010; Chapter 25), although it could be a benefit in Portugal (Santos et al., 2011) and British Columbia in
Canada (Rayne et al., 2009). Important crops in Brazil such as sugarcane and coffee are expected to migrate toward more favorable zones in the South (Pinto, 2007; Pinto et al., 2008; Chapter 27). Sugarcane fresh stalk mass is generally expected to gain from both warming and elevated $\mathrm{CO}_{2}$ in Brazil (Marin et al., 2013). The suitability for coffee crops in Costa Rica, Nicaragua, and El Salvador will be reduced by more than $40 \%$ (Glenn et al., 2013) while the loss of climatic niches in Colombia will force the migration of coffee crops toward higher altitudes by midcentury (Ramirez-Villegas et al., 2012). In the same way, increases in temperature will affect tea production, in particular at low altitudes (Wijeratne et al., 2007).

Consideration of pest, weed, and disease impacts are omitted from most yield projections, yet other studies have focused on projecting impacts of these biotic stressors. For pests and diseases, range expansion has been predicted for the destructive Phytophthora cinnamomi in Europe (Bergot et al., 2004) and for phoma stem canker on oilseed rape in the UK (Evans et al., 2008). Increased generations under climate change for the coffee nematode have been predicted for Brazil (Ghini et al., 2008). Walnut pests in California are predicted to experience increased numbers of generations under climate change scenarios (Luedeling et al., 2011). Luck et al. (2011) summarized the mixed results for the qualitative effects of climate change on pathogens that cause disease of four major food crops-wheat, rice, soybean, and potato-where some diseases increased in risk while others decreased under climate change scenarios. In syntheses, there is a tendency for risk of insect 
damage to plants to increase (Paulson et al., 2009). Typical scenario analyses are limited by simplistic assumptions, and work remains to evaluate how conclusions will change as more complete scenarios, such as those including migration and invasion patterns and other types of global change, are considered (Savary et al., 2005; Garrett et al., 2011). Effects on soil communities represent an area that needs more attention (Pritchard, 2011). Mycotoxins and pesticide residues in food are an important concern for food safety in many parts of the world, and identified as an important issue for climate change effects in Europe (Miraglia et al., 2009).

Weed populations and demographics are expected to change (medium confidence), with an overall poleward migration in response to warming (Ziska et al., 2011). An overview of crop and weed competitive studies indicate that weeds could limit crop yields to a greater extent with rising levels of $\mathrm{CO}_{2}$ per se (Ziska, 2010). This may be related to the greater degree of phenotypic and genotypic plasticity associated with weedy species relative to the uniformity inherent in large cropping systems (Section 4.2.4.6). Chemical control of weeds, which is the preferred management method for large-scale farms, may become less effective (limited evidence, medium agreement), with increasing economic and environmental costs (Section 7.3.2.3).

Climate change effects on productivity will alter land use patterns, both in terms of total area sown to crops and the geographic distribution of that area. For example, the suitability for potato crops is expected to increase in very high latitudes and high tropical altitudes toward 2100 (Schaefleitner et al., 2011). Given expected trends in population, incomes, bioenergy demand, and agricultural technology, global arable area is projected to increase from 2007 to 2050, with projected increases over this period of $+9 \%$ (Bruinsma, 2009), $+8 \%$ (Fischer et al., 2009), +10 to 20\% (Smith et al., 2010), and +18 to $23 \%$ (Lobell et al., 2013b) (medium evidence, medium agreement). Not all such studies included the effects of global warming. Where this is the case, estimates range from a 20\% increase in cropping area to a decline of 9\% (Zhang and Cai, 2011), but with large regional differences (limited evidence, low agreement). Countries at northern latitudes and under the current constraint of low temperature may increase cultivated area (limited evidence, low agreement). The generally lower nutrient quality of soils and the lack of necessary infrastructure required to convert virgin land into productive arable land make estimates of cropping area increases highly uncertain.

\subsubsection{Projected Impacts on Fisheries and Aquaculture}

Many studies have projected impacts of climate change on capture fisheries (Chapters 6 and 30) and only a subset of the more indicative studies at different ecological and geographical scales is included here. Overall, there is high confidence that climate change will impact on fisheries production with significant negative impacts particularly for developing countries in tropical areas, while more northerly, developed countries may experience benefits (Section 6.4.3).

Simulation studies on skipjack and bigeye tuna in the Pacific under both the Special Report on Emissions Scenarios (SRES) B1 and A2 scenarios indicate that catches of skipjack in the region as a whole are likely to increase by approximately 19\% in 2035 compared to recent catch levels while catches of bigeye are projected to increase only marginally. By 2100 , under the B1 scenario, catches of skipjack are projected to be $12.4 \%$ higher than recent levels but $7.5 \%$ lower under the $\mathrm{A} 2$ scenario, while catches of bigeye will be $8.8 \%$ and $26.7 \%$ lower under the B1 and $\mathrm{A} 2$ scenarios, respectively. The models indicate important regional differences, with a general trend that catches of tuna will decrease in the Western Pacific and increase in the Eastern Pacific (Lehodey et al., 2011; see also Sections 6.5.3, 30.6.2.1.1). These changes have important implications for the future of national fishing fleets and canneries in the Western Pacific (Bell et al., 2009). Climate change is expected to impact directly on the productivity of coastal fisheries in the Pacific island countries and territories through increased sea surface temperature and ocean acidification and indirectly through climate-driven damage to coral reefs, mangroves, seagrasses, and intertidal flats (Pratchett et al., 2011). Extreme events such as increased severity of tropical cyclones could also impact on some species. Under both B1 and A2 emissions scenarios, the vulnerability of coastal fisheries as a whole in 2035, as estimated through the framework described in Bell et al. (2009), is considered to be low. Extended to 2100, the projected impacts under the $\mathrm{A} 2$ emissions scenario are more severe, with reductions in coastal fisheries production by 20 to $35 \%$ in the west and 10 to $30 \%$ in the east (Pratchett et al., 2011).

\section{Frequently Asked Questions \\ FAQ 7.2 | How could climate change interact with change in fish stocks and ocean acidification?}

Millions of people rely on fish and aquatic invertebrates for their food security and as an important source of protein and some micronutrients. However, climate change will affect fish stocks and other aquatic species. For example, increasing temperatures will lead to increased production of important fishery resources in some areas but decreased production in others while increases in acidification will have negative impacts on important invertebrate species, including species responsible for building coral reefs that provide essential habitat for many fished species in these areas. The poorest fishers and others dependent on fisheries and subsistence aquaculture will be the most vulnerable to these changes, including those in Small Island Developing States, central and western African countries, Peru and Colombia in South America, and some tropical Asian countries. 
Brown et al. (2010) project that, under the A2 emissions scenario, primary production in the ocean around Australia will increase over the 50-year period from 2000 to 2050 as a result of small increases in nutrient availability from changes in ocean stratification and temperature, although the authors acknowledge considerable model uncertainty. This increase is forecast, in general, to benefit fisheries catch and value. In a complementary study, Fulton (2011) used available end-to-end models to forecast the impacts of climate change under the A2 scenario across approximately two-thirds of Australia's exclusive economic zone. The results indicated that by 2060 , the large-scale commercial fisheries, aided by their adaptive flexibility, would experience an overall increase of more than $90 \%$ in the value of their operations, although differing across sectors. The change in returns for the small-scale sector varied regionally from a decrease of 30 to $51 \%$ to a potential increase of 9 to $14 \%$.

At the global scale, projections based on a dynamic bioclimatological envelope model under the SRES A1B scenario suggested that climate change could lead to an average 30 to $70 \%$ increase in fisheries yield from high-latitude regions ( $>50^{\circ} \mathrm{N}$ in the Northern Hemisphere), but a decrease of up to $40 \%$ in the tropics by 2055 compared to yields obtained in 2005 (Cheung et al., 2010). Another study using a suite of models linking physical, ecological, fisheries, and bioeconomic processes projected that, under the A1B scenario, the global yield from "large" fish could increase by $6 \%$ and that of the "small fish" used in fishmeal production by approximately $3.6 \%$, assuming that marine fisheries and fish resources would be managed sustainably (Merino et al., 2012).

There is limited information available on projected impacts on food production in inland fisheries. Xenopoulus et al. (2005) investigated the effect of climate change and water withdrawal on freshwater fish extinctions under the assumptions of two scenarios consistent with scenarios A2 and B2. They forecast that discharge would increase in between 65 and $70 \%$ of river basins in the world but it would decrease by as much as $80 \%$ in 133 rivers for which fish species data were available. In the latter group, by 2070 , up to $75 \%$ (quartile range, $4-22 \%$ ) of the local fish biodiversity would be "headed toward extinction" because of changes in climate and water consumption, with the highest rates of extinction forecast mainly in tropical and subtropical areas. These results are not directly translatable into changes in fishery production but do give cause for concern for the likely affected areas (limited evidence, low agreement).

Information on future impacts on aquaculture is equally limited. Huppert et al. (2009) considered the impacts on the coast of Washington State, USA. They concluded that inundation of low-lying coastal areas from sea level rise, flooding from major storm events, and increased ocean temperatures and acidification would create significant challenges for the important shellfish aquaculture industry in the state. Inundation of existing shellfish habitats from sea level rise and increased incidence of harmful algal blooms were also contributory factors. Using a structured vulnerability framework and considering the B1 and A2 emission scenarios to project impacts on aquaculture in the tropical Pacific to 2035 and 2100, Pickering et al. (2011) concluded that production of freshwater species such as tilapia, carp, and milkfish will probably benefit from the expected climate changes, while coastal enterprises are expected to encounter problems in the same time horizons, varying according to species. Aquaculture production of calcifying organisms such as molluscs will experience loss of suitable habitats through ocean acidification. This will be particularly pronounced at and in the vicinity of eastern boundary upwelling systems (Section 30.6.2.1.4).

The food security consequences of the different impacts on capture fisheries and aquaculture are more difficult to estimate than the biological and ecological consequences. A preliminary study by Allison et al. (2009) examined the vulnerability of the economies of 132 countries to climate change impacts on fisheries in 2050 under the $\mathrm{A} 1 \mathrm{FI}$ and B2 scenarios. Vulnerability was considered as a composite of three components: exposure to the physical effects of climate change, the sensitivity of the country to impacts on fisheries, and adaptive capacity within the country. This analysis suggested that under both scenarios several of the least developed countries were also among the most vulnerable to climate change impacts on their fisheries. They included countries in central and western Africa, Peru and Colombia in South America, and four tropical Asian countries.

\subsubsection{Projected Impacts on Livestock}

Climate change impacts on livestock will include effects on forage and feed, direct impacts of changes in temperature and water availability on animals, and indirect effects via livestock diseases. Many of the relevant processes and projected impacts for rangelands are discussed in Section 4.3.3.2, as well as in chapters for regions with prominent livestock sectors (Sections 22.3.4.2, 23.4.2, 25.7.2.1). In North American cattle systems, warming is expected to lengthen forage growing season but decrease forage quality, with important variations due to rainfall changes (Craine et al., 2010; Hatfield et al., 2011; Izaurralde et al., 2011). Simulations for French grasslands (Graux et al., 2013) and sown pastures in Tasmania (Perring et al., 2010) also project negative impacts on forage quality. Similarly, legume content of grasslands in most of southern Australia is projected to increase to the 2070s for SRES A2, with larger increases in wetter locations (Moore and Ghahramani, 2013).

There is high confidence that high temperatures tend to reduce animal feeding and growth rates (André et al., 2011; Renaudeau et al., 2011). The impacts of a changing UK climate on dairy cow production were analyzed by Wall et al. (2010), who showed that, in some regions, milk yields will be reduced and mortality increased because of heat stress throughout the current century, with annual production and mortality losses amounting to some $\mathrm{f} 40$ million by the 2080 s under a mediumhigh GHG emission scenario.

Existing challenges of supplying water for an increasing livestock population will be exacerbated by climate change in many places (limited evidence, high agreement). For example, Masike and Urich (2008) project that warming under SRES A1 emission scenario will cause an annual increase of more than $20 \%$ in cattle water demand by 2050 for Kgatleng District, Botswana. At the same time, there is ample scope to improve livestock water productivity considerably (Molden et al., 2010); for example, in mixed crop-livestock systems of sub-Saharan Africa via feed, water, and animal management (Descheemaeker et al., 2010).

Host and pathogen systems in livestock will change their ranges because of climate change (high confidence). Species diversity of some 


\section{Box 7-1 | Projected Impacts for Crops and Livestock in Global Regions and Sub-Regions under Future Scenarios}

Projected impacts for crops and livestock in global regions and sub-regions under future scenarios. Crop yield impacts in parentheses correspond to parentheticals in the scenario column. $-\mathrm{CO}_{2}=$ without $\mathrm{CO}_{2}$ effects; $+\mathrm{CO}_{2}=$ with $\mathrm{CO}_{2}$ effects; $(\mathrm{I})=$ irrigated; $(\mathrm{R})=$ rainfed. $\mathrm{ARPEGE}=\mathrm{Action}$ de Recherche Petite Echelle Grande Echelle; CSIRO = Commonwealth Scientific and Industrial Research Organisation; ECHAM4 = European Centre for Medium Range Weather Forecasts Hamburg 4; GFDLCM2.0/2 = Geophysical Fluid Dynamics Laboratory-Climate Model 2.0/2; HadCM3 = Met Office Hadley Centre Climate Prediction Model 3; HIRHAM = High-Resolution Hamburg Climate Model; MIROC = Model for Interdisciplinary Research On Climate; MPI-OM = Max Planck Institute; MRI-CGCM2.3.2 = Meteorological Research Institute of Japan Meteorological Agency-Coupled General Circulation Model 2.3.2; PRECIS = Providing Regional Climates for Impact Studies; RCA3 = Rossby Centre Regional Atmospheric Model 3.

Regional impacts on crops

\begin{tabular}{|c|c|c|c|c|}
\hline Region & Sub-region & Yield impacts (\%) & Scenario & Reference \\
\hline World & & $\begin{array}{l}\text { - (I) Maize: }-4,-7 \\
\text { (R) Maize: }-2,-12 \\
\text { (I) Rice: }-9.5,-12 \\
\text { (R) Rice: }-1,+0.07 \\
\text { (I) Wheat: }-10,-13 \\
\text { - (R) Wheat: }-4,-10\end{array}$ & $\begin{array}{l}\text { A1B } \\
\text { CSIRO, MIROC } \\
2050\end{array}$ & Nelson et al. (2010) \\
\hline \multirow[t]{5}{*}{ East Asia } & China & $\begin{array}{l}\text { (I) Maize: } \\
-10.9 \text { to }-1.4(-7.8 \text { to }-1.6) \text {, } \\
-21.7 \text { to }-9.8(-16.4 \text { to }-10.2) \text {, } \\
-32.1 \text { to }-4.3(-26.6 \text { to }-3.9) \\
\text { (R) Maize: } \\
-22.2 \text { to }-1.0(-10.8 \text { to }+0.7) \text {, } \\
-27.6 \text { to }-7.9(-18.1 \text { to }-5.6) \text {, } \\
-33.7 \text { to }-4.6(-25.9 \text { to }-1.6) \\
\text { (l) Rice: } \\
-18.6 \text { to }-6.1(-10.1 \text { to }+3.3), \\
-31.9 \text { to }-13.5(-16.1 \text { to }+2.5) \\
-40.2 \text { to }-23.6(-19.3 \text { to }+0.18)\end{array}$ & $\begin{array}{l}+1^{\circ} \mathrm{C},+2^{\circ} \mathrm{C}_{1}+3^{\circ} \mathrm{C} \\
-\mathrm{CO}_{2}\left(+\mathrm{CO}_{2}\right)\end{array}$ & Tao et al. (2011) \\
\hline & Eastern China & $\begin{array}{l}\text { Rice: } \\
-10 \text { to }+3(+7.5 \text { to }+17.5), \\
-26.7 \text { to }+2(0 \text { to }+25), \\
-39 \text { to }-6(-10 \text { to }+25)\end{array}$ & $\begin{array}{l}2030,2050,2080 \\
-\mathrm{CO}_{2}\left(+\mathrm{CO}_{2}\right)\end{array}$ & Tao and Zhang (2013) \\
\hline & Huang-Huai-Hai Plain, China & Wheat-maize: $+4.5 \pm 14.8,-5.8 \pm 25.8$ & $+2^{\circ} \mathrm{C},+5^{\circ} \mathrm{C}$ & Liu et al. (2010) \\
\hline & North China Plain & $\begin{array}{l}\text { - (I) Wheat: }-0.9(+23) \\
\text { (R) Wheat: }-1.9(+28)\end{array}$ & $\begin{array}{l}\mathrm{A} 1 \mathrm{~B} \\
2085-2100 \\
-\mathrm{CO}_{2}\left(+\mathrm{CO}_{2}\right) \\
\text { MIROC }\end{array}$ & Yang et al. (2013) \\
\hline & Yangtze River, China & $\begin{array}{l}\text { - (I) Rice: }-14.8(-3.3) \\
\text { - (R) Rice: }-15.2(-4.1)\end{array}$ & $\begin{array}{l}\mathrm{B} 2 \\
2021-2050 \\
-\mathrm{CO}_{2}\left(+\mathrm{CO}_{2}\right)\end{array}$ & Shen et al. (2011) \\
\hline \multirow[t]{10}{*}{ South Asia } & South Asia & $\begin{array}{l}\text { - Maize: -16 } \\
\text { - Sorghum:-11 }\end{array}$ & 2050 & Knox et al. (2012) \\
\hline & South Asia & Net cereal production -4 to -10 & $+3^{\circ} \mathrm{C}$ & Lal (2011) \\
\hline & \multirow[t]{3}{*}{ India } & Winter sorghum: up to $-7,-11,-32$ & $\begin{array}{l}\text { A2 } \\
2020,2050,2080\end{array}$ & Srivastava et al. (2010) \\
\hline & & $\begin{array}{l}\text { - (I) Rice: }-4,-7,-10 \\
\text { - (R) Rice: }-6,-2.5,-2.5\end{array}$ & $\begin{array}{l}\text { A1B; } \mathrm{A} 2 ; \mathrm{B} 1 ; \mathrm{B} 2 \\
2020,2050,2080 \\
+\mathrm{CO}_{2} \\
\text { MIROC; PRECIS/HadCM3 }\end{array}$ & Kumar et al. (2013) \\
\hline & & $\begin{array}{l}- \text { Monsoon maize: }-21 \text { to } 0,-35 \text { to } 0,-35 \text { to } 0 \\
\text { - Winter maize: }-13 \text { to }+5,-50 \text { to }+5,-60 \text { to }-21\end{array}$ & $\begin{array}{l}\text { A2 } \\
2020,2050,2080 \\
\text { HadCM3 }\end{array}$ & Byjesh et al. (2010) \\
\hline & Northeast India & $\begin{array}{l}- \text { (I) Rice: }-10 \text { to }+5 \\
\text { - (R) Rice: }-35 \text { to }+5 \\
\text { - Maize: up to }-40 \\
\text { - Wheat: up to }-20\end{array}$ & \multirow[t]{3}{*}{$\begin{array}{l}\mathrm{A} 1 \mathrm{~B} \\
2030 \\
+\mathrm{CO}_{2} \\
\text { PRECIS/HadCM3 }\end{array}$} & \multirow[t]{3}{*}{ Kumar et al. (2011) } \\
\hline & Coastal India & $\begin{array}{l}\text { - (I) Rice: }-10 \text { to }+5 \\
\text { - (R) Rice: }-20 \text { to }+15 \\
\text { (I) Maize: }-50 \text { to }-15 \\
\text { - (R) Maize: }-35 \text { to }+10\end{array}$ & & \\
\hline & Western Ghats, India & $\begin{array}{l}\text { - (I) Rice: }-11 \text { to }+5 \\
\text { - (R) Rice: }-35 \text { to }+35 \\
\text { - Maize: up to }-50 \\
\text { - Sorghum: up to }-50\end{array}$ & & \\
\hline & \multirow[t]{2}{*}{ Pakistan } & Wheat: $-7,-24$ (Swat) $;+14,+23$ (Chitral) & $+1.5^{\circ} \mathrm{C},+3^{\circ} \mathrm{C}$ & Section 24.4.4.3 \\
\hline & & $\begin{array}{l}\text { - Wheat: }-6,-8 \\
\text { - Rice: }-16,-19\end{array}$ & $\begin{array}{l}\mathrm{B} 2, \mathrm{~A} 2 \\
2080\end{array}$ & Iqbal et al. (2009) \\
\hline
\end{tabular}


Box 7-1 (continued)

\begin{tabular}{|c|c|c|c|c|}
\hline Region & Sub-region & Yield impacts (\%) & Scenario & Reference \\
\hline West Asia & Yarmouk Basin, Jordan & $\begin{array}{l}\text { - Barley: }-8,+5 \\
\text { - Wheat: }-20,+18\end{array}$ & $-20 \%,+20 \%$ precipitation & Al-Bakri et al. (2010) \\
\hline \multirow[t]{4}{*}{ Africa } & All regions & $\begin{array}{l}\text { - Wheat: }-17 \\
\text { - Maize: }-5 \\
\text { - Sorghum: }-15 \\
\text { - Millet: }-10\end{array}$ & 2050 & Knox et al. (2012) \\
\hline & All regions & Maize: $-24 \pm 19$ & $\begin{array}{l}2090 \\
+5^{\circ} \mathrm{C}\end{array}$ & Thornton et al. (2011) \\
\hline & East Africa & $\begin{array}{l}\text { Maize: }-3.1 \text { to }+15.0,-8.6 \text { to }+17.8 \\
\text { Beans: }-1.5 \text { to }+21.8,-18.1 \text { to }+23.7\end{array}$ & $\begin{array}{l}\text { A1Fl; B1 } \\
\text { 2030, } 2050 \\
\text { HadCM3; ECHam4 }\end{array}$ & Thornton et al. (2010) \\
\hline & Sahel & Millet: $-20,-40$ & $+2^{\circ} \mathrm{C},+3^{\circ} \mathrm{C}$ & Ben Mohamed (2011) \\
\hline \multirow[t]{9}{*}{$\begin{array}{l}\text { Central \& } \\
\text { South America }\end{array}$} & Northeastern Brazil & $\begin{array}{l}\text { - Maize: } 0 \text { to }-10 \\
\text { - Wheat: }-1 \text { to }-14 \\
\text { Rice: }-1 \text { to }-10\end{array}$ & 2030 & $\begin{array}{l}\text { Table 27-5; Lobell et al. } \\
\text { (2008) }\end{array}$ \\
\hline & Southern Brazil & $\begin{array}{l}\text { - Maize: }-15 \\
\text { - Bean: up to +45 }\end{array}$ & $\begin{array}{l}\mathrm{A} 2 \\
2080 \\
+\mathrm{CO}_{2} \\
\mathrm{HadCM} 3\end{array}$ & $\begin{array}{l}\text { Table 27-5; Costa et al. } \\
\text { (2009) }\end{array}$ \\
\hline & Paraguay & $\begin{array}{l}\text { - Wheat: }+4,-9,-13(-1,+1,-5) \\
\text { - Maize: }+3,+3,+8(+3,+1,+6) \\
\text { - Soybean: } 0,-10,-15(0,-15,-2)\end{array}$ & $\begin{array}{l}\text { A2 (B2) } \\
\text { 2020, 2050, } 2080 \\
\text { PRECIS }\end{array}$ & Table 27-5; ECLAC (2010) \\
\hline & \multirow[t]{2}{*}{ Central America } & $\begin{array}{l}\text { - Wheat: }-1 \text { to }-9 \\
\text { - Rice: } 0 \text { to }-10\end{array}$ & 2030 & $\begin{array}{l}\text { Table 27-5; Lobell et al. } \\
\text { (2008) }\end{array}$ \\
\hline & & $\begin{array}{l}- \text { Maize: } 0,0,-10,-30 \\
\text { - Bean: }-4,-19,-29,-87 \\
\text { - Rice: }+3,-3,-14,-63\end{array}$ & $\begin{array}{l}A 2 \\
2030,2050,2070,2100\end{array}$ & Table 27-5; ECLAC (2010) \\
\hline & Panama & Maize: $-0.5,+2.4,+4.5(-0.1,-0.8,+1.5)$ & $\begin{array}{l}\mathrm{A} 2(\mathrm{~B} 1) \\
2020,2050,2080 \\
+\mathrm{CO}_{2}\end{array}$ & $\begin{array}{l}\text { Table 27-5; Ruane et al. } \\
\text { (2013) }\end{array}$ \\
\hline & Andean region & $\begin{array}{l}\text { - Wheat: }-14 \text { to }+2 \\
\text { - Barley: } 0 \text { to }-13 \\
\text { - Potato: } 0 \text { to }-5 \\
\text { - Maize: } 0 \text { to }-5\end{array}$ & 2030 & $\begin{array}{l}\text { Table 27-5; Lobell et al. } \\
\text { (2008) }\end{array}$ \\
\hline & Chile & $\begin{array}{l}\text { - Maize: }-5 \% \text { to }-10 \% \\
\text { Wheat: }-10 \% \text { to }-20 \%\end{array}$ & $\begin{array}{l}\mathrm{A} 1 \mathrm{FI} \\
2050 \\
+\mathrm{CO}_{2} \\
\mathrm{HadCM} 3\end{array}$ & $\begin{array}{l}\text { Table 27-5; Meza and Silva } \\
\text { (2009) }\end{array}$ \\
\hline & Argentina & $\begin{array}{l}\text { - Wheat: }-16,-11(+3,+3) \\
\text { - Maize: }-24,-15(+1,0) \\
\text { - Soybean: }-25,-14(+14,+19)\end{array}$ & $\begin{array}{l}\mathrm{A} 2, \mathrm{~B} 2 \\
2080 \\
-\mathrm{CO}_{2}\left(+\mathrm{CO}_{2}\right) \\
\text { PRECIS }\end{array}$ & Table 27-5; ECLAC (2010) \\
\hline \multirow[t]{5}{*}{ North America } & Midwestern United States & $\begin{array}{l}\text { - Maize: }-2.5(-1.5) \\
\text { - Soy: +1.7 (+9.1) }\end{array}$ & \multirow[t]{3}{*}{$\begin{array}{l}+0.8^{\circ} \mathrm{C} \\
-\mathrm{CO}_{2}\left(+\mathrm{CO}_{2}\right)\end{array}$} & \multirow[t]{3}{*}{ Hatfield et al. (2011) } \\
\hline & Southeastern United States & $\begin{array}{l}\text { - Maize: }-2.5(-1.5) \\
\text { - Soy: }-2.4(+5.0)\end{array}$ & & \\
\hline & United States Great Plains & Wheat: $-4.4(+2.4)$ & & \\
\hline & Northwestern United States & $\begin{array}{l}\text { Winter wheat: }+19.5,+29.5 \\
\text { - Spring wheat: }-2.2,-5.6\end{array}$ & $\begin{array}{l}\mathrm{A} 1 \mathrm{~B} \\
2040,2080 \\
+\mathrm{CO}_{2} \\
\end{array}$ & Stöckle et al. (2010) \\
\hline & Canadian prairies & $\begin{array}{l}\text { - Small grains: }-48 \text { to }+18 \\
\text { - Oilseeds: }-50 \text { to }+25\end{array}$ & $\begin{array}{l}+1^{\circ} \mathrm{C},+2^{\circ} \mathrm{C},+20 \% \text { precipiation, } \\
-20 \% \text { precipitation }\end{array}$ & Kulshreshtha (2011) \\
\hline \multirow[t]{9}{*}{ Europe } & Boreal & Wheat, maize, soybean: +34 to +54 & \multirow{9}{*}{$\begin{array}{l}\text { A2, B2 } \\
2080 \\
\text { HadCM3/HIRHAM, ECHAM4/RCA3 }\end{array}$} & \multirow[t]{9}{*}{ Iglesias et al. (2012) } \\
\hline & Alpine & Wheat, maize, soybean: +20 to +23 & & \\
\hline & Atlantic North & Wheat, maize, soybean: -5 to +22 & & \\
\hline & Atlantic Central & Wheat, maize, soybean: +5 to +19 & & \\
\hline & Atlantic South & Wheat, maize, soybean: -26 to -7 & & \\
\hline & Continental North & Wheat, maize, soybean: -8 to +4 & & \\
\hline & Continental South & Wheat, maize, soybean: +11 to +33 & & \\
\hline & Mediterranean North & Wheat, maize, soybean: -22 to 0 & & \\
\hline & Mediterranean South & Wheat, maize, soybean: -27 to +5 & & \\
\hline
\end{tabular}




\section{Box 7-1 (continued)}

\begin{tabular}{|c|c|c|c|c|}
\hline Region & Sub-region & Yield impacts (\%) & Scenario & Reference \\
\hline \multirow[t]{2}{*}{ Australia } & South & Wheat: $-15,-12$ & $\begin{array}{l}\text { A2; Low, high plant available } \\
\text { water capacity } \\
2080 \\
+\mathrm{CO}_{2} \\
\text { CCAM }\end{array}$ & Luo et al. (2009) \\
\hline & Southeast & Wheat: -29 (-25) & $\begin{array}{l}\mathrm{B} 2, \mathrm{~A} 2, \mathrm{~A} 1 \mathrm{FI} \\
2080 \\
-\mathrm{CO}_{2}\left(+\mathrm{CO}_{2}\right) \\
\mathrm{CCAM}\end{array}$ & Anwar et al. (2007) \\
\hline
\end{tabular}

\section{Regional impacts on livestock}

\begin{tabular}{|c|c|c|c|c|}
\hline Region & Sub-region & Climate change impacts & Scenarios & Reference \\
\hline \multirow[t]{5}{*}{ Africa } & Botswana & $\begin{array}{l}\text { Cost of supplying water from boreholes could increase by } 23 \% \\
\text { due to increased hours of pumping, under drier and warmer } \\
\text { conditions. }\end{array}$ & \multirow[t]{4}{*}{$\begin{array}{l}\mathrm{A} 2, \mathrm{~B} 2 \\
2050\end{array}$} & \multirow[t]{4}{*}{ Section 22.3.4.2 } \\
\hline & Lowlands of Africa & $\begin{array}{l}\text { Reduced stocking of dairy cows, a shift from cattle to sheep and } \\
\text { goats, due to high temperature. }\end{array}$ & & \\
\hline & Highlands of East Africa & Livestock keeping could benefit from increased temperature. & & \\
\hline & East Africa & $\begin{array}{l}\text { Maize stover availability per head of cattle may decrease due to } \\
\text { water scarcity. }\end{array}$ & & \\
\hline & South Africa & Dairy yields decrease by $10-25 \%$. & $\begin{array}{l}\text { A2 } \\
2046-2065 / 2080-2100 \\
\text { ECHAM5/MPI-OM, GFDL-CM2.0/2, } \\
\text { MRI-CGCM2.3.2 }\end{array}$ & $\begin{array}{l}\text { Nesamvuni et al. } \\
\text { (2012) }\end{array}$ \\
\hline \multirow[t]{7}{*}{ Europe } & Netherlands & Dairy production affected at daily mean temperatures above $18^{\circ} \mathrm{C}$ & & \multirow[t]{2}{*}{ Section 23.4 .2} \\
\hline & Italy & $\begin{array}{l}\text { Mortality risk to dairy cattle increased by } 60 \% \text { by exposure to } \\
\text { high air temperature and high air humidity during breeding. }\end{array}$ & & \\
\hline & French Uplands & $\begin{array}{l}\text { Annual grassland production system significantly reduced by } \\
\text { 4-year exposure to climatic conditions. }\end{array}$ & $\begin{array}{l}\text { A2 } \\
2070\end{array}$ & Cantarel et al. (2013) \\
\hline & France & No impact on dairy yields. & $\begin{array}{l}\text { A2 } \\
\text { 1970-1999, 2020-2049, 2070-2099 } \\
\text { ARPEGE }\end{array}$ & Graux et al. (2011) \\
\hline & Ireland, France & $\begin{array}{l}\text { Grassland dairy system increases potential of dairy production, } \\
\text { with increased risk of summer-autumn forage failure in France. }\end{array}$ & $\begin{array}{l}\text { A1B } \\
\text { By the end of century }\end{array}$ & \\
\hline & \multirow[t]{2}{*}{ Overall Europe } & $\begin{array}{l}\text { Spread of bluetongue virus (BTV) in sheep and ticks in cattle due } \\
\text { to climate warming. }\end{array}$ & \multirow[t]{2}{*}{2080} & Graux et al. (2011) \\
\hline & & $\begin{array}{l}\text { No increase in risk of incursion of Crimean-Congo hemorrhagic } \\
\text { fever virus in livestock. }\end{array}$ & & Section 23.4 .2 \\
\hline \multirow[t]{9}{*}{ Australia } & Northern Australia & $\begin{array}{l}3^{\circ} \mathrm{C} \text { increase in temperature will result in } 21 \% \text { reduction in forage } \\
\text { production for } \mathrm{CO}_{2} \text { at } 350 \mathrm{ppm} \text { level and no change at } 650 \mathrm{ppm} \\
\text { level. Changes of } \pm 10 \% \text { in rainfall were exacerbated to } \pm 15 \% \\
\text { change in forage production at } 350 \mathrm{ppm} \mathrm{CO}_{2} \text {. }\end{array}$ & $\begin{array}{l}\text { A1B } \\
2030\end{array}$ & McKeon et al. (2009) \\
\hline & Australia (other than Tasmania) & Dairy output will decline under $1^{\circ} \mathrm{C}$ increase in temperature. & $\begin{array}{l}\text { A1B } \\
2030\end{array}$ & \multirow[t]{2}{*}{ Section 25.7.2.1 } \\
\hline & 25 sites in southern Australia & $\begin{array}{l}\text { Profitability of fodder supply production declinedat most sites } \\
\text { due to shorter growing season. }\end{array}$ & $\begin{array}{l}\text { A2 } \\
2050\end{array}$ & \\
\hline & Southern Australia & $\begin{array}{l}\text { Decline in NPP of grassland from historical climate will be } 9 \% \\
\text { in 2030, } 7 \% \text { in } 2050 \text {, and } 14 \% \text { in } 2070 \text {. Declines in ANPP were } \\
\text { larger at lower rainfall locations. Operating profit (at constant } \\
\text { prices) fell by an average of } 27 \% \text { in } 2030,32 \% \text { in } 2050 \text {, and } 48 \% \\
\text { in } 2070 .\end{array}$ & $\begin{array}{l}\text { A2 } \\
2030,2050,2070\end{array}$ & $\begin{array}{l}\text { Moore and } \\
\text { Ghahramani (2013) }\end{array}$ \\
\hline & Tasmania & Dairy yields increase $0.5-6.2 \%$ & \multirow{4}{*}{$\begin{array}{l}\text { A1B, } \\
\text { ECHAM5/MPI-OM } \\
2050\end{array}$} & \multirow[t]{4}{*}{ Hanslow et al. (2014) } \\
\hline & Victoria & Dairy yields decrease $1.3-6.7 \%$ & & \\
\hline & New South Wales & Dairy yields decrease $1.4-6.6 \%$ & & \\
\hline & Southern Australia & Dairy yields decrease $2.2-8.1 \%$ & & \\
\hline & New Zealand & $\begin{array}{l}\text { Change in agricultural production: } \\
\text { - Dairy: }-2.8 \%,-4.3 \% \\
\text { - Sheep and beef: }-6.1 \%,-8.8 \%\end{array}$ & $\begin{array}{l}2030 \\
\text { Global temperature change } 25 \% \text {, } \\
75 \% \text { of the way between lower and } \\
\text { upper bounds of scenarios in IPCC } \\
2001 \text { Third Assessment Report. }\end{array}$ & Wratt et al. (2008) \\
\hline
\end{tabular}


Box 7-1 (continued)

\begin{tabular}{|c|c|c|c|c|}
\hline Region & Sub-region & Climate change impacts & Scenarios & Reference \\
\hline \multirow{4}{*}{$\begin{array}{l}\text { Central } \\
\text { and South } \\
\text { America }\end{array}$} & Andean Mountain countries & $\begin{array}{l}\text { Beef and dairy cattle, pigs, and chickens could decrease between } \\
0.9 \text { and } 3.2 \% \text { while sheep could increase by } 7 \% \text {. }\end{array}$ & $\begin{array}{l}2060 \\
\text { Hot and dry scenario }\end{array}$ & \multirow[t]{3}{*}{ Section 27.3.4.1 } \\
\hline & $\begin{array}{l}\text { Colombia, Venezuela, and } \\
\text { Ecuador }\end{array}$ & Beef cattle choice declined. & $\begin{array}{l}2060 \\
\text { Milder and wet scenario }\end{array}$ & \\
\hline & Argentina and Chile & Beef cattle choice increased. & Future climate change & \\
\hline & Pernambuco, Brazil & Milk production and feed intake in cattle strongly affectetd. & Future climate change & Silva et al. (2009) \\
\hline $\begin{array}{l}\text { North } \\
\text { America }\end{array}$ & Central United States & Dairy yields decrease $16-30 \%$. & $\begin{array}{l}\text { Baseline } \mathrm{CO}_{2}, 2 \times \mathrm{CO}_{2}, 3 \times \mathrm{CO}_{2} \\
\text { CGCMI/Hadley }\end{array}$ & Mader et al. (2009) \\
\hline
\end{tabular}

pathogens may decrease in lowland tropical areas as temperatures increase (Mills et al., 2010). The temperate regions may become more suitable for tropical vector-borne diseases such as Rift Valley fever and malaria, which are highly sensitive to climatic conditions (Rocque et al., 2008). Vector-borne diseases of livestock such as African horse sickness and bluetongue may expand their range northward to the Northern Hemisphere because rising temperatures increase the development rate and winter survival of vectors and pathogens (Lancelot et al., 2008). Diseases such as West Nile virus and schistosomiasis are projected to expand into new areas (Rosenthal, 2009). The distribution, composition, and migration of wild bird populations that harbor the genetic pool of avian influenza viruses will all be affected by climate change, although in ways that are somewhat unpredictable (Gilbert et al., 2008). The changing frequency of extreme weather events, particularly flooding, will affect diseases too. For example, outbreaks of Rift Valley fever in East Africa are associated with increased rainfall and flooding due to ENSO events (Gummow, 2010; Pfeffer and Dobler, 2010). In general, the impacts of climate change on livestock diseases remain difficult to predict and highly uncertain (Mills et al., 2010; Tabachnick, 2010).

Box 7-1 summarizes impacts on a regional basis for crops and livestock. Developing countries rely heavily on climate-dependent agriculture and especially in conjunction with poverty and rapid increase in population they are vulnerable to climate change. While food insecurity is concentrated mostly in developing countries situated in the tropics (St. Clair and Lynch, 2010; Ericksen et al., 2011; Berg et al., 2013) global food supply may also be affected by heat stress in both temperate and subtropical regions (Teixeira et al., 2013). Chapter 22 identifies Africa as one of the regions most vulnerable to food insecurity. Climate change will also affect crop yields, food security, and local economies in Central America, northeast Brazil, and parts of the Andean region (Chapter 27) as well as in South Asia (Iqbal et al., 2009; see also Chapter 24). As shown in Box 7-1, in spite of uncertainties in responses at regional/ national and subnational level, there is high confidence that most developing countries will be negatively affected by climate change in the future, although climate change may have positive effects in some regions. In high latitudes (such as Russia, northern Europe, Canada, South America) global warming may increase yields and expand the growing season and acreage of agricultural crops, although yields may be low due to poor soil fertility and water shortages in some regions (Kiselev et al., 2013; see also Chapters 23, 24, 26, 27). Although there is slim evidence, some studies do indicate a significant increase in crops yields in some parts of China, Africa, and India. Like crops, livestock are also negatively affected by climate change in almost all the continents, as evidenced by the regional chapters of Working Group II. The dairy, meat, and wool systems primarily rely on fodders, grasslands, and rangelands. Climate change can impact the amount and quality of produce, profitability, and reliability of production (Chapters 23, 25). Higher temperature would lead to decline in dairy production, reduced animal weight gain, stress on reproduction, increased cost of production, and lower food conversion efficiency in warm regions. Disease incidence among livestock is expected to be exacerbated by climate change as most of the diseases are transmitted by vectors such as ticks and flies (Chapter 23), whose proliferation depends on climatic parameters of temperature and humidity.

\subsubsection{Projected Impacts on Food Prices and Food Security}

AR4 presented a summary of food price projections based on five studies that used projected yield impacts as inputs to general or partial equilibrium models of commodity trade. Many additional projections of this type have been made since AR4, expanding the number of trade models used, the diversity of yield projections considered, and the disaggregation of prices by commodity (Hertel et al., 2010; Calzadilla et al., 2013; Lobell et al., 2013b; Nelson et al., 2013). Many of the studies did not include $\mathrm{CO}_{2}$ effects, which is sometimes justified on the grounds that studies are concerned with "worst-case" scenarios, or that the bias from omitting positive $\mathrm{CO}_{2}$ effects balances the known bias from omitting negative effects of elevated $\mathrm{O}_{3}$ and increased weed and pest damage. Studies also typically ignore potential changes in yield variability (Figure 7-6) and policy responses such as export bans which have important international price effects (Section 7.2.2).

Based on the studies cited above, it is very likely that changes in temperature and precipitation, without considering effects of $\mathrm{CO}_{2}$, will lead to increased food prices by 2050, with estimated increases ranging from 3 to $84 \%$. The combined effect of climate and $\mathrm{CO}_{2}$ change (but ignoring $\mathrm{O}_{3}$ and pest and disease impacts) appears about as likely as not to increase prices, with a range of projected impacts from $-30 \%$ to $+45 \%$ by 2050 . One lesson from recent model intercomparison experiments (Nelson et al., 2014) is that the choice of economic model matters at least as much as the climate or crop model for determining 
price response to climate change, indicating the critical role of economic uncertainties for projecting the magnitude of price impacts.

The AR4 concluded that climate changes are expected to result in higher real prices for food past 2050. This conclusion remains intact with medium confidence, albeit with a relative lack of new studies exploring price changes to 2100 or beyond. Of course, international prices are only one indicator of global food security, with the pathways by which price changes can affect food security outlined in Section 7.3.3. A limited number of studies have estimated the effects of price changes on food security and related health outcomes. Nelson et al. (2009) project that, without accelerated investment in planned adaptations, climate change by 2050 would increase the number of undernourished children under the age of 5 by 20 to 25 million (or 17 to $22 \%$ ), with the range including projections with and without $\mathrm{CO}_{2}$ fertilization. Lloyd et al. (2011) used the projected changes in undernourishment from Nelson et al. (2009) to project the impact of climate change on human nutrition, estimating a relative increase in moderate stunting of 1 to $29 \%$ in 2050 compared with a future without climate change. Severe stunting was projected to increase by $23 \%$ (central Africa) to $62 \%$ (South Asia).

In summary, if global yields are negatively impacted by climate change, an increase in both international food prices and the global headcount of food-insecure people is expected (limited evidence, high agreement). However, it is only about as likely as not that the net effect of climate and $\mathrm{CO}_{2}$ changes on global yields will be negative by 2050, but likely that such changes will occur later in the 21st century. At the same time, it is likely that socioeconomic and technological trends, including changes in institutions and policies, will remain a relatively stronger driver of food security over the next few decades than climate change (Goklany, 2007; Parry et al., 2009). Importantly, all of the studies that project price impacts assume some level of on-farm agronomic adaptation, often by optimizing agronomic practices within the model. Most, but not all, also prescribe income growth rates as exogenous factors, despite the fact that incomes are heavily dependent on agriculture in many poor countries. One study that accounted for income effects found that, in countries such as Indonesia that had both a large share of poverty in agriculturally dependent households and yield impacts that were small relative to other regions, poverty was reduced by the effects of climate change (Hertel et al., 2010). However, in most countries the positive income effects of higher prices could not outweigh the costs of reduced productivity and higher food prices.

Recent work has also highlighted that productivity in many sectors besides agriculture are significantly influenced by warming, with generally negative effects of warming on economic output in tropical countries (Hsiang, 2010; Dell et al., 2012). Given the importance of incomes to food access, incorporating these effects into future estimates of food security impacts will be important. Conflict is also known to be an important factor in food security (FAO, 2010), and evidence of climate variability effects on conflict risk (Hsiang et al., 2011) indicates a need to also consider this dimension in future work (Chapter 12).

Since the impacts of climate change on food production and food security depends on multiple interacting drivers, the timing of extreme events, which are expected to become more frequent (IPCC, 2012), is critical. Extremes contribute to variability in productivity (Figure 7-6) and can form part of compound events that are driven by common external forcing (e.g., El Niño), climate system feedbacks, or causally unrelated events (IPCC, 2012). Such compound events, where extremes have simultaneous impacts in different regions, may have negative impacts on food security, particularly against the backdrop of increased food price volatility (Figure 7-3). There are very few projections of compound extreme events, and interactions between multiple drivers are difficult to predict. Effective monitoring and prediction, and building resilience into food systems, are likely to be two key tools in avoiding the negative impacts resulting from these interactions (Misselhorn et al., 2010).

\subsection{Adaptation and Managing Risks in Agriculture and Other Food System Activities}

\subsubsection{Adaptation Needs and Gaps Based on Assessed Impacts and Vulnerabilities}

7.5.1.1. Methods of Treating Impacts in Adaptation Studies-Incremental to Transformational

The pervasiveness of climate impacts on food security and production (Section 7.2), the commitment to future climate change from past GHG emissions (WGI AR5 SPM), and the very high likelihood of additional and likely greater climate changes from future GHG emissions (WGI AR5 SPM) mean that some level of adaptation of food systems to climate change will be necessary. Here we take adaptation to mean reductions in risk and vulnerability through the actions of adjusting practices, processes, and capital in response to the actuality or threat of climate change. This often involves changes in the decision environment, such as social and institutional structures, and altered technical options that can affect the potential or capacity for these actions to be realized. Adaptation can also enhance opportunities from climate change (WGII AR4 Chapter 5; Section 17.2.3). These adaptations will need to be taken in the context of a range of other pressures on food security such as increasing demand as a result of population growth and increasing per capita consumption (Section 7.1).

Following the AR4, the literature on adaptation and food production has increased substantially, although there has been less focus on adaptations to food systems and on value chains: the linked sets of activities that progressively add value as inputs are converted into products the market demands. Many adaptation frameworks or approaches have been published, informing the approach in the AR4 that addressed both autonomous and planned adaptations. Autonomous adaptations are incremental changes in the existing system including through the ongoing implementation of extant knowledge and technology in response to the changes in climate experienced. They include coping responses and are reactive in nature. Planned adaptations are proactive and can either adjust the broader system or transform it (Howden et al., 2010). Adaptations can occur at a range of scales from field to policy. There is an increasing recognition in the literature that while many adaptation actions are local and build on past climate risk management experience, effective adaptation will often require changes in institutional arrangements and policies to strengthen the conditions favorable for effective adaptation 
including investment in new technologies, infrastructure, information, and engagement processes (Sections 14.3-4, 15.2.4). Building adaptive capacity by decision makers at all scales (Nelson et al., 2008) is an increasingly important part of the adaptation discourse which has also further addressed costs, benefits, barriers, and limits of adaptation (Adger et al., 2009). The sector-specific nature of many adaptations means that sectors are initially addressed separately below.

\subsection{Cropping}

Effective adaptation of cropping could be critical in enhancing food security and sustainable livelihoods, especially in developing countries (WGII AR4 Chapter 5; Section 9.4.3.1). There is increasing evidence that farmers in some regions are already adapting to observed climate changes in particular altering cultivation and sowing times, crop cultivars and species, and marketing arrangements (Fujisawa and Koyabashi, 2010; Olesen et al., 2011; see also Section 9.4.3.1), although this response is not ubiquitous (Bryan et al., 2009). There are a large number of potential adaptations for cropping systems and for the food systems of which they are part, many of them enhancements of existing climate risk management and all of which need to be embedded in the wider farm systems and community contexts.

The possibility of extended growing seasons due to higher temperatures increasing growth in cooler months means that changing planting dates is a frequently identified option for cereals and oilseeds provided there is not an increase in drought at the end of the growing season (Krishnan et al., 2007; Deressa et al., 2009; Magrin et al., 2009; Mary and Majule, 2009; Meza and Silva, 2009; Tingem and Rivington, 2009; Travasso et al., 2009; Laux et al., 2010; Shimono et al., 2010; Stöckle et al., 2010; Tao and Zhang, 2010; Van de Geisen et al., 2010; Olesen et al., 2011; Cho et al., 2012). Aggregated across studies, changing planting dates may increase yields by a median of 3 to $17 \%$ but with substantial variation (Table 7-2). Early sowing is being facilitated by improvements in machinery and by the use of techniques such as dry sowing (Passioura and Angus, 2010), seedling transplanting, and seed priming and these adaptations can be integrated with varieties with greater thermal time requirements so as to maximize production benefits and to avoid late spring frosts (Tingem and Rivington, 2009; Cho et al., 2012). There can, however, be practical constraints to early sowing such as seedbed condition (van Oort et al., 2012). In some situations early sowing may allow double cropping or intercropping where currently only a single crop is feasible. For example, this could occur for irrigated maize in central Chile (Meza et al., 2008) and the double crop wheat/soybean in the southern pampas of Argentina (Monzon et al., 2007), increasing productivity per unit land although increasing nitrogen and water demand at the same time. However, in Mediterranean climates, early sowing of cereals is dependent on adequate planting rains in autumn and climate projections indicate that this may decrease in many regions (WGI AR5 SPM), limiting the effectiveness of this adaptation and possibly resulting in later sowings than are currently practiced. In such circumstances, use of short duration cultivars could be desirable so as to reduce exposure to end-of-season droughts and high-temperature events (Orlandini et al., 2008; Walter et al., 2010). There is medium confidence that optimization of crop varieties and planting schedules appears to be effective adaptations, increasing yields by up to $23 \%$ compared with current management when aggregated across studies (medium evidence, high agreement; Table 7-2). This flexibility in planting dates and varieties according to seasonal conditions could be increasingly important with ongoing climate change (Meza et al., 2008; Deressa et al., 2009) and especially in dealing with projections of increased climate variability (Figure 7-6). Approaches that integrate climate forecasts at a range of scales in some cases are able to better inform crop risk management (Cooper et al., 2009; Baethgen, 2010; Li et al., 2010; Sultana et al., 2010) although such forecasts are not always useable or useful (Lemos and Rood, 2010; Dilling and Lemos, 2011; see also Section 9.4.4).

Warmer conditions may also allow range expansion of cropping activities polewards in regions where low temperature has been a past limitation (limited evidence, medium agreement) provided varieties with suitable daylength response are available and soil and other conditions suitable. This may particularly occur in Russia, Canada, and the Scandinavian nations although the potential may be less than earlier analyses indicated

Frequently Asked Questions

\section{FAQ 7.3 | How could adaptation actions enhance food security and nutrition?}

More than $70 \%$ of agriculture is rain fed. This suggests that agriculture, food security, and nutrition are all highly sensitive to changes in rainfall associated with climate change. Adaptation outcomes focusing on ensuring food security under a changing climate could have the most direct benefits on livelihoods, which have multiple benefits for food security, including enhancing food production, access to markets and resources, and reduced disaster risk. Effective adaptation of cropping can help ensure food production and thereby contribute to food security and sustainable livelihoods in developing countries, by enhancing current climate risk management. There is increasing evidence that farmers in some regions are already adapting to observed climate changes, in particular altering cultivation and sowing times and crop cultivars and species. Adaptive responses to climate change in fisheries could include management approaches and policies that maximize resilience of the exploited ecosystems, ensuring fishing and aquaculture communities have the opportunity and capacity to respond to new opportunities brought about by climate change, and the use of multi-sector adaptive strategies to reduce the consequence of negative impacts in any particular sector. However, these adaptations will not necessarily reduce all of the negative impacts of climate change, and the effectiveness of adaptations could diminish at the higher end of warming projections. 
Table 7-2 | The simulated median benefit (difference between the yield change from baseline for the adapted and non-adapted cases) for different crop management adaptations: cultivar adjustment; planting date adjustment; adjusting planting date in combination with cultivar adjustment; adjusting planting date in combination with other adaptations; irrigation optimization; fertilizer optimization; other management adaptations. $\mathrm{N}$ represents the number of estimates used for each adaptation. The numbers in parentheses are the 25th and 75th percentiles. Data points where assessed benefits of management changes are negative are not included as farmers are unlikely to adopt these intentionally. Only studies with both a "no adaptation" and an "adaptation" assessment are used. Data taken from Rosenzweig et al. (1994); Karim et al. (1996); El-Shaher et al. (1997); Lal et al. (1998); Moya et al. (1998); Yates and Strzepek (1998); Alexandrov (1999); Kaiser (1999); Reyenga et al. (1999); Southworth et al. (2000); Tubiello et al. (2000); DeJong et al. (2001); Aggarwal and Mall (2002); Alexandrov et al. (2002); Corobov (2002); Easterling et al. (2003); Matthews and Wasmann (2003); Droogers (2004); Howden and Jones (2004); Butt et al. (2005); Erda et al. (2005); Ewert et al. (2005); Gbetibouo and Hassan (2005); Xiao et al. (2005); Zhang and Liu (2005); Abraha and Savage (2006); Challinor et al. (2009); Tingem and Rivington (2009); Thornton et al. (2010); Deryng et al. (2011); Lal (2011); Tao and Zhang (2011b).

\begin{tabular}{|c|c|c|c|c|c|c|}
\hline $\begin{array}{c}\text { Management } \\
\text { option }\end{array}$ & $\begin{array}{l}\text { Cultivar adjustment } \\
\qquad(\mathrm{N}=56)\end{array}$ & $\begin{array}{l}\text { Planting date } \\
\text { adjustment } \\
(\mathrm{N}=19)\end{array}$ & $\begin{array}{l}\text { Planting date and } \\
\text { cultivar adjustment } \\
(\mathrm{N}=152)\end{array}$ & $\begin{array}{l}\text { Irrigation } \\
\text { optimization } \\
(\mathrm{N}=17)\end{array}$ & $\begin{array}{c}\text { Fertilizer } \\
\text { optimization } \\
(\mathrm{N}=10)\end{array}$ & $\begin{array}{l}\text { Other } \\
(\mathrm{N}=9)\end{array}$ \\
\hline $\begin{array}{l}\text { Benefit }(\%) \text { from } \\
\text { using adaptation }\end{array}$ & $\begin{array}{c}23 \\
(6.8,35.9)\end{array}$ & $\begin{array}{c}3 \\
(2.1,8.3)\end{array}$ & $\begin{array}{c}17 \\
(9.9,26.1)\end{array}$ & $\begin{array}{c}3.2 \\
(2,8.2)\end{array}$ & $\begin{array}{c}1 \\
(0.25,4.8)\end{array}$ & $\begin{array}{c}6.45 \\
(3.2,12.8)\end{array}$ \\
\hline
\end{tabular}

owing to increased climate extremes, water limitations, and various institutional barriers (Alcamo et al., 2007; Bindi and Olesen, 2011; Dronin and Kirilenko, 2011; Kulshreshtha, 2011; Kvalvik et al., 2011; Tchebakova et al., 2011). In many of these cases, the northerly range expansion may only offset the reduction in southerly cropping areas and yields due to lower rainfall, water shortages, and high temperatures (limited evidence, high agreement).

Improving cultivar tolerance to high temperature is a frequently identified adaptation for almost all crops and environments worldwide as high temperatures are known to reduce both yield and quality (Krishnan et al., 2007; Challinor et al., 2009; Luo et al., 2009; Wassmann et al., 2009; Shimono et al., 2010; Stöckle et al., 2010), noting that a new cultivar usually takes between 8 and 20 years to deliver and so it is important to be selecting cultivars for expected future climate and atmospheric conditions (Ziska et al., 2012). Improving gene conservation and access to extensive gene banks could facilitate the development of cultivars with appropriate thermal time and thermal tolerance characteristics (Mercer et al., 2008; Wassmann et al., 2009) as well as to take advantage of increasing atmospheric $\mathrm{CO}_{2}$ concentrations (Ziska et al., 2012) and respond to changing pest, disease, and weed threats with these developments needing to be integrated with in situ conservation of local varieties (IAASTD, 2009).

Similarly, the prospect of increasing drought conditions in many cropping regions of the world (Olesen et al., 2011) raises the need for breeding additional drought-tolerant crop varieties (Naylor et al., 2007; Mutekwa, 2009; Tao and Zhang, 2011a), for enhanced storage and access to irrigation water, more efficient water delivery systems, improved irrigation technologies such as deficit irrigation, more effective water harvesting, agronomy that increases soil water retention through practices such as minimum tillage and canopy management, agroforestry, increase in soil carbon, and more effective decision support (Verchot et al., 2007; Lioubimtseva and Henebry, 2009; Luo et al., 2009; Falloon and Betts, 2010; Piao et al., 2010; Olesen et al., 2011), among many other possible adaptations (Sections 22.4.2, 22.4.3). There is medium confidence (limited evidence, high agreement) that crop adaptations can lead to moderate yield benefits (mean of 10 to 20\%) under persistently drier conditions (Deryng et al., 2011) and that irrigation optimization for changed climate can increase yields by a median of $3.2 \%$ (Table 7-2) as well as having a range of other beneficial effects (Section 3.7).
Diversification of activities is another climate adaptation option for cropping systems (Lioubimtseva and Henebry, 2009; Thornton et al., 2010). For example, Reidsma and Ewert (2008) found that regional farm diversity reduces the risk that is currently associated with unfavorable climate conditions in Europe. Diversification of activities often incorporates higher value activities or those that increase efficiency of a limited resource such as through increased water use efficiency (Thomas, 2008) or to reduce risk (Seo and Mendelsohn, 2008; Seo, 2010; Seo et al., 2010). In some cases, increased diversification outside of agriculture may be favored (Coulthard, 2008; Mary and Majule, 2009; Mertz et al., 2009a,b).

The above adaptations, either singly or in combination, could significantly reduce negative impacts of climate change and increase the benefit of positive changes as found in WGII AR4 Chapter 5 (medium evidence, high agreement). To quantify the benefits of adaptation, a meta-analysis of recent crop adaptation studies has been undertaken for wheat, rice, and maize (see Figure 7-4). This meta-analysis adds more recent studies to that undertaken in the WGII AR4 Chapter 5. It indicates that the average benefit (the yield difference between the adapted and nonadapted cases) of adapting crop management is equivalent to about 15 to $18 \%$ of current yields (Figure $7-8$ ). This response is, however, extremely variable, ranging from negligible benefit from adaptation (even potential dis-benefit) to very substantial. The responses are dissimilar between wheat, maize, and rice (Figure 7-4) with temperate wheat and tropical rice showing greater benefits of adaptation. The responses also differ markedly between adaptation management options (Table 7-2). For example, when aggregated over studies, cultivar adaptation (23\%) and altering planting date in combination with other adaptations ( 3 to $17 \%$ ) provide on average more benefit than optimizing irrigation (3.2\%) or fertilization ( $1 \%$ ) to the new climatic conditions. These limits to yield improvements from agronomic adaptation and the increasingly overall negative crop yield impact with ongoing climate change (Figures 7-4, 7-5) mean a substantial challenge in ensuring increases in crop production of $14 \%$ per decade given a population of 9 billion people in 2050 . This could be especially so for tropical wheat and maize, where impacts from increases in temperature of more than $3^{\circ} \mathrm{C}$ may more than offset benefits from agronomic adaptations (limited evidence, medium agreement).

Potential increased variability of crop production means that other climate-affected aspects of food systems such as food reserve, storage, and distribution policies and systems may need to be enhanced (IAASTD, 


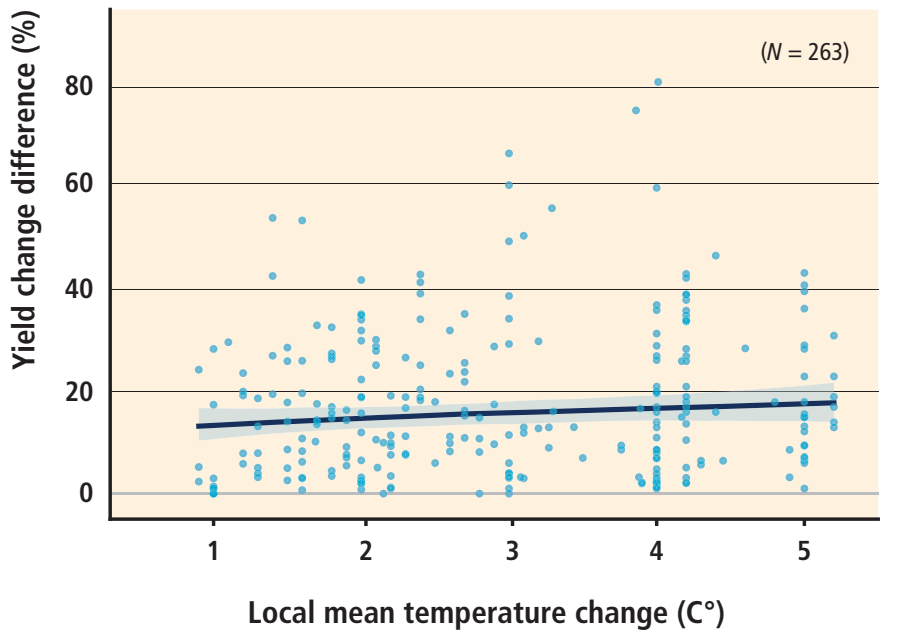

Figure 7-8 | Simulated yield benefit from adaptation calculated as the difference between the yield change from baseline (\%) for paired non-adapted and adapted cases as affected by temperature and aggregated across all crops. The shaded bands at the $95 \%$ confidence interval are calculated as for Figure $7-4$. Data points $(N=31)$ where assessed benefit of management changes are negative are not included as farmers are unlikely to intentionally adopt these. Data sources are the same as for Table 7-2 and only studies that examine both a "no adaptation" and an "adaptation" scenario are used so as to avoid the issues arising from unpaired studies documented in Figure 7-4 for tropical maize.

2009; Stathers et al., 2013) (medium evidence, high agreement) along with a range of broader, value-chain issues such as provision of effective insurance markets, clarity in property rights, building adaptive capacity, and developing effective participatory research cultures (Chapter 9; WGII AR4 Chapter 5).

It is notable that most of the above adaptations raised above and used in this analysis are essentially either incremental changes to existing agricultural systems or are systemic changes that integrate new aspects into current systems. Few could be considered to be transformative changes. Consequently, the potential adaptation benefits could be understated (limited evidence, medium agreement; Rickards and Howden, 2012).

\subsection{Fisheries}

Many of the resources for capture fisheries are already fully or overexploited, with an estimated 30\% of stocks overexploited in 2009 and $57 \%$ fully exploited (FAO, 2012). Comparable global statistics are not available for inland fisheries but the status of those stocks may not be any better. Overfishing is widely regarded as the primary pressure on marine fishery resources but other human activities including coastal and offshore mining, oil and gas extraction, coastal zone development, land-based pollution, and other activities are also negatively impacting stock status and production (Rosenberg and Macleod, 2005; Cochrane et al., 2009). In inland fisheries, overfishing is also widespread, coupled with many other impacts from other human activities (Allan et al., 2005). Climate change adds another compounding influence in both cases.

Adaptive responses to reduce the vulnerability of fisheries and fishing communities could include management approaches and policies that strengthen the livelihood asset base; improved understanding of the existing response mechanisms to climate variability to assist in adaptation planning; recognizing and responding to new opportunities brought about by climate change; monitoring biophysical, social, and economic indicators linked to management and policy responses; and adoption of multi-sector adaptive strategies to minimize negative impacts (Allison et al., 2009; Badjeck et al., 2010; MacNeil et al., 2010). Complementary adaptive responses include occupational flexibility, changing target species and fishing operations, protecting key functional groups, and the establishment of insurance schemes (Coulthard, 2008; Daw et al., 2009; FAO, 2009a; MacNeil et al., 2010; Koehn et al., 2011). Fishers and fish farmers will be vulnerable to extreme events such as flooding and storm surges that will require a range of adaptations including developing early warning systems for extreme events, provision of hard defenses against flooding and surges, ensuring infrastructure such as ports and landing sites are protected, effective disaster response mechanisms, and others (Daw et al., 2009).

Governance and management of fisheries will need to follow an ecosystem approach to maximize resilience of the ecosystem, and to be adaptive and flexible to allow for rapid responses to climate-induced change (Daw et al., 2009; FAO, 2009a; see also Section 6.4.2). Within an ecosystem approach, habitat restoration will frequently be a desirable adaptation option, particularly in freshwater and coastal environments (Koehn et al., 2011). A wide range of management tools and strategies have been developed to manage fisheries. These are all necessary but not sufficient for adaptation to climate change in fisheries (Grafton, 2010). Grafton argued that the standard tools for fisheries management were developed to control fishing mortality and to maintain adequate levels of recruitment to fishery stocks but without necessarily addressing the needs for resilience to change or to be able to function under changing climates. He therefore proposed that these conventional management tools must be used within processes that (1) have a core objective to encourage ecosystems that are resilient to change and (2) explicitly take into account uncertainties about future conditions and the effect of adaptation, and make use of models to explore the implications of these (Grafton, 2010). There are also opportunities for fisheries to contribute to mitigation efforts (FAO, 2009a; Grafton, 2010).

Aquaculture is the fastest-growing animal-food-producing sector with per capita consumption of products increasing at an average rate of $7.1 \%$ per year between 1980 and 2010 (FAO, 2012). Adaptive responses in aquaculture include use of improved feeds and selective breeding for higher temperature tolerance strains to cope with increasing temperatures (De Silva and Soto, 2009) and shifting to more tolerant strains of molluscs to cope with increased acidification (Huppert et al., 2009). Better planning and improved site selection to adapt to expected changes in water availability and quality; integrated water use planning that takes into account the water requirements and human benefits of fisheries and aquaculture in addition to other sectors; and improving the efficiency of water use in aquaculture operations are some of the other adaptation options (De Silva and Soto, 2009).

Integrated water use planning will require making trade-offs between different land and water uses in the watershed (Mantua et al., 2010). Insurance schemes accessible to small-scale producers would help to increase their resilience (De Silva and Soto, 2009). In some near-shore 
locations there may be a need to shift property lines as the mean high water mark is displaced landwards by rising sea level (Huppert et al., 2009).

There are no simple, generic recipes for fisheries adaptation with Bell et al. (2011) suggesting a list of 25 separate but inter-related actions, together with supporting policies to adapt fisheries and aquaculture in the tropical Pacific to climate change (see also Section 30.6.2.1.1). These actions fall into three categories according to the primary objective: economic development and government revenue; maintaining the contribution of fish to food security; and maximizing sustainable livelihoods. Actions and policies for adaptation in fisheries and aquaculture must complement those for other sectors. Similar case-bycase, integrated planning will be required in all other regions and at scales from community to regional to achieve clearly defined adaptation goals.

\subsection{Livestock}

Extensive livestock systems occur over a huge range of biophysical and socio-ecological systems, with a consequent large range of potential adaptations. In many cases, these livestock systems are highly adapted to past climate risk, and there is high confidence that this provides a sound starting point for climate change adaptation (medium evidence, high agreement; Thornton et al., 2009a). These adaptations include matching stocking rates with pasture production; adjusting herd and watering point management to altered seasonal and spatial patterns of forage production; managing diet quality (using diet supplements, legumes, choice of introduced pasture species and pasture fertility management); more effective use of silage, pasture spelling, and rotation; fire management to control woody thickening; using more suitable livestock breeds or species; migratory pastoralist activities; and a wide range of biosecurity activities to monitor and manage the spread of pests, weeds, and diseases (Fitzgerald et al., 2008; Howden et al., 2008; Nardone et al., 2010; Ghahramani and Moore, 2013; Moore and Ghahramani, 2013). Combining adaptations can result in substantial increases in benefits in terms of production and profit when compared with single adaptations (Ghahramani and Moore, 2013; Moore and Ghahramani, 2013). In some regions, these activities can in part be informed by climate forecasts at differing time scales to enhance opportunities and reduce risks including soil degradation (McKeon et al., 2009). Many livestock systems are integrated with or compete for land with cropping systems and one climate adaptation may be to change these relationships. For example, with increased precipitation, farmers in Africa may need to reduce their livestock holdings in favor of crops, but with rising temperatures, they may need to substitute small ruminants in place of cattle with small temperature increases or reduce stocking rates with larger temperature rises (Kabubo-Mariara, 2009; Thornton et al., 2010). As with other food systems there is a range of barriers to adaptation that could be addressed on-farm and off-farm by changes in infrastructure, establishment of functioning markets, improved access to credit, improved access to water and water management technologies, enhanced animal health services, and enhanced knowledge adoption and information systems (Howden et al., 2008; Kabubo-Mariara, 2008; Mertz et al., 2009b, Silvestri et al., 2012).

Heat stress is an existing issue for livestock in some regions (robust evidence, high agreement), especially in higher productivity systems
(Section 7.3.2.6). For example, some graziers in Africa are already making changes to stock holdings in response to shorter term variations in temperatures (Thornton et al., 2009a; see also 9.4.3.1). Breeding livestock with increased heat stress resistance is an adaptation often identified but there are usually trade-offs with productivity as well as benefits including animal welfare and so this option needs careful evaluation (Nardone et al., 2010). Increased shade provision through trees or cost-effective structures can substantially reduce the incidence of high heat stress days, reduce animal stress, and increase productivity, with spraying a less effective option (Gaughan et al., 2010; Nidumolu et al., 2013). In cooler climates, warming may be advantageous because of lesser need for winter housing and feed stocks.

\subsection{Indigenous knowledge}

Indigenous knowledge (IK) has developed to cope with climate hazards contributing to food security in many parts of the world. Examples in the Americas include Alaska, where the Inuit knowledge of climate variability ensured the source of food to hunters and reduced various risks (Alessa et al., 2008; Ford, 2009; Weatherhead et al., 2010) down to the southern Andes, where the Inca traditions of crop diversification, genetic diversity, raised bed cultivation, agroforestry, weather forecasting, and water harvesting are still used in agriculture (Goodman-Elgar, 2008; Renard et al., 2011; McDowell and Hess, 2012; see also Sections 9.4.3.1, 27.3.4.2). In Africa, weather forecasting, diversity of crops and agropastoralism strategies have been useful in the Sahel (Nyong et al., 2007). Rainwater harvesting has been a common practice in sub-Saharan Africa (Biazin et al., 2012) to cope with dry spells and improve crop productivity, while strategies from agropastoralists in Kenya are related to drought forecasting based on the fauna, flora, moon, winds, and other factors (Speranza et al., 2010). In South Africa, farmers' early warming indicators of wet or dry periods in Namibia based on animals, plants, and climate observations contributed to deal with climatic variability (Newsham and Thomas, 2011). In the same way, in Asia and Australia IK plays an important role to ensure food security of certain groups (Salick and Ross, 2009; Green et al., 2010; Marin, 2010; Speranza et al., 2010; Kalanda-Joshua et al., 2011; Pareek and Trivedi, 2011; Biazin et al., 2012), although IK and the opportunities to implement it can differ according to gender and age in some communities (Rengalakshmi, 2007; Turner and Clifton, 2009; Kalanda-Joshua et al., 2011; see also Section 9.3.5), leading to distinct adaptive capacities and options.

In addition to changes already occurring in climate (seasonal changes, changes in extreme events; IPCC 2012) projected changes beyond historical conditions could reduce the reliance on indigenous knowledge (Speranza et al., 2010; Kalanda-Joshua et al., 2011; McDowell and Hess, 2012) affecting the adaptive capacity of a number of peoples globally (medium evidence, medium agreement).

Moreover, there is medium confidence that some policies and regulations leading to limit the access to territories, promoting sedentarization, the substitution of traditional livelihoods, reduced genetic diversity and harvesting opportunities, as well as loss of transmission of indigenous knowledge, may contribute to limit the adaptation to climate change in many regions (medium evidence, medium agreement; Nakashina et al., 2012). 


\subsubsection{Practical Regional Experiences of Adaptation, Including Lessons Learned}

Given the early stages of climate change, there are relatively few unequivocal examples of adaptation (Section 7.5.2) additional to existing climate risk management. Where there have been management changes these have often been in response to several driving variables of which climate is only one (Smit and Wandel, 2006; Mertz et al., 2009a; Chen et al., 2011; Odgaard et al., 2011; see also Section 9.4.3.1). The preparedness to consider adaptation even within an industry varies regionally (Battaglini et al., 2009) and in some regions there already appears to be adaptation to climate change occurring (Fujisawa and Koyabashi, 2010; Olesen et al., 2011; Bohensky et al., 2012; Section 9.4.3.1). Activities to build adaptive capacity to better manage climate change are more widespread (Twomlow et al., 2008) but there remain questions as to how this capacity will evolve and be maintained (Nelson et al., 2009). Crucial in this will be devolution of the decision-making process so as to integrate local, contextual information into adaptation decision making (Nelson et al., 2008).

\subsubsection{Observed and Expected Barriers and Limits to Adaptation}

Adaptation is strongly influenced by factors including institutional, technological, informational, and economic and there can be barriers (restrictions that can be addressed) and limits in all these factors (robust evidence, high agreement; Chapters 14, 15, 16). Several barriers to adaptation of food systems have been raised including inadequate information on the climate and climate impacts and on the risks and benefits of the adaptation options, lack of adaptive capacity, inadequate extension, institutional inertia, cultural acceptability, financial constraints including access to credit, insufficient fertile land, infrastructure, lack of functioning markets, and insurance systems (Bryan et al., 2009; Deressa et al., 2009; Kabubo-Mariara, 2009; De Bruin and Dellink, 2011, Silvestri et al., 2012; see also Chapter 16). Limits to adaptation can occur for example where crop yields drop below the level required to sustain critical infrastructure such as sugar or rice mills (Park et al., 2012). In some cases, these can be effectively irreversible. Some studies have shown that access to climate information is not the principal limitation to improving decision making and it can result in perverse outcomes, increasing inequities and widening gender gaps (Coles and Scott, 2009). Incomplete adoption of adaptations may also occur. Lack of technical options can also be a barrier to adaptation. New varieties of crops or breeds of livestock provide possible core adaptations of production systems (medium evidence, high agreement; Mercer et al., 2008; Tingem and Rivington, 2009); however, there is substantial investment needed to develop these along with delays before they are available, both of which can act as adaptation barriers. This may be addressed in part by investments to improve local crop varieties or livestock breeds that are easily adopted (IAASTD, 2009). There also can be physiological limits to performance such as upper temperature limits for heat tolerance (WGII AR4 Chapter 5).

\subsubsection{Facilitating Adaptation and Avoiding Maladaptation}

Adaptation actions would usually be expected to provide benefits to farmers, the food industry along the value chain, or perhaps to a broader community. However, there are possible maladaptations that arise from adapting too early or too late, by changing the incorrect elements of the food system or changing them by the incorrect amount (Section 14.7). A key maladaptation would be one which increased emissions of GHGs, this making the underlying problem worse (robust evidence, high agreement; Smith and Olesen, 2010; WGIII AR4 Chapter 11). A recent review of agricultural climate change adaptation options found they tend to reduce GHG emissions (Smith and Olesen, 2010; Falloon and Betts, 2010) (medium evidence, medium agreement). These adaptations include measures that reduce soil erosion and loss of nutrients such as nitrogen and phosphorus and for increasing soil carbon, conserving soil moisture, and reducing temperature extremes by increasing vegetative cover. There is a strong focus on incremental adaptation of existing food systems in the literature since AR4, however, and this may result in large opportunity costs that could arise from not considering more systemic adaptation or more transformative change (limited evidence, medium agreement; Howden et al., 2010; Kates et al., 2012). For example, in the USA, changes in farming systems (i.e., the combination of crops) have been assessed as providing significant adaptation benefit in terms of net farm income (Prato et al., 2010) although in other regions this might be minor (Mandryk et al., 2012). There is a need to also engage farmers, policymakers, and other stakeholders in evaluating transformative, pro-active, planned adaptations such as structural changes (Mäder et al., 2006; McCrum et al., 2009; Olesen et al., 2011). This could involve changes in land allocation and farming systems, breeding of functionally different crop varieties, new land management techniques, and new classes of service from lands such as ecosystem services (Rickards and Howden, 2012). In Australia, industries including the wine, rice, and peanut sectors are already attempting transformative changes such as change in location so as to be early adopters of what are perceived as opportunities arising from change (Park et al., 2012). There is substantial commonality in adaptation actions within different agricultural systems. For example, changing varieties and planting times are incremental adaptations found in studies of many different cropping systems as evidenced by the sample size in the meta-analysis in this chapter. Collating information on the array of adaptation options available for farmers, their relative cost and benefit, and their broad applicability could be a way of initiating engagement with decision makers. In the climate mitigation domain, this has been attempted using marginal abatement cost curves that identify mitigation options, their relative cost, and the potential size of emission reductions (WGIII AR4 Chapter 11). These curves can be used in setting investment priorities and informing policy discussions. The local nature of many adaptation decisions, their interactions with other highly contextual driving factors, and the time and climate change-sensitive nature of adaptation decisions mean, however, that global, time-independent curves are not feasible. The studies aggregated in Table 7-2 indicate that some options may be more relevant and useful to consider than others. These results illustrate the potential scope and benefit of developing effective adaptation options if implemented in an adaptive management approach.

\subsubsection{Food System Case Studies of Adaptation-Examples of Successful and Unsuccessful Adaptation}

Incremental, systemic, and transformational adaptation to climate change is beginning to be documented, though the peer-reviewed 
literature largely covers vulnerability assessments and intentions to act, not adaptation actions (Berrang-Ford et al., 2010).

\section{Case 1: Incremental Adaptation in the Sahel}

Much of the literature covers incremental, reactive adaptation, but given actors are constantly adapting to changing social and economic conditions, incremental adaptation to climate change is difficult to distinguish from other actions (Berrang-Ford et al., 2010; Speranza et al., 2010), and in fact is usually a response to a complex of factors. This case, of the zaï soil management practice in the Sahel region, is an example of a complex of factors driving local actions, and factors such as growing land scarcity and new market opportunities, rather than climate, may be the primary factors (Barbier et al., 2009; Mertz, 2009b). Inherent poor soil quality and human activities have resulted in soil degradation — crusting, sealing, erosion by water and wind, and hardpan formation (Fatondji et al., 2009; Zougmoré et al., 2010). Zaï, a traditional integrated soil and water management practice, can combat land degradation and improve yield and decrease yield variability by concentrating runoff water and organic matter in small pits (20 to $40 \mathrm{~cm}$ in diameter and 10 to $15 \mathrm{~cm}$ deep) dug manually during the dry season and combined with contour stone bunds to slow runoff. A handful of animal manure or compost is placed in each pit. By breaking the soil crust, the pits facilitate greater water infiltration, while the applied organic matter improves soil nutrient status and attracts termites, which have a positive effect on soil structure. The zaï technique is very labor intensive, requiring some 60 days of labor per hectare. Innovations to the system, involving animal-drawn implements, can reduce labor substantially.

\section{Case 2: Mixed Farming Systems in Tanzania}

In Morogoro, Tanzania, farming households have adapted in many ways to climatic and other stresses (Paavola, 2008). They have extended cultivation through forest clearance or reducing the length of the fallow period. Intensification is under way, through change in crop choices, increased fertilizer use and irrigation, and especially greater labor inputs. Livelihood diversification has been the main adaptation strategy - this has involved more non-farm income-generating activities, tapping into natural resources for subsistence and cash income (e.g., charcoal production), and has included artisanal gold and gemstone mining. Households have also altered their cropping systems, for example, by changing planting times. Migration is another frequently used strategywith farmers moving to gain land, access to markets, or employment.
Parents also send children to cities to work for upkeep and cash income to reduce the household numbers that need to be supported by uncertain agricultural income. While many of these strategies help in terms of the short-term needs, in the longer term they may be reducing the capacity of households to cope. For instance, land cover change interacting with climate changes has negative impacts on current and future water supplies for irrigation (Natkhin et al., 2013), and deforestation and forest degradation means faltering forest-based income sources. This will be particularly problematic to the more vulnerable groups in the community, including women and children.

\subsubsection{Key Findings from Adaptations-Confidence Limits, Agreement, and Level of Evidence}

There have been many studies of crop adaptation since the AR4. In aggregate these show that adaptations to changed temperature and precipitation will bring substantial benefit (robust evidence, high agreement), with some adaptations (e.g., cultivar adaptation and planting date adjustment) assessed as on average being more effective than others (e.g., irrigation optimization; Section 7.5.1.1.1). Most studies have assessed key farm-level adaptations such as changing planting dates and associated decisions to match evolving growing seasons and improving cultivar tolerance to high temperature, drought conditions, and elevated $\mathrm{CO}_{2}$ levels. Limits to adaptation will increasingly emerge for such incremental adaptations as the climate further changes, raising the need for more systemic or transformational changes (limited evidence, medium agreement; Section 7.5.1.1). An example of transformational change is latitudinal expansion of cold-climate cropping zones polewards, but this may be largely offset by reductions in cropping production in the mid-latitudes as a result of rainfall reduction and temperature increase (medium confidence, limited evidence; Section 7.5.1.1.1). Adaptations to food systems additional to the production phase have been identified and sometimes implemented but the benefits of these have largely not been quantified.

Livestock and fisheries systems also have available a large range of possible adaptations often tailored to local conditions but there is not adequate information to aggregate the possible value of these adaptations although there is high confidence (medium evidence, high agreement) that they will bring substantial benefit, particularly if implemented in

Table 7-3 | Schematic key risks for food security and the potentials for adaptation in the near and long term for high and low levels of warming.

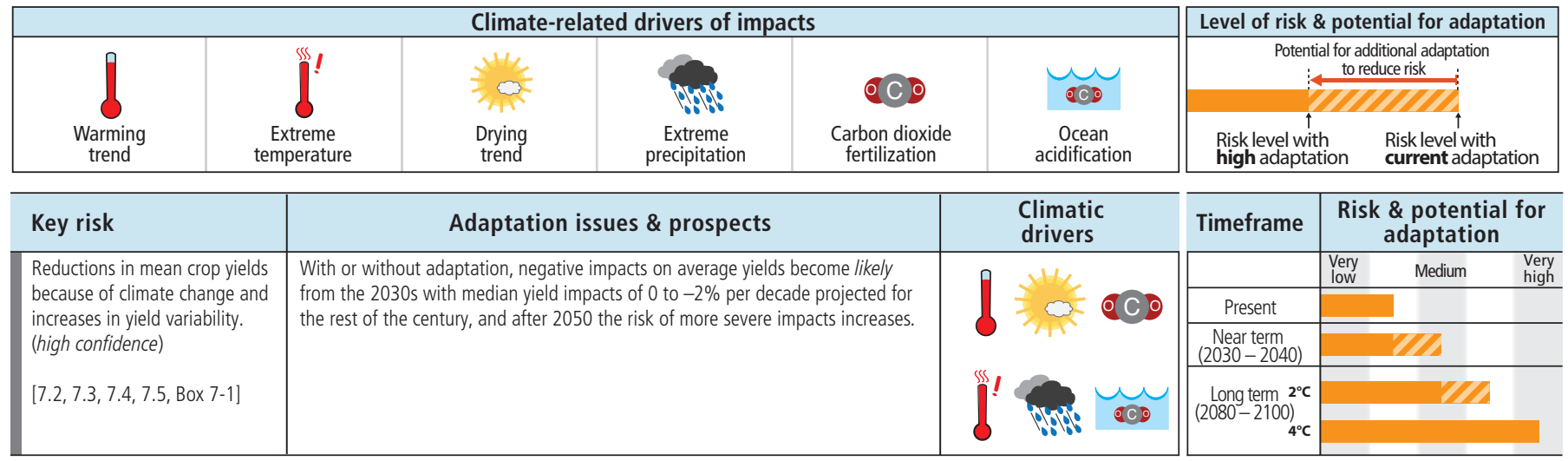


combination (Sections 7.5.1.1.2-3). Key livestock adaptations include matching stocking rates with pasture availability; water management; monitoring and managing the spread of pests, weeds, and diseases; livestock breeding; and adjusting to changed frequencies of heat stress and cold conditions (Section 7.5.1.1.3). Fishery adaptations include management approaches and policies that strengthen the livelihood asset base, take a risk-based ecosystem approach to managing the resource, and adopt multi-sector adaptive strategies to minimize negative impacts. Importantly, there is an emerging recognition that existing fishery management tools and strategies are necessary but not sufficient for adaptation to climate (Section 7.5.1.1.2).

Indigenous knowledge is an important resource in climate risk management and is important for food security in many parts of the world. Climate changes may be reducing reliance on indigenous knowledge in some locations but also some policies and regulation may be limiting the contribution that indigenous knowledge can make to effective climate adaptation (medium evidence, medium agreement; Section 7.5.1.1.4).

The focus on incremental adaptations and few studies on more systemic and transformational adaptation or adaptation across the food system mean that there may be underestimation of adaptation opportunities and benefits (limited evidence, medium agreement; Section 7.5.1.1). In addition to this, there is a range of limits and barriers to adaptation and many of these could be addressed by devolution of the decision-making process so as to integrate local, contextual information into adaptation decision making. A schematic summary of these issues is given in Table 7-3.

\subsection{Research and Data Gaps-Food Security as a Cross-Sectoral Activity}

Research and data gaps reflect that most work since AR4 has continued to concentrate on food production and has not included other aspects of the food system that connect climate change to food security. Features such as food processing, distribution, access, and consumption have recently become areas of research interest in their own right but only tangentially attached to climate change.

Many studies either do not examine yield variability or do not report it. Closer attention should be paid to yield variability in the quantity and quality of food production, especially given observed price fluctuations associated with climate events. We expect environmental thresholds and tipping points, such as high temperatures, droughts, and floods, to become more important in the future. Specific recommendations are for food production experiments in which changes in variability reflect predicted changes for given warming scenarios. Including thresholds in impact models, for especially high levels of global warming (i.e., 4 to $6^{\circ} \mathrm{C}$ above preindustrial), are highly likely to result in lower projections of yield, given changes in climate variability and increasing mean temperatures. Important gaps in knowledge continue to be studies of weeds, pests, and diseases, including animal diseases, in response to climate change and how related adaptation activities can be robustly incorporated into food security assessments. Yield and other agronomic data, at a range of spatial scales, are crucial to the development, evaluation, and improvement of models. Model development is currently limited by lack of data.

Adaptation studies for cropping systems typically assess relatively minor agronomic management changes under future climate conditions only. Forthcoming studies should examine the impact of proposed adaptations when employed in the current climate. In this way management changes that are beneficial in a range of environments can be separated from management changes that are specifically targeted at climate change. Further, studies should be inclusive of the broader range of systemic and transformational adaptation options open to agriculture.

Current forecasts of changes in distribution and productivity of marine fish species and communities are typically at a global or regional scale and include adaptations to only a limited extent. Increasing the resolution to forecast impacts and changes at the national and local ecosystem scale would provide valuable information to governments and stakeholders and enable them to prepare more effectively for expected impacts on food production and security offered by fisheries.

Possibilities for agronomic and breeding adaptations of food production to global warming are possible up to high levels of climate change. However, food security studies are urgently required to estimate the actual range of adaptations open to farmers and other actors in the food system and the implementation paths for these, especially when possible changes in climate variability are included.

\section{References}

Abraha, M.G. and M.J. Savage, 2006: Potential impacts of climate change on grain yield of maize for the midlands of KwaZulu-Natal, South Africa. Agriculture Ecosystems and Environment, 115(1-4), 150-160.

Abou-Hadid, A.F., 2006: Assessment of Impacts, Adaptation, and Vulnerability to Climate Change in North Africa: Food Production and Water Resources. AIACC Final Report Project No. AF 90, Washington, DC, USA, 128 pp.

Adger, W., S. Dessai, M. Goulden, M. Hulme, I. Lorenzoni, D. Nelson, L. Naess, J. Wolf, and A. Wreford, 2009: Are there social limits to adaptation to climate change? Climatic Change, 93(3-4), 335-354.

Aggarwal, P.K. and R.K. Mall, 2002: Climate change and rice yields in diverse agroenvironments of India. II. Effect of uncertainties in scenarios and crop models on impact assessment. Climatic Change, 52(3), 331-343.

Ainsworth, E.A. and J.M. McGrath, 2010: Direct effects of rising atmospheric carbon dioxide and ozone on crop yields. In: Climate Change and Food Security: Adapting Agriculture to a Warmer World [Lobell, D. and M. Burke (eds.)]. Springer, Dordrech, Netherlands and New York, NY, USA, pp. 109-130.

Ainsworth, E.A., A. Leakey, D.R. Ort, and S.P. Long, 2008: FACE-ing the facts: inconsistencies and interdependence among field, chamber and modeling studies of elevated $\mathrm{CO}_{2}$ impacts on crop yield and food supply. New Phytologist, 179, 5-9.

Akhtar, N., M. Yamaguchi, H. Inada, D. Hoshino, T. Kondo, M. Fukami, R. Funada, and T. Izuta, 2010: Effects of ozone on growth, yield and leaf gas exchange rates of four Bangladeshi cultivars of rice (Oryza sativa L.). Environmental Pollution, 158, 2970-2976.

Aksoy, A. and A. Isik-Dikmelik, 2008: Are Low Food Prices Pro-Poor? Net Food Buyers and Sellers in Low-Income Countries. World Bank Policy Research Working Paper No. 4642, World Bank, Washington DC, USA, 30 pp.

Aksoy, A., J. Beverinotti, K. Covarrubias, and A. Zezza, 2010: Household income structures in low-income countries. In: Food Prices and Rural Poverty [Aksoy, M. and B. Hoekstra (eds.)]. World Bank, Washington DC, USA, pp. 89-112.

Al-Bakri, J., A. Suleiman, F. Abdulla, and J. Ayad, 2010: Potential impact of climate change on rainfed agriculture of a semi-arid basin in Jordan. Physics and Chemistry of the Earth, Parts A/B/C, 36(5-6), 125-134. 
Alcamo, J., N. Dronin, M. Endejan, G. Golubev, and A. Kirilenko, 2007: A new assessment of climate change impacts on food production shortfalls and water availability in Russia. Global Environmental Change, 17(3-4), 429-444.

Alderman, H., 2010: Safety nets can help address the risks to nutrition from increasing climate variability. Journal of Nutrition, 140(Suppl. 1), 148S-152S.

Alessa, L., A. Kliskey, P.Williams, and M. Barton, 2008: Perception of change in freshwater in remote resource dependent Artic communities. Global Environmental Change, 18, 153-164.

Alexandratos, N. and J. Bruinsma, 2012: World Agriculture towards 2030/2050: The 2012 Revision. ESA Working Paper No. 12-03, Agricultural Development Economics Division (ESA), Food and Agriculture Organization of the United Nations (FAO), Rome, Italy, 147 pp.

Alexandrov, V., 1999: Vulnerability and adaptation of agronomic systems in Bulgaria. Climate Research, 12(2-3), 161-173.

Alexandrov, V. and G. Hoogenboom, 2000: The impact of climate variability and change on crop yield in Bulgaria. Agricultural and Forest Meteorology, 104(4), 315-327.

Alexandrov, V., J. Eitzinger, V. Cajic, and M. Oberforster, 2002: Potential impact of climate change on selected agricultural crops in north-eastern Austria. Global Change Biology, 8(4), 372-389.

Allan, D.J., R. Abell, Z. Hogan, C. Revenga, B.W. Taylor, R.L. Welcomme, and K. Winemiller, 2005: Overfishing of inland waters. BioScience, 55(12), 1041-1051.

Allison, E.H., A.L. Perry, M. Badjeck, W. Neil Adger, K. Brown, D. Conway, A.S. Halls, G.M. Pilling, J.D. Reynolds, N.L. Andrew, and N.K. Dulvy, 2009: Vulnerability of national economies to the impacts of climate change on fisheries. Fish and Fisheries, 10, 173-196.

Ambardekar, A.A., T.J. Siebenmorgen, P.A. Counce, S.B. Lanning, and A. Mauromoustakos, 2011: Impact of field-scale nighttime air temperatures during kernel development on rice milling quality. Field Crops Research, 122(3), 179-185.

Amthor, J.S., 2001: Effects of atmospheric $\mathrm{CO}_{2}$ concentration on wheat yield: review of results from experiments using various approaches to control $\mathrm{CO}_{2}$ concentration. Field Crops Research, 73, 1-34.

André, G., B. Engel, P. Berentsen, T.V. Vellinga, and A. Oude Lansink, 2011: Quantifying the effect of heat stress on daily milk yield and monitoring dynamic changes using an adaptive dynamic model. Journal of Dairy Science, 94, 4502-4513.

Antle, J.M. and C.C. Crissman, 1990: Risk, efficiency, and the adoption of modern crop varieties: evidence from the Philippines. Economic Development and Cultural Change, 38(3), 517-537.

Anwar, M.R., G. O'Leary, D. McNeil, H. Hossain, and R. Nelson, 2007: Climate change impact on rainfed wheat in south-eastern Australia. Field Crops Research, 104(1-3), 139-147.

Archambault, D.J., 2007: Efficacy of herbicides under elevated temperature and $\mathrm{CO}_{2}$. In: Agroecosystems in a Changing Climate [Newton, P.C.D., A. Carran, G.R. Edwards, and P.A. Niklaus (eds.)]. CRC Press, Boston, MA, USA, pp. 262-279.

Arndt, C., K. Strzepeck, F. Tarp, J. Thurlow, C. Fant IV, and L. Wright, 2011: Adapting to climate change: an integrated biophysical and economic assessment for Mozambique. African Regional Perspectives, 6(1), 7-20.

Asseng, S., I. Foster, and N.C. Turner, 2011: The impact of temperature variability on wheat yields. Global Change Biology, 17, 997-1012.

Asseng, S., F. Ewert, C. Rosenzweig, J.W. Jones, J.L. Hatfield, A. Ruane, K.J. Boote, P. Thorburn, R.P. Rötter, D. Cammarano, N. Brisson, B. Basso, P. Martre, P.K. Aggarwal, C. Angulo, P. Bertuzzi, C. Biernath, A.J. Challinor, J. Doltra, S. Gayler, R. Goldberg, R. Grant, L. Heng, J. Hooker, L.A. Hunt, J. Ingwersen, R.C. Izaurralde, K.C. Kersebaum, C. Müller, S.N. Kumar, C. Nendel, G. O'Leary, J.E. Olesen, T.M. Osborne, T. Palosuo, E. Priesack, D. Ripoche, M.A. Semenov, I. Shcherbak, P. Steduto, C. Stöckle, P. Stratonovitch, T. Streck, I. Supit, F. Tao, M. Travasso, K. Waha, D. Wallach, J.W. White, J.R. Williams, and J. Wolf, 2013: Uncertainty in simulating wheat yields under climate change. Nature Climate Change, 3(9), 827-832.

Auffhammer, M., V. Ramanathan, and J.R. Vincent, 2012: Climate change, the monsoon, and rice yield in India. Climatic Change, 111(2), 411-424.

Avnery, S., D.L. Mauzerall, J. Liu, and L.W. Horowitz, 2011a: Global crop yield reductions due to surface ozone exposure: 1. Year 2000 crop production losses and economic damage. Atmospheric Environment, 45(13), 2284-2296.

Avnery, S., D.L. Mauzerall, J. Liu, and L.W. Horowitz, $2011 \mathrm{~b}$ : Global crop yield reductions due to surface ozone exposure: 2. Year 2030 potential crop production losses and economic damage under two scenarios of $\mathrm{O}_{3}$ pollution. Atmospheric Environment, 45(13), 2296-2309.

Badjeck, M., E. Allison, A. Halls, and N. Dulvey, 2010: Impacts on climate variability and change on fishery-based livelihoods. Marine Policy, 34(3), 375-383.
Baethgen, W.E., 2010: Climate risk management for adaption to climate variability and change. Crop Science, 50(2), 70-76.

Baldocchi, D. and S. Wong, 2008: Accumulated winter chill is decreasing in the fruit growing regions of California. Climatic Change, 87, 153-166.

Barati, F., B. Agung, P. Wongsrikeao, M. Taniguchi, T. Nagai, and T. Otoi, 2008: Meiotic competence and DNA damage of porcine oocytes exposed to an elevated temperature. Theriogenology, 69, 767-772.

Barbier, B., H. Yacouba, H. Karambiri, M. Zorome, and B. Some, 2009: Human vulnerability to climate variability in the Sahel: farmers' adaptation strategies in northern Burkina Faso. Environmental Management, 43, 790-803.

Battaglini, A., G. Barbeau, M. Bindi, and F. Badeck, 2009: European winegrowers' perception of climate change impact and options for adaption. Regional Environmental Change, 9(2), 61-73.

Bearchell, S.J., B.A. Fraaije, M.W. Shaw, and B.D. Fitt, 2005: Wheat archive links longterm fungal pathogen population dynamics to air pollution. Proceedings of the National Academy of Sciences of the United States of America, 102, 54385442.

Bell, J., M. Batty, A. Ganachaud, P. Gehrke, A. Hobday, O. Hoegh-Guldberg, J. Johnson, R. Le Borgne, P. Lehodey, J. Lough, T. Pickering, M. Pratchett, M. Sheaves, and M. Waycott, 2009: Preliminary Assessment of the Effects of Climate Change on Fisheries and Aquaculture in the Pacific. Secretariat of the Pacific Community, Noumea, New Caledonia, 15 pp.

Bell, J., N.L. Andrew, M.J. Batty, L.B. Chapman, J.M. Dambacher, B. Dawson, A.S. Ganachaud, P.C. Gehrke, J. Hampton, A.J. Hobday, O. Hoegh-Guldberg, J.E. Johnson, J.P. Kinch, R. Le Borgne, P. Lehody, J.M. Lough, T.D. Pickering, M.S. Pratchett, A. Vunisea, and M. Waycott. 2011:Adapting tropical Pacific fisheries and aquaculture to climate change: management measures, policies and investments. In: Vulnerability of Tropical Pacific Fisheries and Aquaculture to Climate Change [Bell, J.D., J.E. Johnson, and A.J. Hobday (eds.). Secretariat of the Pacific Community, Noumea, New Caledonia, pp. 803-876.

Ben Mohamed, A., 2011: Climate change risks in Sahelian Africa. Regional Environmental Change, 11(1), 109-117.

Bellocchi, G., M. Rivington, M. Donatelli, and K. Matthews, 2010: Validation of biophysical models: issues and methodologies. A review. Agronomy for Sustainable Development, 30, 109-130.

Berg, A., M. de Noblet-Ducoudre, B. Sultan, M. Langaigne, and M. Guimberteau, 2013: Projections of climate change impacts on potential $\mathrm{C}_{4}$ crop productivity over tropical regions. Agricultural and Forest Meteorology, 170, 89-102.

Bergot, M., E. Cloppet, V. Pérnaud, M. Déqué, B. Marçais, and M. Desprez-Loustau, 2004: Simulation of potential range expansion of oak disease caused by Phytophthora cinnamomi under climate change. Global Change Biology, 10, 1539-1552.

Berrang-Ford, L., J. Ford, and J. Paterson, 2010: Are we adapting to climate change? Global Environmental Change, 21, 25-33.

Biazin, B., G. Sterk, M. Temesgen, A. Abdulkedir, and L. Stroosnijder, 2012: Rainwater harvesting and management in rainfed agricultural systems in sub-Saharan Africa - a review. Physics and Chemistry of the Earth, 48, 139-151.

Bindi, M. and J. Olesen, 2011: The responses of agriculture in Europe to climate change. Regional Environmental Change, 11(Suppl. 1), 151-158.

Bloem, M.W., R. Semba, and K. Kraemer, 2010: Caster Gandolfo Workshop: an introduction to the impact of climate change, the economic crisis and the increases in the food prices on malnutrition. Journal of Nutrition, 140(Suppl. 1), 132S-135S.

Bohensky, E., A. Smaigl, and T. Brewer, 2012: Patterns in household-level engagement with climate change in Indonesia. Nature Climate Change, 3, 348-351.

Bondeau, A., P.C. Smith, S. Zaehle, S. Schaphoff, W. Lucht, W. Cramer, D. Gerten, H. Lotze-Campen, C. Müller, M. Reichstein, and B. Smith, 2007: Modelling the role of agriculture for the $20^{\text {th }}$ century global terrestrial carbon balance. Global Change Biology, 13, 679-706.

Booker, F., R. Muntifering, M. McGrath, K. Burkey, D. Decoteau, E. Fiscus, W. Manning, S. Krupa, A. Chappelka, and D. Grantz, 2009: The ozone component of global change: potential effects on agricultural and horticultural plant yield, product quality and interactions with invasive species. Journal of Integrative Plant Biology, 51, 337-351.

Brander, K., 2007: Global fish production and climate change. Proceedings of the National Academy of Sciences of the United States of America, 104, 1970919714.

Brander, K., 2010: Impacts of climate change on fisheries. Journal of Marine Systems, 79, 389-402. 
Brassard, J.P. and B. Singh, 2007: Effects of climate change and $\mathrm{CO}_{2}$ increase on potential agricultural production in Southern Québec, Canada. Climate Research, 34, 105-117.

Brassard, J.P. and B. Singh, 2008: Impacts of climate change and $\mathrm{CO}_{2}$ increase on crop yields and adaptation options for Southern Quebec, Canada. Mitigation and Adaptation Strategies for Global Change, 13, 241-265.

Bridges, D.C., 1992: Crop Losses Due to Weeds in the United States. Weed Science Society of America, Champaign, IL, USA, 403 pp.

Brinkman, H.S., S. de Pee, I. Aanogao, L. Subran, and M.W. Bloem, 2010: High food prices and the global financial crisis have reduced access to nutritious food and worsened nutritional status and health. Journal of Nutrition, 140(Suppl. 1), 153S-161S

Brisson, N., P. Gate, D. Gouache, G. Charmet, F. Oury, and F. Huard, 2010: Why are wheat yields stagnating in Europe? A comprehensive data analysis for France. Field Crops Research, 119, 201-212.

Brown, C.J., E.A. Fulton, A.J. Hobday, R.J. Matear, H.P. Possingham, C. Bulman, V. Christensen, R.E. Forrest, P.C. Gehrke, N.A. Gribble, S.P. Griffiths, H. LozanoMontes, J.M. Martin, S. Metcalf, T.A. Okey, R. Watson, and A.J. Richardson, 2010: Effects of climate-driven primary production change on marine food webs: implications for fisheries and conservation. Global Change Biology, 16, 1194-1212.

Bruinsma, J., 2009. The resource outlook to 2050: by how much do land, water and crop yields need to increase by 2050? In: Proceedings of the Expert Meeting on How to Feed the World in 2050, 24-26 June 2009, FAO Headquarters, Rome. Food and Agriculture Organization of the United Nations (FAO), Rome, Italy, $33 \mathrm{pp}$.

Bryan, E., T. Deressa, G. Gbetibouo, and C. Ringler, 2009: Adaptation to climate change in Ethiopia and South Africa: options and constraints. Environmental Science and Policy, 12, 413-426.

Bunce, J.L., 2012: Responses of cotton and wheat photosynthesis and growth to cyclic variation in carbon dioxide concentration. Photosynthetica, 50, 395-400.

Burke, L., K. Reytar, M. Spalding, and A. Perry, 2011: Reefs at Risk Revisited. Executive Summary. World Resources Institute, Washington, DC, USA, 10 pp.

Burke, M.B., D.B. Lobell, and L. Guarino, 2009: Shifts in African crop climates by 2050, and the implications for crop improvement and genetic resources conservation. Global Environmental Change, 19, 317-325.

Butt, T.A., B.A. McCarl, J. Angerer, P.T. Dyke, and J.W. Stuth, 2005: The economic and food security implications of climate change in Mali. Climatic Change, 68(3), 355-378.

Byjesh, K.S., S. Naresh Kumar, and P.K. Aggarwal, 2010: Simulating impacts, potential adaptation and vulnerability of maize to climate change in India. Mitigation and Adaptation Strategies for Global Change, 15(5), 413-431.

Calzadilla, A., T. Zhu, K. Rehdanz, R.S.J. Tol, and C. Ringer, 2009: Economywide Impacts of Climate Change on Agriculture in Sub-Saharan Africa. International Food Policy Research Institute (IFPRI) Discussion Paper No. 873, IFPRI Environment and Production Technology Division, Washington, DC, USA, $35 \mathrm{pp}$.

Calzadilla, A., K. Rehdanz, R. Betts, P. Falloon, A. Wiltshire, and R.S.J. Tol, 2013: Climate change impacts on global agriculture. Climatic Change, 120(1-2), 357-374.

Campbell, A.A., S. de Pee, K. Sun, K. Kraemer, A. Thorne-Lyman, and R. Moench-Pfanner, 2010: Household rice expenditure and maternal and child nutritional status in Bangladesh. Journal of Nutrition, 140(Suppl. 1), 189S-194S.

Cannon, R.J.C., 1998: The implications of predicted climate change for insect pests in the UK, with emphasis on non-indigenous species. Global Change Biology, 4, 785-796.

Cantarel, A.A.M., J.M.G. Bloor, and J.F. Soussana, 2013: Four years of simulated climate change reduces aboveground productivity and alters functional diversity in a grassland ecosystem. Journal of Vegetation Science, 24, 113-126.

Carter, M.R. and T.J. Lybbert, 2012: Consumption versus asset smoothing: testing the implications of poverty trap theory in Burkina Faso. Journal of Development Economics, 99, 255-264.

Ceccarelli, S., S. Grando, M. Maatougui, M. Michael, M. Slash, R. Haghparast, M. Rahmanian, A. Taheri, A. Al-Yassin, A. Benbelkacem, M. Labdi, H. Mimoun, and M. Nachit, 2010: Plant breeding and climate changes. The Journal of Agricultural Science, 148, 627-637.

Chakraborty, S., J. Luck, A. Freeman, R.M. Norton, K.A. Garrett, K.E. Percy, A.A. Hopkin, C. Davis, and D.F. Karnosky, 2008: Impacts of global change on diseases of agricultural crops and forest types. CAB Reviews: Perspectives in Agriculture, Veterinary Science, Nutrition, and Natural Resources, 3, No. 054,1-15.

Chakraborty, S. and A.C. Newton, 2011: Climate change, plant diseases and food security: an overview. Plant Pathology, 60, 2-14.
Challinor, A.J. and T.R. Wheeler, 2008: Use of a crop model ensemble to quantify $\mathrm{CO}_{2}$ stimulation of water-stressed and well-watered crops. Agricultural and Forest Meteorology, 148, 1062-1077.

Challinor, A.J., T.R. Wheeler, D. Hemming, and H.D. Upadhyaya, 2009: Ensemble yield simulations: crop and climate uncertainties, sensitivity to temperature and genotypic adaptation to climate change. Climate Research, 38(2), 117-127.

Challinor, A.J., E.S. Simelton, E.G. Fraser, and D. Hemming, 2010: Increased crop failure due to climate change: assessing adaptation options using models and socio-economic data for wheat in China. Environmental Research Letters, 5(3), 034012.

Chen, C., E. Wang, Q. Yu, and Y. Zhang, 2010: Quantifying the effects of climate trends in the past 43 years (1961-2003) on crop growth and water demand in the North China Plain. Climatic Change, 100, 559-578.

Chen, C., C. Lei, A. Deng, C. Qian, W. Hoogmoed, and W. Zhang, 2011: Will higher minimum temperatures increase corn production in Northeast China? An analysis of historical data over 1965-2008. Agricultural and Forest Meteorology, 151, 1580-1588.

Cheung, W., V. Lam, J. Sarmiento, K. Kearney, R. Watson, D. Zeller, and D. Pauly, 2010: Large scale redistribution of maximum fisheries catch in the global ocean under climate change. Global Change Biology, 16(1), 24-35.

Cheung, W.L., R. Watson, and D. Pauly, 2013: Signature of ocean warming in global fisheries catch. Nature, 497, 365-368.

Chhetri, N., W.E. Easterling, A. Terando, and L. Mearns, 2010: Modeling path dependence in agricultural adaptation to climate variability and change. Annals of the Association of American Geographers, 100(4), 894-907.

Chipanshi, A.C., R. Chanda, and O. Totolo, 2003: Vulnerability assessment of maize and sorghum crops to climate change in Botswana. Climatic Change, 61, 339360.

Cho, K., P. Falloon, J. Gornall, R. Betts, and Clark, 2012: Winter wheat yields in the UK: uncertainities in climate and management impacts. Climate Research, 54, 49-68.

Christidis, N., P.A. Stott, S. Brown, G.C. Hegerl, and J. Caesar, 2005: Detection of changes in temperature extremes during the second half of the $20^{\text {th }}$ century. Geophysical Research Letters, 32(20), L20716, doi:10.1029/2005GL023885.

Cinner, J.E., T.R. McClanahan, N.A.J. Graham, T.M. Daw, J. Maina, S.M. Stead, A. Wamukota, K. Brown, and Ö. Bodin, 2012:Vulnerability of coastal communities to key impacts of climate change on coral reef fisheries. Global Environmental Change, 22, 12-20.

Ciscar, J., A. Iglesias, L. Feyen, L. Szabo, D. Regemorter, B. Amelung, R. Nicholls, P. Watkiss, O. Christensen, R. Dankers, L. Garrote, C. Goodess, A. Hunt, A. Moreno, J. Richards, and A. Soria, 2011: Physical and economic consequences of climate change in Europe. Proceedings of the National Academy of Sciences of the United States of America, 108, 2678-2683.

Cochrane, K., W. Emerson, and R. Willmann, 2009: Sustainable fisheries: the importance of the bigger picture. In: Sustainable Fisheries: Multi-Level Approaches to a Global Problem [Taylor, W., A. Lynch, and M. Schechter (eds.)]. American Fisheries Society, Herndon, VA, USA, pp. 3-19.

Cochrane, K.L., N.L. Andrew, and A.M. Parma, 2011: Primary fisheries management: a minimum requirement for provision of sustainable human benefits in smallscale fisheries. Fish and Fisheries, 12, 275-288.

Coles, A. and C. Scott, 2009: Vulnerability and adaptation to climate change and variability in semi-arid rural southeastern Arizona, USA. Natural Resources Forum, 33(4), 297-309.

Cook, R.M. and M.R. Heath, 2005: The implications of warming climate for the management of North Sea demersal fisheries. ICES Journal of Marine Science, $62,1322-1326$

Cooper, P., K.P.C. Rao, P. Singh, J. Dimes, P.S. Traore, K. Rao, P. Dixit, and S.J. Twomlow, 2009: Farming with current and future climate risk: advancing a "Hypothesis of Hope" for rainfed agriculture in semi-arid tropics. Journal of Semi-Arid Tropics Agricultural Research, 7, 1-19.

Corobov, R., 2002: Estimations of climate change impacts on crop production in the Republic of Moldova. GeoJournal, 57(3), 195-202.

Costa, L.C., F. Justino, L.J.C. Oliveira, G.C. Sediyama, W.P.M. Ferreira, and C.F. Lemos, 2009: Potential forcing of $\mathrm{CO}_{2}$, technology and climate changes in maize (Zea mays) and bean (Phaseolus vulgaris) yield in southeast Brazil. Environmental Research Letters, 4(1), 014013, doi:10.1088/1748-9326/4/1/014013.

Cotty, J.L. and R. Jaime-Garcia, 2007: Influences of climate on aflatoxin producing fungi and aflatoxin contamination. International Journal of Food Microbiology, $119,109-115$ 
Coulthard, S., 2008: Adapting to environmental change in artisanal fisheries insights from a South Indian Lagoon. Global Environmental Change, 18(3), 479-489.

Cozzolino, D., W.U. Cynkar, R.G. Dambergs, M. Gishen, and P. Smith, 2010: Grape (Vitis vinifera) compositional data spanning ten successive vintages in the context of abiotic growing parameters. Agriculture, Ecosystems \& Environment, $139,565-570$.

Craine, J.M., A.J. Elmore, K.C. Olson, and D. Tolleson, 2010: Climate change and cattle nutritional stress. Global Change Biology, 16, 2901-2911.

Craufurd, P.Q. and T.R. Wheeler, 2009: Climate change and the flowering time of annual crops. Journal of Experimental Botany, 60, 2529-2539.

Craufurd, P.Q., V. Vadez, S.V.K. Jagadish, P.V.V. Prasad, and M. Zaman-Allah, 2013: Crop science experiments designed to inform crop modeling. Agricultural and Forest Meteorology, 170, 8-18.

DaMatta, F.M., A. Grandis, B.C. Arenque, and M.S. Buckeridge, 2010: Impacts of climate changes on crop physiology and food quality. Food Research International, 43, 1814-1823.

Daw, T., W. Adger, K. Brown, and M. Badjeck, 2009: Climate change and capture fisheries: potential impacts, adaptation and mitigation. In: Climate Change Implications for Fisheries and Aquaculture: Overview of Current Scientific Knowledge [Cochrane, K., C. De Young, D. Soto, and T. Bahri (eds.)]. Food and Agricultural Organization of the United Nations (FAO) Fisheries and Aquaculture Technical Paper No. 530, FAO, Rome, Italy, pp. 107-150.

De Bruin, K.C. and R. Dellink, 2011: How harmful are restrictions on adapting to climate change? Global Environmental Change, 21(1), 34-45.

DEFRA, 2006: Food Security and the UK: An Evidence and Analysis Paper. Department for Environment, Food, and Rural Affairs (DEFRA), Food Chain Analysis Group, London, UK, $87 \mathrm{pp}$.

De Jong, R., K.Y. Li, A. Bootsma, T. Huffman, G. Rohloff, and S. Gameda, 2001: Crop Yield and Variability under Climate Change and Adaptive Crop Management Scenarios. Final Report for Climate Change Action Fund Project A080, Eastern Cereal and Oilseed Research Centre (ECORC), Government of Canada Department of Agriculture and Agri-Food Canada, Ottowa, Ontario, Canada, 49 pp.

Deryng, D., W.J. Sacks, C.C. Barford, and N. Ramankutty, 2011: Simulating the effects of climate and agricultural management practices on global crop yield, Global Biogeochemical Cycles, 25, GB2006, doi:10.1029/2009GB003765.

De Silva, S.S. and D. Soto, 2009: Climate change and aquaculture: potential impacts, adaptation and mitigation. In: Climate Change Implications for Fisheries and Aquaculture: Overview of Current Scientific Knowledge [Cochrane, K., C. De Young, D. Soto, and T. Bahri (eds.)]. Food and Agricultural Organization of the United Nations (FAO) Fisheries and Aquaculture Technical Paper 530, FAO, Rome, Italy, pp. 151-212.

Dell, M., B.F. Jones, and B.A. Olken, 2012: Temperature shocks and economic growth: evidence from the last half century. American Economic Journal: Macroeconomics, 4, 66-95.

Dercon, S., 2004: Growth and shocks: evidence from rural Ethiopia. Journal of Development Economics, 74, 309-329.

Dercon, S. 2006: Economic reform, growth and the poor. Evidence from rural Ethiopia. Journal of Development Economics, 81(1), 1-24.

Dercon, S. and L. Christiaensen, 2011: Consumption risk, technology adoption and poverty traps: evidence from Ethiopia. Journal of Development Economics, 96, 159-173.

Deressa, T., R. Hassan, C. Ringler, T. Alemu, and M. Yesuf, 2009: Determinants of farmers' choice of adaptation methods to climate change in the Nile basin of Ethiopia. Global Environmental Change, 19, 248-255.

Deryng, D., W.J. Sacks, C.C. Barford, and N. Ramankutty, 2011: Simulating the effects of climate and agricultural management practices on global crop yield. Global Biogeochemical Cycles, 25, GB2006, doi:10.1029/2009GB003765.

Descheemaeker, K., T. Amede, and A. Haileslassie, 2010: Improving water productivity in mixed crop-livestock farming systems of sub-Saharan Africa. Agricultural Water Management, 97, 579-586.

Dikmen, S. and P.J. Hansen, 2009: Is the temperature-humidity index the best indicator of heat stress in lactating dairy cows in a subtropical environment? Journal of Dairy Science, 92, 109-116.

Dilling, L. and M.C. Lemos, 2011: Creating usable science: opportunities and constraints for climate knowledge use and their implications for science policy. Global Environmental Change, 21, 680-689.

Dronin, N. and A. Kirilenko, 2011: Climate change, food stress, and security in Russia. Regional Environmental Change, 11(Suppl. 1), 167-178.
Droogers, P., 2004: Adaptation to climate change to enhance food security and preserve environmental quality: example for southern Sri Lanka. Agricultural Water Management, 66(1), 15-33.

Duchêne, E., F. Huard, V. Dumas, C. Schneider, and D. Merdinoglu, 2010: The challenge of adapting grapevine varieties to climate change. Climate Research, 41(3), 193-204.

Duval, B.D., P. Dijkstra, S.M. Natali, J.P. Megonigal, M.E. Ketterer, B.G. Drake, M.T. Lerdau, G. Gordon, A.D. Anbar, and B.A. Hungate, 2011: Plant-soil distribution of potentially toxic elements in response to elevated atmospheric $\mathrm{CO}_{2}$. Environmental Science and Technology, 45, 2570-2574.

Eastburn, D.M., A.J. McElrone, and D.D. Bilgin, 2011: Influence of atmospheric and climatic change on plant-pathogen interactions. Plant Pathology, 60, 54-69.

Easterling, W.E., N. Chhetri, and X. Niu, 2003: Improving the realism of modeling agronomic adaptation to climate change: simulating technological substitution. Climatic Change, 60, 149-173.

El-Maayar, M. and O. Sonnentag, 2009: Crop model validation and sensitivity to climate change scenarios. Journal of Climate Research, 39, 47-59.

El-Shaher, H.M., C. Rosenzweig, A. Iglesias, M.H. Eid, and D. Hillel, 1997: Impact of climate change on possible scenarios for Egyptian agriculture in the future. Mitigation and Adaptation Strategies for Global Change, 1, 233-250.

El-Sharkawy, M.A., 2012: Stress-tolerant cassava: the role of integrative ecophysiology-breeding research in crop improvement. Open Journal of Soil Science, 2(2), 162-186.

Emberson, L.D., P. Büker, M.R. Ashmore, G. Mills, L.S. Jackson, M. Agrawal, M.D. Atikuzzaman, S. Cinderby, M. Engardt, C. Jamir, K. Kobayashi, N.T.K. Oanh, Q.F. Quadir, and A. Wahid, 2009: A comparison of North American and Asian exposureresponse data for ozone effects on crop yields. Atmospheric Environment, 43, 1945-1953.

Erbs, M., R. Manderscheid, G. Jansen, S. Seddig, A. Pacholski, and H. Weigel, 2010: Effects of free-air $\mathrm{CO}_{2}$ enrichment and nitrogen supply on grain quality parameters and elemental composition of wheat and barley grown in a crop rotation. Agriculture, Ecosystem and Environment, 136, 59-68.

Erda, L., X. Wei, J. Hui, X. Yinlong, L. Yue, B. Liping, and X. Liyong, 2005: Climate change impacts on crop yield and quality with $\mathrm{CO}_{2}$ fertilization in China. Philosophical Transactions of the Royal Society B, 360, 2149-2154.

Ericksen, P., 2008: Conceptualizing food systems for global environmental change research. Global Environmental Change, 18, 234-245.

Ericksen, P., B. Stewart, J. Dixon, D. Barling, P. Loring, M. Anderson, and J. Ingram, 2010: The value of a food system approach. In: Food Security and Global Environmental Change [Ingram, J., P. Ericksen, and D. Liverman (eds.)]. Earthscan, London, UK, pp. 25-45.

Ericksen, P., P. Thornton, A. Notenbaert, L. Cramer, P. Jones, and M. Herero, 2011: Mapping Hotspots of Climate Change and Food Insecurity in the Global Tropics. CCAFS Report No. 5, CGIAR Research Program on Climate Change, Agriculture, and Food Security (CCAFS), Copenhagen, Denmark, 56 pp.

Evans, N., A. Baierl, M.A. Semenov, P. Gladders, and B.D.L. Fitt, 2008: Range and severity of a plant disease increased by global warming. Journal of the Royal Society Interface, 5, 525-531.

Ewert, F., M.D.A. Rounsevell, I. Reginster, M.J. Metzger, and R. Leemans, 2005: Future scenarios of European agricultural land use: I. Estimating changes in crop productivity. Agriculture Ecosystems \& Environment, 107(2-3), 101-116.

Fafchamps, M., 1992: Solidarity networks in pre-industrial societies: rational peasants with a moral economy. Economic Development and Cultural Change, 41, 147-174.

Fafchamps, M., 1999: Rural Poverty, Risk and Development. Economic and Social Development Paper, No. 144, Food and Agricultural Organization of the United Nations (FAO), Rome, Italy, 131 pp.

Fafchamps, M., 2009: Vulnerability, Risk Management, and Agricultural Development. Center for Effective Global Action (CEGA) Working Paper No. AfD-0904, CEGA AfD Working Paper Series containing papers presented at the "Agriculture for Development in Sub-Saharan Africa Conference," May 28-30, 2009, Mombasa, Kenya, sponsored by CEGA and the African Economic Research Consortium (AERC), CEGA, University of California, Berkeley, Berkeley, CA, USA, 29 pp.

Falloon, B. and R. Betts, 2010: Climate impacts on European agriculture and water management in the context of adaptation and mitigation - the importance of an integrated approach. Science of the Total Environment, 408, 5667-5687.

FAO, 1996: Rome Declaration and World Food Summit Plan of Action. Food and Agricultural Organization of the United Nations (FAO) World Food Summit, Rome, Italy, 13-17 November 1996, FAO, Rome, Italy, www.fao.org/docrep/ 003/w3613e/w3613e00.HTM. 
FAO, 2008: The State of Food Insecurity in the World: High Food Prices and Food Security-Threats and Opportunities. Food and Agricultural Organization of the United Nations (FAO), Rome, Italy, $56 \mathrm{pp}$.

FAO, 2009a: Introduction. In: Climate Change Implications or Fisheries and Aquaculture: Overview of Current Scientific Knowledge [Cochrane, K., C. De Young, D. Soto, and T. Bahri (eds.)]. Food and Agricultural Organization of the United Nations (FAO) Fisheries and Aquaculture Technical Paper 530, FAO, Rome, Italy, pp. 1-5.

FAO, 2009b: The State of Agricultural Commodity Markets 2009: High Food Prices and the Food Crisis - Experiences and Lessons Learned. Food and Agricultural Organization of the United Nations (FAO), Rome, Italy, $63 \mathrm{pp}$.

FAO, 2010: The State of Food Insecurity in the World: Addressing Food Insecurity in Protracted Crises. Food and Agricultural Organization of the United Nations (FAO), Rome, Italy, $50 \mathrm{pp}$.

FA0, 2011: The State of Food Insecurity in the World: How does International Price Volatility affect Domestic Economies and Food? Food and Agricultural Organization of the United Nations (FAO), Rome, Italy, 52 pp.

FAO, 2012: The State of World Fisheries and Aquaculture 2012. Food and Agricultural Organization of the United Nations (FAO), Rome, Italy, $209 \mathrm{pp}$.

FA0, WFP, and IFAD, 2012: The State of Food Insecurity in the World: Economic Growth is Necessary but not Sufficient to Accelerate Reduction of Hunger and Malnutrition. Food and Agricultural Organization of the United Nations (FAO), the International Fund for Agricultural Development (IFAD), and the World Food Programme (WFP), FAO, Rome, Italy, $62 \mathrm{pp}$.

Farag, A.A., A.A. Khalil, and M.K. Hassanein, 2010: Chilling requirement for deciduous fruit under climate change in Egypt. Research Journal of Agriculture and Biological Sciences, 6, 815-822.

Fatondji, D., C. Martius, R. Zougmore, P. Vlek, C. Bielders, and S. Koala, 2009: Decomposition of organic amendment and nutrient release under the Zai technique in the Sahel. Nutrient Cycling in Agroecosystems, 85, 225-239.

Feder, G., R. Just, and D. Zilberman, 1985: Adoption of agricultural innovations in developing countries: a survey. Economic Development and Cultural Change, $33,255-298$.

Feng, J., M. Zhang, S. Zheng, P. Xie, and A. Ma, 2008a: Effects of high temperature on multiple parameters of broilers in vitro and in vivo. Poultry Science, 87, 2133-2139.

Feng, Z., K. Koyabashi, and E.A. Ainsworth, 2008b: Impact of elevated ozone concentration on growth, physiology and yield of wheat (Triticum aestivum L.): a meta analysis. Global Change Biology, 14, 2696-2708.

Feng, Z., J. Pang, K. Kobayashi, J. Zhu, and D.R. Ort, 2011: Differential responses in two varieties of winter wheat to elevated ozone concentration under fully openair field conditions. Global Change Biology, 17, 580-591.

Fernando, N., J. Panozzo, M. Tausz, R. Norton, G. Fitzgerald, and S. Seneweera, 2012: Rising atmospheric $\mathrm{CO}_{2}$ concentration affects mineral content and protein concentration of wheat grain. Food Chemistry, 133, 1307-1311.

Ficke, A.D., C.A. Myrick, and L.J. Hansen, 2007: Potential impacts of global climate change on freshwater fisheries. Review in Fish Biology and Fisheries, 17, 581 613.

Fischer, G., E. Hizsnyik, S. Prieler, M. Shah, and H. van Velthuizen, 2009: Biofuels and Food Security. Report by the International Institute for Applied Systems Analysis (IIASA) for the OPEC Fund for International Development (OFID), OFID, Vienna, Austria, $223 \mathrm{pp}$.

Fishman, J., J.K. Creilson, P.A. Parker, E.A. Ainsworth, G.G. Vining, J. Szarka, F.L. Booker, and X. Xu, 2010: An Investigation of widespread ozone damage to the soybean crop in the upper Midwest determined from ground-based and satellite measurements. Atmospheric Environment, 44, 2248-2256.

Fitzgerald, J., A. Brereton, and N. Holden, 2008: Assessment of the adaptation potential of grass-based dairy systems to climate change in Ireland - the maximised production scenario. Agricultural and Forest Meteorology, 149(2), 244-255.

Fleisher, D.H., D.J. Timlin, and V.R. Reddy, 2008: Interactive effects of carbon dioxide and water stress on potato canopy growth and development. Agronomy Journal, $100,711-719$.

Ford, D., 2009: Vulnerability of Inuit food systems to food insecurity as a consequence of climate change: a case study from Igloolik, Nunavut. Regional Environmental Change, 9, 83-100.

Fraser, E., M. Termansen, N. Sun, D. Guan, E. Simelton, P. Dodds, K. Feng, and Y. Yu, 2008: Quantifying socioeconomic characteristics of drought-sensitive regions: evidence from Chinese provincial agricultural data. Comptes Rendus Geoscience, 340(9-10), 679-688.
Fuhrer, J., 2009: Ozone risk for crops and pastures in present and future climates. Naturwissenschaften, 96, 173-194.

Fujisawa, M. and K. Koyabashi, 2010: Apple (Malus pumila var. domestica) phenology is advancing due to rising air temperature in northern Japan. Global Change Biology, 16(10), 2651-2660.

Fulton, E.A., 2011: Interesting times: winners, losers, and system shifts under climate change around Australia. ICES Journal of Marine Science, 68, 1329-1342.

García-Mozo, H., A. Mestre, and C. Galán, 2010: Phenological trends in southern Spain: a response to climate change. Agricultural and Forest Meteorology, 150, 575-580.

Garrett, K.A., G.A. Forbes, S. Savary, P. Skelsey, A.H. Sparks, C. Valdivia, A.H.C. van Bruggen, L. Willocquet, A. Djurle, E. Duveiller, H. Eckersten, S. Pande, C. Vera Cruz, and J. Yuen, 2011: Complexity in climate-change impacts: an analytical framework for effects mediated by plant disease. Plant Pathology, 60(1), 1530.

Gaughan, J.B., S. Bonner, I. Lozxton, T.L. Mader, A. Lisle and R. Lawrence, 2010: Effect of shade on body temperature and performance of feedlot steers. Journal of Animal Science, 88(12), 4056-4067.

Gbetibouo, G.A. and R.M. Hassan, 2005: Measuring the economic impact of climate change on major South African field crops: a Ricardian approach. Global and Planetary Change, 47(2-4), 143-152.

Ghahramani, A. and A. Moore, 2013: Climate change and broadacre livestock production across southern Australia. 2. Adaptation options via grassland management. Crop and Pasture Science, 64(6), 615-630.

Ghini, R., E. Hamada, M.J. Pedro, J.A. Marengo, and R.R.V. Gonçalves, 2008: Risk analysis of climate change on coffee nematodes and leaf miner in Brazil. Pesquisa Agropecuária Brasileira, 43, 187-195.

Ghorbanian, D., S. Harutyunyan, D. Mazaheri, and F. Rejali, 2011: Effects of mycorrhizal symbiosis and different levels of phosphorus on yield, macro and micro elements of Zea mays L. under water stress condition. Journal of Agricultural Research, 6, 5481-5489.

Giannakopoulos, C., P. Le Seger, M. Bindi, M. Moriondo, E. Kostopoulou, and C. Goodess, 2009: Climatic changes and associated impacts in the Mediterranean resulting from a $2{ }^{\circ} \mathrm{C}$ global warming. Global and Planetary Change, 68, 209224.

Gilbert, M., J. Slingenbergh, and X. Xiao, 2008: Climate change and avian influenza. Revue Scientifique et Technique (Office International des Epizooties), 27, 459466.

Gillespie, K.M., F. Xu, K.T. Richter, J.M. McGrath, R.J.C. Markelz, D.R. Ort, and A.D.B. Leakey, 2012: Greater anti-oxidant and respiratory metabolism in field grown soybean exposed to elevated $\mathrm{O}_{3}$ under both ambient and elevated $\mathrm{CO}_{2}$. Plant, Cell \& Environment, 35, 169-184.

Gleadow, R.M., J.R. Evans, S. McCaffrey, and T.R. Cavagnara, 2009: Growth and nutritive value of cassava (Manihot esculenta Cranz.) are reduced when grown in elevated $\mathrm{CO}_{2}$. Plant Biology, 11, 76-82.

Glenn, M., S.Y. Kim, J. Ramirez-Villegas, and P. Laderach, 2013: Chapter 2: Response of perennial horticultural crops to climate change. In: Horticultural Reviews [Janick, J. (ed.)]. Vol. 41, Wiley-Blackwell, Hoboken, NJ, USA, pp. 47-130.

Goklany, I.M., 2007: Integrated strategies to reduce vulnerability and advance adaptation, mitigation and sustainable development. Mitigation and Adaptation Strategies for Global Change, 12, 755-786.

Goodman-Elgar, M., 2008: Evaluating soil resilience in long-term cultivation: a study of pre-Columbian terraces from the Paca Valley, Peru. Journal of Archaeological Science, 35(12), 3072-3086.

Goswami, S.B., S. Matin, S. Aruna, and G.D. Bairagi, 2012: A review: the application of remote sensing, GIS and GPS in precision agriculture. Journal of Advanced Technology and Engineering Research, 2, 50-54.

Grab, S. and A. Craparo, 2011: Advance of apple and pear tree full bloom dates in response to climate change in the southwestern Cape, South Africa: 1973-2009. Agricultural and Forest Meteorology, 151, 406-413.

Grafton, R.Q., 2010: Adaptation to climate change in marine capture fisheries. Marine Policy, 34, 606- 615.

Graux, A.-I., M. Gaurut, J. Agabriel R. Baumont, R. Delagarde, L. Delaby, and J.-F. Soussana, 2011: Development of the Pasture Simulation Model for assessing livestock production under climate change. Agriculture, Ecosystems and Environment, 144, 69-91.

Graux, A.-I., G. Bellocchi, R. Lardy, and J. Soussana, 2013: Ensemble modelling of climate change risks and opportunities for managed grasslands in France. Agricultural and Forest Meteorology, 170, 114-131. 
Green, D., J. Billy, A. Tapim, 2010: Indigenous Australians' knowledge of weather and climate. Climate Change, 100, 337-354.

Gregory, P. J., S. N. Johnson, A. C. Newton and J. S. I. Ingram, 2009: Integrating pests and pathogens into the climate change/food security debate. Journal of Experimental Botany, 60 (10), 2827-2838.

Gregory, P.J. and B.E. Marshall, 2012: Attribution of climate change: a methodology to estimate the potential contribution to increases in potato yield in Scotland since 1960. Global Change Biology, 18, 1372-1388.

Guis, H., C. Caminade, C. Calvete, A.P. Morse, A. Tran, and B. Baylis, 2012: Modelling the effects of past and future climate on the risk of bluetongue emergence in Europe. Journal of the Royal Society Interface, 9, 339-350.

Gummow, B., 2010: Challenges posed by new and re-emerging infectious diseases in livestock production, wildlife and humans. Livestock Science, 130, 41-46.

Hall, A. and G.V. Jones, 2009: Effect of potential atmospheric warming on temperaturebased indices describing Australian winegrape growing conditions. Australian Journal of Grape and Wine Research, 15, 97-119.

Hannukkala, A.O., T. Kaukoranta, A. Lehtinen, and A. Rahkonen, 2007: Late-blight epidemics on potato in Finland, 1933-2002; increased and earlier occurrence of epidemics associated with climate change and lack of rotation. Plant Pathology, 56, 167-176.

Hanslow, K., D. Gunesekera, B.R. Cullen, and D. Newth, 2014: Economic impacts of climate change on the Australian dairy sector. Australian Journal of Agricultural and Resource Economics, 58, 60-77.

Hasegawa, T., H. Sakai, T. Tokida, H. Nakamura, C. Zhu, Y. Usui, M. Yoshimoto, M. Fukuoka, H. Wakatsuki, N. Katayanagi, T. Matsunami, Y. Kaneta, T. Sato, F. Takakai, R. Sameshima, M. Okada, T. Mae, and A. Makino, 2013: Rice cultivar responses to elevated $\mathrm{CO}_{2}$ at two free-air $\mathrm{CO}_{2}$ enrichment (FACE) sites in Japan. Functional Plant Biology, 40, 148-159.

Hatfield, J.L., K.J. Boote, B.A. Kimball, L.H. Ziska, R.C. Izaurralde, D. Ort, A.M. Thomson, and D. Wolfe, 2011: Climate impacts on agriculture: implications for crop production. Agronomy Journal, 103(2), 351-370.

Hawkins, E., T.M. Osborne, C.K. Hoa, and A.C. Challinor, 2012: Calibration and bias correction of climate projections for crop modelling: an idealised case study over Europe. Agricultural and Forest Meteorology, 170, 19-31.

Hayes, F., G. Mills, H. Harmens, and D. Norris, 2007: Evidence of Widespread Ozone Damage to Vegetation in Europe (1990-2006). Centre for Ecology and Hydrology, Natural Environment Research Council, Bangor, Wales, UK, pp. 1-58.

Headey, D. and S. Fan, 2010: Reflections on the Global Food Crisis: How Did It Happen? How Has It Hurt? And How Can We Prevent The Next One? International Food Policy Research Institute (IFPRI), Washington DC, USA, 122 pp.

Hellmann, J.J., J.E. Byers, B.G. Bierwagen, and J.S. Dukes, 2008: Five potential consequences of climate change for invasive species. Conservation Biology, 22, 534-543.

Heltberg, R. and F. Tarp, 2002: Agricultural supply response and poverty in Mozambique. Food Policy, 27(2), 103-124.

Hermans, C., I. Geijzendorffer, F. Ewert, M. Metzger, P. Vereijken, G. Woltjer, and A. Verhgen, 2010: Exploring the future of European crop production in a liberalized market, with specific consideration of climate and the regional competitiveness. Ecological Modeling, 221, 2177-2187.

Hertel, T.W., M.B. Burke, and D.B. Lobell, 2010: The poverty implications of climateinduced crop yield changes by 2030. Global Environmental Change, 20, 577-585.

HLPE, 2011: Price Volatility and Food Security. A Report by the High Level Panel of Experts (HLPE) on Food Security and Nutrition of the Committee on World Food Security, HLPE, Rome, Italy, 79 pp.

Hoddinot, J., J. Maluccio, J.R. Behrman, R. Flores, and R. Martorell, 2008: Effect of a nutrition intervention during early childhood on economic productivity in Guatemalan adults. The Lancet, 371, 411-416.

Hoegh-Guldberg, 0., 2011: Coral reef ecosystems and anthropogenic climate change. Regional Environmental Change, 11, 215-227.

Hoegh-Guldberg, O., P.J. Mumby, A.J. Hooten, R.S. Steneck, P. Greenfield, E. Gomez, C.D. Harvell, P.F. Sale, A.J. Edwards, K. Caldeira, N. Knowlton, C.M. Eakin, R. Iglesias-Prieto, N. Muthiga, R.H. Bradbury, A. Dubi, and M.E. Hatziolos, 2007: Coral reefs under rapid climate change and ocean acidification. Science, 318, 1737-1742.

Hoffmann, I., 2010: Climate change and the characterization, breeding and conservation of animal genetic resources. Animal Genetics, 41, 32-46.

Högy, P. and A. Fangmeier, 2009: Atmospheric $\mathrm{CO}_{2}$ enrichment affects potatoes: 1 . Above-ground biomass production and tuber yield. European Journal of Agronomy, 30, 78-84.
Högy, P., H. Wiesier, P. Kohler, K. Schwadorf, J. Breuer, J. Franzaring, R. Muntifering, and A. Fangmeier, 2009: Effects of elevated $\mathrm{CO}_{2}$ on grain yield and quality of wheat: results from a 3-year free-air $\mathrm{CO}_{2}$ enrichment experiment. Plant Biology, 11(Suppl. 1), 60-69.

Hollaway, M.J., S.R. Arnold, A.J. Challinor, and L.D. Emberson, 2011: Intercontinental trans-boundary contribution to ozone-induced crop yield losses in Northern Hemisphere. Biogeosciences Discussion, 8, 8645-8691.

Howden, M. and R.N. Jones, 2004: Risk assessment of climate change impacts on Australia's wheat industry. In: New Directions for a Diverse Planet: Proceedings of the 4th International Crop Science Congress, 26 September - 1 October 2004, Brisbane, Australia [Fischer, T., N. Turner, J. Angus, L. McIntyre, M. Robertson, A. Borrell, and D. Lloyd (eds.)]. The Regional Institute Ltd., Gosford, Australia, www.cropscience.org.au/icsc2004/symposia/6/2/1848_howdensm.htm.

Howden, M., S.J. Crimp, and C.J. Stokes, 2008: Climate change and Australian livestock systems: impacts, research and policy issues. Australian Journal of Experimental Agriculture, 48, 780-788.

Howden, M., S. Crimp, and R. Nelson, 2010: Australian agriculture in a climate of change. In: Managing Climate Change: Papers from the GREENHOUSE 2009 Conference [Jubb, I., P. Holper, and W. Cai (eds.)]. Commonwealth Scientific and Industrial Research Organization (CSIRO) Publishing, Collingwood, Australia, pp. 101-111.

Hsiang, S.M., 2010: Temperatures and cyclones strongly associated with economic production in the Caribbean and Central America. Proceedings of the National Academy of Sciences of the United States of America, 107(35), 15367-15372.

Hsiang, S.M., K.C. Meng, and M.A. Cane, 2011: Civil conflicts are associated with the global climate. Nature, 476, 438-441.

Huppert, D.D., A. Moore, and K. Dyson, 2009: Impacts of climate change on the coasts of Washington State. In: Washington Climate Change Impacts Assessment: Evaluating Washington's Future in a Changing Climate (Elsner, M.M., J. Littel, and L. Whitely Binder (eds.)]. Climate Impacts Group, University of Washington, Seattle, WA, USA, 285-310.

Hurley, T., 2010: Review of Agricultural Production Risk in the Developing World. HarvestChoice Working Paper 11, International Food Policy Research Institute (IFPRI), Washington, DC, USA, $56 \mathrm{pp}$.

IAASTD, 2009: Synthesis Report: A Synthesis of the Global and Sub-Global IAASTD Reports. International Assessment of Agricultural Knowledge, Science and Technology for Development (IAASTD), Island Press, Washington, DC, USA, 95 pp., www.unep.org/dewa/agassessment/reports/IAASTD/EN/Agriculture\%20at $\% 20$ a\%20Crossroads_Synthesis\%20Report\%20(English).pdf.

IFAD, 2010: The Rural Poverty Report 2011: New Realities, New Challenges: New Opportunities for Tomorrow's Generation. International Fund for Agricultural Development (IFAD), Rome, Italy, 317 pp.

Iglesias, A., C. Rosenzweig, and D. Pereira, 2000: Agricultural impacts of climate change in Spain: developing tools for a spatial analysis. Global Environmental Change, 10, 69-80.

Iglesias, A., L. Garrote, S. Quiroga, and M. Moneo, 2012: A regional comparison of the effects of climate change on agricultural crops in Europe. Climatic Change, 112(1), 29-46.

lizumi, T., M. Yokozawa, and M. Nishimori, 2009: Parameter estimation and uncertainty analysis of a large-scale crop model for paddy rice: application of a Bayesian approach. Agricultural and Forest Meteorology, 149, 333-348.

lizumi, T., M. Yokozawa, and M. Nishimori, 2011: Probabilistic evaluation of climate change impacts on paddy rice productivity in Japan. Climatic Change, 107, 391-415.

Ingram, J., 2011: A food systems approach to researching interactions between food security and global environmental change. Food Security, 3(4), 417-431.

IPCC, 2012: Managing the Risks of Extreme Events and Disasters to Advance Climate Change Adaptation. A Special Report of Working Groups I and II of the Intergovernmental Panel on Climate Change [Field, C.B., V. Barros, T.F. Stocker, D. Qin, D.J. Dokken, K.L. Ebi, M.D. Mastrandrea, K.J. Mach, G.-K. Plattner, S.K. Allen, M. Tignor, and P.M. Midgley (eds.)]. Cambridge University Press, Cambridge, UK and New York, NY, USA, $582 \mathrm{pp}$.

Iqbal, M.A., J. Eitzinger, H. Formayer, A. Hassan, and L.K. Heng, 2011: A simulation study for assessing yield optimization and potential for water reduction for summer-sown maize under different climate change scenarios. Journal of Agricultural Science, 149, 129-143.

Iqbal, M.M., M.A. Goheer, and A.M. Khan, 2009: Climate-change aspersions on food security of Pakistan. Science Vision, 15(1), 15-23.

Ivanic, M. and W. Martin, 2008: Implications of higher global food prices for poverty in low-income countries. Agricultural Economics, 39, 405-416. 
Ivanic, M., W. Martin, and H. Zaman, 2011: Estimating the Short-Run Poverty Impacts of the 2010-11 Surge in Food Price. Policy Research Working Paper 5633, The World Bank, Washington, DC, USA, 33 pp.

Izaurralde, R., D. Adams, R. Alig, C. Betz, C. Hutchins, B. McCarl, K. Skog, and B. Sohngen, 2001: Assessing socioeconomic impacts of climate change on US forests, wood-product markets, and forest recreation. BioScience, 51, 753-764.

Izaurralde, R.C., A.M. Thomson, N.J. Rosenberg, and R.A. Brown, 2005: Climate change impacts for the conterminous USA: an integrated assessment. Part 6 Distribution and productivity of unmanaged ecosystems. Climatic Change, 69 , 107-126.

Izaurralde, R.C., A.M. Thomson, J.A. Morgan, P.B. Fay, H.W. Polley, and J.L. Hatfield, 2011: Climate impacts on agriculture: implications for forage and rangeland production. Agronomy Journal, 103(2), 371-381.

Jadadish, K., P.Q. Craufurd, and T.R. Wheeler, 2007: High temperature stress and spikelet fertility in rice (Oryza Sativa L.). Journal of Experimental Biology, $\mathbf{5 8}$ 1627-1635.

Jaggard, K., A. Qi, and M.A. Semenov, 2007: The impact of climate change on sugarbeet yield in the UK: 1976-2004. The Journal of Agricultural Science, 145, 367-375.

Jarvis, A., J. Ramirez-Villegas, B. Herrera Campo, and C. Navarro-Racines, 2012: Is cassava the answer to African climate change adaptation? Tropical Plant Biology, 51, 9-29.

Jones, P.G. and P.K. Thornton, 2003. The potential impacts of climate change on maize production in Africa and Latin America in 2055. Global Environmental Change, 13(1), 51-59.

Jones, P.G. and P.K. Thornton, 2009: Croppers to livestock keepers: livelihood transitions to 2050 in Africa due to climate change. Environmental Science \& Policy, 12 , 427-437.

Jones, G.V., M.A. White, O.R. Cooper, and K. Storchmann, 2005: Climate change and global wine quality. Climatic Change, 73(3), 319-343.

Jones, G.V., A.A. Duff, A. Hall, and J.W. Myers, 2010: Spatial analysis of climate winegrape growing regions in the western United States. American Journal of Enology and Vitculture, 61(3), 313-326.

Jorquera-Fontena, E. and R. Orrego-Verdugo, 2010: Impact of global warming on the phenology of a variety of grapevine grown in southern Chile. Agrociencia, 44(4), 427-435.

Joshi, M., R. Sutton, J. Lowe, and D. Frame, 2011: Projections of when temperature change will exceed $2{ }^{\circ} \mathrm{C}$ above pre-industrial levels. Nature Climate Change, $1,407-412$

Kabubo-Mariara, J., 2008: Climate change adaptation and livestock activity choices in Kenya: an economic analysis. Natural Resources Forum, 32, 131-141.

Kabubo-Mariara, J., 2009: Global warming and livestock husbandry in Kenya: impacts and adaptations. Ecological Economics, 68(7), 1915-1924.

Kalanda-Joshua, M., C. Ngongondo, L. Chipeta, and F. Mpembeka, 2011: Integrating indigenous knowledge with conventional science: enhancing localised climate and weather forecasts in Nessa, Mulanje, Malawi. Physics and Chemistry of the Earth, 36(14), 996-1003.

Kaiser, H.M., 1999: Assessing research on the impacts of climate change on agriculture. In: Global Environmental Change and Agriculture: Assessing the Impacts [Frisvold, G. and B. Kuhn (eds.)]. Edward Elgar Publishing, Cheltenham, UK, pp. 221-238.

Kang, Y., S. Khan, and X. Ma, 2009: Climate change impacts on crop yield, crop water productivity and food security - a review. Progress in Natural Science, 19, 16651674.

Kapetanaki, G. and C. Rosenzweig, 1997: Impact of climate change on maize yield in central and northern Greece: a simulation study with Ceres-Maize. Mitigation and Adaptation Strategies for Global Change, 1(3), 251-271.

Karfakis, P., M. Knowles, M. Smulders, and J. Capaldo, 2011: Effects of Global Warming on Vulnerability to Food Insecurity in Rural Nicaragua. ESA Working Paper No. 11-18, Agricultural Development Economics Division (ESA), Food and Agricultural Organization of the United Nations (FAO), Rome, Italy, $33 \mathrm{pp}$.

Karim, Z., S.G. Hussain, and M. Ahmed, 1996: Assessing impacts of climatic variations on food grain production in Bangladesh. In: Climate Change Vulnerability and Adaptation in Asia and the Pacific [Erda, L., W.C. Bolhofer, S. Huq, S. Lenhart, S.K. Mukherjee, J.B. Smith, and J. Wisniewski (eds.)]. Regional Workshop, 15-19 January 1996, Manila, Philippines, Reprinted from Water, Air, and Soil Pollution, 92(1-2), 1996 edition, Springer, Dordrecht, Netherlands, pp. 53-62.

Kassie, M., J. Pender, Y. Mahmud, G. Kohlin, R. Bluffstone, and E. Mulugeta, 2008: Estimating returns to soil conservation adoption in the Northern Ethiopian Highlands. Agricultural Economics, 38, 213-232.
Kates, R., W. Travis, and T. Wilbanks, 2012: Transformational adaptation when incremental adaptations to climate change are insufficient. Proceedings of the National Academy of Sciences of the United States of America, 109, 7156-7161.

Kazianga, H. and C. Udry, 2006: Consumption smoothing? Livestock, insurance and drought in rural Burkina Faso. Journal of Development Economics, 79, 413446.

Kearney, J., 2010: Food consumption trends and drivers. Philosophical Transactions of the Royal Society B, 365, 2793-2807.

Kim, C., S. Lee, H. Jeong, J. Jang, Y. Kim, and C.Lee, 2010: Impacts of Climate Change on Korean Agriculture and its Counterstrategies. Korea Rural Economic Institute, Seoul, South Korea, $282 \mathrm{pp}$.

Kimball, B.A., 2010: Lessons from FACE: $\mathrm{CO}_{2}$ effects and interactions with water nitrogen and temperature. In: Handbook of Climate Change and Agroecosystems: Impacts, Adaptation and Mitigation [Hillel, D. and C. Rozenweig (eds.)]. Imperial College Press, London, UK, pp. 87-107.

Kirsch, T., C. Wadhwani, L. Sauer, S. Doocy, and C. Catlett, 2012: Impact of the 2010 Pakistan floods on rural and urban populations at six months. PLoS Currents Disasters, August 22, Edition 1, doi:10.1371/4fdfb212d2432.

Kiselev, S., R. Romashkin, G. Nelson, D. Mason-D'Croz, and A. Plazzo, 2013: Russia's Food Security and Climate Change: Looking into the Future. Economics Discussion Papers, No. 2013-16, Kiel Institute for the World Economy, Kiel, Germany, 58 pp.

Knox, J., T. Hess, A. Daccache, and T. Wheeler, 2012: Climate change impacts on crop productivity in Africa and South Asia. Environmental Research Letters, 7, 034032, doi:10.1088/1748-9326/7/3/034032.

Koehler, A., A. J. Challinor, E. Hawkins, and S. Asseng, 2013: Influences of increasing temperature on Indian wheat: quantifying limits to predictability. Environmental Research Letters, 8, 034016, doi:10.1088/1748-9326/8/3/034016.

Koehn, J.D., A.J. Hobday, M.S. Pratchett, and B.M. Gillanders, 2011: Climate change and Australian marine and freshwater environments, fishes and fisheries: synthesis and options for adaptation. Marine and Freshwater Research, 62(9), 1148-1164.

Krishnan, P., D. Swain, B. Bhaskar, S. Nayak, and R. Dash, 2007: Impact of elevated $\mathrm{CO}_{2}$ and temperature on rice yield and methods of adaptation as evaluated by crop simulation studies. Agricultural Ecosystems and Environment, 122, 233242.

Kucharik, C.J. and S.P. Serbin, 2008: Impacts of recent climate change on Wisconsin corn and soybean yield trends. Environmental Research Letters, 3, 034003, doi:10.1088/1748-9326/3/3/034003.

Kulshreshtha, S.N., 2011: Climate change, prairie agriculture, and prairie economy: the new normal. Canadian Journal of Agricultural Economics, 59(1), 19-44.

Kumar, S.N., P.K. Aggarwal, S. Rani, S. Jain, R. Saxena, and N. Chauhan, 2011: Impact of climate change on crop productivity in Western Ghats, coastal and northeastern regions of India. Current Science, 101(3), 332-341.

Kumar, S.N., P.K. Aggarwal, R. Saxena, S. Rani, S. Jain, and N. Chauhan, 2013: An assessment of regional vulnerability of rice to climate change in India. Climatic Change, 118(3-4), 683-699.

Kvalvik, I., S. Dalmannsdottir, H. Dannevig, G. Hovelsrud, L. Rønning, and E. Uleberg, 2011: Climate change vulnerability and adaptive capacity in the agricultural sector in Northern Norway. Acta Agriculturae Scandinavica, Section B - Soil \& Plant Science, 61(S1), 27-37.

Lal, M., 2011: Implications of climate change in sustained agricultural productivity in South Asia. Regional Environmental Change, 11(Suppl. 1), S79-594.

Lal, M., K.K. Singh, L.S. Rathore, G. Srinivasan, and S.A. Saseendran, 1998: Vulnerability of rice and wheat yields in NW India to future changes in climate. Agricultural and Forest Meteorology, 89(2), 101-114.

Lancelot, R., S. de La Rocque, and V. Chevalier, 2008: Bluetongue and Rift Valley fever in livestock: a climate change perspective with a special reference to Europe, the Middle East and Africa. In: Livestock and Global Climate Change: Proceedings of the British Society of Animal Science (BSAS) International Conference on Livestock and Global Climate Change in Hammamet, Tunisia, 17-20 May 2008 [Rowlinson, P., M. Steele, and A. Nefzaoui (eds.)]. Cambridge University Press, Cambridge, UK, pp. 87-89.

Lanning, S.B., T.J. Siebenmorgen, P.A. Counce, A.A. Ambardekar, and A. Mauromoustakos, 2011: Extreme nighttime air temperatures in 2010 impact rice chalkiness and milling quality. Field Crops Research, 124, 132-136.

Last, P., W. White, D. Gledhill, A. Hobday, R. Brown, G. Edgar, and G. Pecl, 2011: Long term shifts in abundance and distribution of a temperate fish fauna: a response to climate change and fishing practices. Global Ecology and Biogeography, 20, 58-72. 
Laux, P., G. Jacket, R. Tingem, and H. Kunstmann, 2010: Impact of climate change on agricultural productivity under rainfed conditions in Cameroon - a method to improve attainable crop yields by planting date adaptations. Agricultural and Forest Meteorology, 150, 1258-1271.

Leakey, A.D.B., 2009: Rising atmospheric carbon dioxide concentration and the future of $C_{4}$ crops for food and fuel. Proceedings of the Royal Society B, 276(1666), 2333-2343.

Lehodey, P., J. Hampton, R.W. Brill, S. Nicol, I. Senina, B. Calmettes, H. Portner, L. Bopp, T. Llyina, J.D. Bell, and J. Sibert, 2011: Vulnerability of oceanic fisheries in the tropical Pacific to climate change. In: Vulnerability of Tropical Pacific Fisheries and Aquaculture to Climate Change [Bell, J.D., J.E. Johnson, and A.J. Hobday (eds.)]. Secretariat of the Pacific Community, Noumea, New Caledonia, pp. 433492.

Lemos, M.C. and R.B. Rood, 2010: Climate projections and their impact on policy and practice. Wiley Interdisciplinary Reviews: Climate Change, 1, 13.

Lenz-Wiedemann, V.I.S., C.W. Klar, and K. Schneider, 2010: Development and test of a crop growth model for application within a global change decision support system. Ecological Modelling, 221, 314-329.

Li, S., T. Wheeler, A. Challinor, E. Lin, H. Ju, and Y. Xu, 2010: The observed relationships between wheat and climate in China. Agricultural and Forest Meteorology, $150,1412-1419$.

Li, X., T. Takahashi, S. Nobuhiro, and H.M. Kaiser, 2011: The impact of climate change on maize yields in the United States and China. Agricultural Systems, 104(4), 348-353.

Licker, R., C.J. Kucharik, T. Doré, M.J. Lindeman, and D. Makowski, 2013: Climatic impacts on winter wheat yields in Picardy, France and Rostov, Russia: 19732010. Agricultural and Forest Meteorology, 176, 25-37.

Lioubimtseva, E. and G.M. Henebry, 2009: Climate and environmental change in arid Central Asia: impacts, vulnerability and adaptations. Journal of Arid Environments, 73(11), 963-977.

Liu, S., X. Mo, Z. Lin, Y. Xu, J. Ji, G. Wen, and J. Richey, 2010: Crop yield responses to climate change in the Huang-Huai-Hai plain of China. Agricultureal Water Management, 97(8), 1195-1209.

Liu, Y., E. Wang, X. Yang, and J. Wang, 2009: Contributions of climatic and crop varietal changes to crop production in the North China Plain, since 1980s. Global Change Biology, 16(8), 2287-2299.

Lloyd, S.J., R.S. Kovats, and Z. Chalabi, 2011: Climate change crop yields and undernutrition: development of a model to quantify the impact of climate scenarios on child undernutrition. Environmental Health Perspectives, 119, 1817-1823.

Lobell, D.B. and M.B. Burke, 2008: Why are agricultural impacts of climate change so uncertain? The importance of temperature relative to precipitation. Environmental Research Letters, 3, 034007, doi:10.1088/1748-9326/3/3/034007.

Lobell, D.B. and M.B. Burke, 2010: On the use of statistical models to predict crop yield responses to climate change. Agricultural and Forest Meteorology, 150, 1443-1452.

Lobell, D.B. and C.B. Field, 2007: Global scale climate-crop yield relationships and the impacts of recent warming. Environmental Research Letters, 2, 014002, doi:10.1088/1748-9326/2/1/014002.

Lobell, D.B. and C.B. Field, 2011: California perennial crops in a changing climate. Climatic Change, 109 (Suppl. 1), S317-S333.

Lobell, D.B. and J.I. Ortiz-Monasterio, 2007: Impacts of day versus night temperatures on spring wheat yields. Agronomy Journal, 99, 469-477.

Lobell, D.B. , J.I. Ortiz-Monasterio, G.P. Asner, P.A. Matson, R.L. Naylor, and W.P. Falcon, 2005: Analysis of wheat yield and climatic trends in Mexico. Field Crops Research, 94, 250-256.

Lobell, D.B., M.B. Burke, C. Tebaldi, M.D. Mastrandrea, W.P. Falcon, and R.L. Naylor, 2008: Prioritizing climate change adaptation needs for food security in 2030. Science, 319, 607-610.

Lobell, D.B., W. Schlenker, and J. Costa-Roberts, 2011a: Climate trends and global crop production since 1980. Science, 333(6042), 616-620.

Lobell, D.B., M. Banziger, C. Magorokosho, and B. Vivek, 2011 b: Nonlinear heat effects on African maize as evidenced by historical yield trials. Nature Climate Change, 1(1), 42-45.

Lobell, D.B., A. Sibley, and J.I. Ortiz-Monasterio, 2012: Extreme heat effects on wheat senescence in India. Nature Climate Change, 2(3), 186-189.

Lobell, D.B., G.L. Hammer, G. McLean, C. Messina, M.J. Roberts, and W. Schlenker, 2013a: The critical role of extreme heat for maize production in the United States. Nature Climate Change, 3, 497-501.
Lobell, D.B., U.L. C. Baldos, and T.W. Hertel, 2013b: Climate adaptation as mitigation: the case of agricultural investments. Environmental Research Letters, 8, 015012, doi10.1088/1748-9326/8/1/015012.

Loladze, I., 2002: Rising atmospheric $\mathrm{CO}_{2}$ and human nutrition: toward globally imbalanced plant stoichiometry? Trends in Ecology and Evolution, 17, 457-461.

Long, S.P., 2012: Virtual Special Issue on food security - greater than anticipated impacts of near-term global atmospheric change on rice and wheat. Global Change Biology, 18, 1489-1490, doi: 10.1111/j.1365-2486.2012.02676.x.

Lopez, A.D., C.D. Mathers, M. Ezzati, D.T. Jamison, and C.J. Murray, 2006: Global and regional burden of disease and risk factors, 2001: systematic analysis of population health data. The Lancet, 367, 1747-1757.

Luck, J., M. Spackman, A. Freeman, P. Trebicki, W. Griffiths, K. Finlay, and S. Chakraborty, 2011: Climate change and diseases of food crops. Plant Pathology, $60,113-121$.

Ludwig, F., S. Milroy, and S. Asseng, 2009: Impacts of recent climate change on wheat production systems in Western Australia. Climatic Change, 92, 495-517.

Luedeling, E., K.P. Steinmann, M. Zhang, P.H. Brown, J. Grant, and E.H. Girvetz, 2011: Climate change effects on walnut pests in California. Global Change Biology, $17,228-238$.

Luo, Q., W. Bellotti, M. Williams, and E. Wang, 2009: Adaptation to climate change of wheat growing in South Australia: analysis of management and breeding strategies. Agriculture Ecosystems and Environment, 129, 261-267.

Luo, Q., M.A.J. Williams, W. Bellotti, and B. Bryan, 2003: Quantitative and visual assessments of climate change impacts on South Australian wheat production. Agricultural Systems, 77(3), 173-186.

MacNeil, M., N. Graham, J. Cinner, N. Dulvy, P. Loring, S. Jennings, N. Polunin, A. Fisk, and T. McClanahan, 2010: Transitional states in marine fisheries: adapting to predicted global change. Philosophical Transactions of the Royal Society $B$, 365(1558), 3753-3763.

Mäder, P., A. Fliessbach, D. Dubois, L. Gunst, W. Jossi, F. Widmer, A. Oberson, E. Frossard, F. Oehl, A. Wiemken, A. Gattinger, and U. Niggli, 2006: The DOK Experiment (Switzerland). In: Long-Term Field Experiments in Organic Farming [Raupp, J., C. Pekrun, M. Oltmanns, and U. Köpke (eds.)]. International Society of Organic Agricultural Research (ISOFAR) Scientific Series No. 1, Verlag Dr. Köster, Berlin, Germany, pp. 41-58.

Mader, T.L., K.L. Frank, J.A. Harrington G.L. Hahn, and J.A. Nienaber, 2009: Potential climate change effects on warm-season livestock production in the Great Plains. Climatic Change, 97, 529-541.

Magrin, G., M. Travasso, G. Rodríguez, S. Solman, and M. Núñez, 2009: Climate change and wheat production in Argentina. International Journal of Global Warming, 1, 214-226.

Mandryk, M., P. Reidsma, and M.K. van Ittersum, 2012: Scenarios of long-term farm structural change for application in climate change impact assessment. Landscape Ecology, 27(4), 509-527.

Manea, A., M.R. Leishman, and P.O. Downey, 2011: Exotic $\mathrm{C}_{4}$ grasses have increased tolerance to glyphosate under elevated carbon dioxide. Weed Science, 59, 28-36.

Mantua, N., I.M. Tohver, and A.F. Hamlet, 2010: Climate change impacts on streamflow extremes and summertime stream temperature and their possible consequences for freshwater salmon habitat in Washington State. Climatic Change, 102, 187 223.

Marin, A., 2010: Rider under storms: contributions of nomadic herders' obervations to analysing climate change in Mongolia. Global Environmental Change, 20(1), 162-176.

Marin, F.R., J.W. Jones, A. Singels, F. Royce, E.D. Assad, G.Q. Pellegrino, and F. Justino, 2013: Climate change impacts on sugarcane attainable yield in Southern Brazil. Climatic Change, 117, 227-239.

Marshall, B.E., 2012: Does climate change really explain changes in the fisheries productivity of Lake Kariba (Zambia-Zimbabwe)? Transactions of the Royal Society of South Africa, 67, 45-51.

Mary, A.L. and A. Majule, 2009: Impacts of climate change, variability and adaptation strategies on agriculture in semi arid areas of Tanzania: the case of Manyoni District in Singida Region, Tanzania. African Journal of Environmental Science and Technology, 3, 206-218.

Masike, S. and P. Urich, 2008: Vulnerability of traditional beef sector to drought and the challenges of climate change: the case of Kgatleng District, Botswana. Journal of Geography and Regional Planning, 1(1), 12-18.

Masike, S. and P.B. Urick, 2009: The projected cost of climate change to livestock water supply and implications in Kgatleng Districh, Botswana. World Journal of Agricultural Sciences, 5(5), 597-603. 
Matthews, R. and R. Wassmann, 2003: Modelling the impacts of climate change and methane emission reductions on rice production: a review. European Journal of Agronomy, 19(4), 573-598.

Maxwell, S. and M. Smith, 1992: Part I. Household food security; a conceptual review. In: Household Food Security: Concepts, Indicators, Measurements: A Technical Review [Maxwell, S. and T.R. Frankenberger (eds.)]. United Nations Children's Fund (UNICEF), New York, NY, USA, and the International Fund for Agricultural Development (IFAD), Rome, Italy, pp. 1-72.

McCrum, G., K. Blackstock, K. Matthews, M. Rivington, D. Miller, and K. Buchan, 2009 Adapting to climate change in land management: the role of deliberative workshops in enhancing social learning. Environmental Policy and Governance, 19, 413-426.

McDowell, J. and J. J. Hess, 2012: Accessing adaptation: multiple stressors on livelihoods in the Bolivian Highlands under a changing climate. Global Environmental Change, 22(2), 342-352.

McGrath, J.M. and D.B. Lobell, 2011: An independent method of deriving the carbon dioxide fertilization effect in dry conditions using historical yield data from wet and dry years. Global Change Biology, 17, 2689-2696.

McKeon, G.M., G.S. Stone, J.I. Syktus, J.O. Carter, N.R. Floof, D.G. Ahrens, D.N. Bruget, C.R. Chilcott, D.H. Cobon, R.A. Cowley, S.J. Crimp, G.W. Fraser, S.M. Howden, P.W. Johnston, J.G. Ryan, C.J. Stokes, and K.A. Day, 2009: Climate change impacts on northern Australian rangeland livestock carrying capacity: a review of issues. The Rangeland Journal, 31, 1-29.

Melloy, P., G. Hollaway, J. Luck, R. Norton, E. Aitken, and S. Chakraborty, 2010: Production and fitness of Fusarium pseudograminearum inoculum at elevated carbon dioxide in FACE. Global Change Biology, 16, 3363-3373.

Mercer, K., A. Martinez-Vasquez, and H. Perales, 2008: Asymmetrical local adaptation of maize landraces along an altitudinal gradient. Evolutionary Applications, 1, 489-500.

Merino, G., M. Barange, J.L. Blanchard, J. Harle, R. Holmes, I. Allen, E.H. Allison, M.C. Badjeck, N.K. Dulvy, J. Holt, S. Jennings, C. Mullon, and L.D. Rodwell, 2012: Can marine fisheries and aquaculture meet fish demand from a growing human population in a changing climate? Global Environmental Change, 22, 795-806.

Mertz, O., K. Halsnaes, J. Olesen, and K. Rasmussen, 2009a: Adaptation to climate change in developing countries. Environmental Management, 43, 743-752.

Mertz, O., C. Mbow, A. Reenberg, and A. Diouf, 2009b: Farmers' perceptions of climate change and agricultural adaptation strategies in rural Sahel. Environmental Management, 43, 804-816.

Meza, F. and D. Silva, 2009: Dynamic adaptation of maize and wheat production to climate change. Climatic Change, 94(1-2), 143-156.

Meza, F., D. Silva, and H. Vigil, 2008: Climate change impacts on irrigated maize in Mediterranean climates: evaluation of double cropping as an emerging adaptation alternative. Agricultural Systems, 98, 21-30.

Mills, G., A. Buse, B. Gimeno, V. Bermejo, M. Holland, L. Emberson, and H. Pleijel, 2007: A synthesis of AOT40-based response functions and critical levels of ozone for agricultural and horticultural crops. Atmospheric Environment, 41, 2630-2643.

Mills, G., F. Hayes, S. Wilkinson, and W.J. Davies, 2009: Chronic exposure to increasing background ozone impairs stomatal functioning in grassland species. Global Change Biology, 15, 1522-1533.

Mills, J.N., K.L. Gage, and A.S. Khan, 2010: Potential influence of climate change on vector-borne and zoonotic diseases: a review and proposed research plan. Environmental Health Perspectives, 118(11), 1507-1514.

Min, S., X. Zhang, F.W. Zwiers, and G.C. Hegerl, 2011: Human contribution to moreintense precipitation extremes. Nature, 470, 378-381.

Miraglia, M., H.J.P. Marvin, G.A. Kleter, P. Battilani, C. Brera, E. Coni, F. Cubadda, L. Croci, B. De Santis, S. Dekkers, L. Filippi, R.W. Hutjes, M.Y. Noordam, M. Pisante, G. Piva, A. Prandini, L. Toti, G.J. van den Born, and A.Vespermann, 2009: Climate change and food safety: an emerging issue with special focus on Europe. Food and Chemical Toxicology, 47(5), 1009-1021.

Misselhorn, A., A. Challinor, P. Thornton, J.W. Jones, R. Schaldach, and V. PlocqFichelet, 2010: Chapter 20: Surprises and possibilities. In: Food Security and Global Environmental Change [Ingram, J., P. Ericksen, and D. Liverman (eds.)]. Earthscan, London, UK and Washington, DC, USA, pp. 318-341.

Mo, X., S. Liu, Z. Lin, and R. Guo, 2009: Regional crop yield, water consumption and water use efficiency and their responses to climate change in the North China Plain. Agriculture, Ecosystems \& Environment, 134, 67-78.

Molden, D., T. Oweis, P. Steduto, P. Bindraban, M.A. Hanjra, and J. Kijne, 2010: Improving agricultural water productivity: between optimism and caution. Agricultural Water Management, 97, 528-535.
Monzon, J.P., V.O. Sadras, P.A. Abbate, and O.P. Caviglia, 2007: Modelling management strategies for wheat-soybean double crops in the south-eastern pampas. Field Crops Research, 101(1), 44-52.

Moore, A.D. and A. Gharamani, 2013: Climate change and broadacre livestock production across Southern Australia: II. Impacts of climate change on pasture and livestock productivity, and on sustainable level of profitability. Global Change Biology, 19, 1440-1455.

Morgan, P.B., T.A. Mies, G.A. Bollero, R.L. Nelson, and S.P. Long, 2006: Season long elevation of ozone concentration to projected 2050 levels under fully open air conditions substantially decreases the growth and production of soybean. New Phytologist, 170, 333-343.

Moriondo, M., M. Bindi, Z. Kundzewicz, M. Szwed, A. Chorynski, P. Matczak, M. Radziejewski, D. McEvoy, and A. Wreford, 2010: Impact and adaptation opportunities for European agriculture in response to climatic change and variability. Mitigation and Adaptation in Strategies for Global Change, 15, 657-679.

Moriondo, M., C. Giannakopoulos, and M. Bindi, 2011: Climate change impact assessment: the role of climate extremes in crop yield simulation. Climatic Change, 104, 679-701.

Mortensen, C.J., Y.H. Choi, K. Hinrichs, N.H. Ing, D.C. Kraemer, S.G. Vogelsang, and M.M. Vogelsang, 2009: Embryo recovery from exercised mares. Animal Reproduction Science, 110(3-4), 237-244.

Moya, T.B., L.H. Ziska, O.S. Namuco, and D. Olszyk, 1998: Growth dynamics and genotypic variation in tropical, field-grown paddy rice (Oryza sativa L.) in response to increasing carbon dioxide and temperature. Global Change Biology, 4(6), 645-656.

Müller, C., A. Bondeau, A. Popp, K. Waha, and M. Fadar, 2010: Climate Change Impacts on Agricultural Yields. Background note for the World Development Report 2010: Development and Climate Change, Potsdam Institute for Climate Impact Research (PIK), The World Bank, Washington, DC, USA, 11 pp.

Müller, C. and R.D. Robertson, 2014: Projecting future crop productivity for global economic modeling. Agricultural Economics, 45, 37-50.

Mueller, S., J. Anderson, and T. Wallington, 2011: Impact of biofuel production and other supply and demand factors on food price increases in 2008. Biomass and Bioenergy, 35, 1623-1632.

Munday, P.L., G.P. Jones, M.S. Pratchett, and A.J. William, 2008: Climate change and the future for coral reef fishes. Fish and Fisheries, 9(3), 261-285.

Mutekwa, V., 2009: Climate change impacts and adaptation in the agricultural sector: the case of smallholder farmers in Zimbabwe. Journal of Sustainable Development in Africa, 11, 237-256.

Nakashina, D., K. Galloway McLean, H.D. Thulstrup, A. Ramos Castillo, and J.T. Rubis, 2012: Weathering Uncertainty: Traditional Knowledge for Climate Change Assessment and Adaptation. United Nations Educational, Scientific and Cultural Organization (UNESCO), Paris, France, and the United Nations University (UNU), Darwin, Australia, 120 pp.

Natkhin, M., O. Dietrich, M.P. Schafer, and G. Lischeid, 2013: The effects of climate and changing land use on the discharge regime of a small catchment in Tanzania. Regional Environmental Change, doi:10.1007/s10113-013-0462-2.

Nardone, A., B. Ronchi, N. Lacetera, M.S. Ranieri, and U. Bernabucci, 2010: Effects of climate changes on animal production and sustainability of livestock systems. Livestock Science, 130(1), 57-69.

Naylor, R., D. Battisti, D. Vimont, W. Falcon, and M. Burke, 2007: Assessing risks of climate variability and climate change for Indonesian rice agriculture. Proceedings of the National Academy of Sciences of the United States of America, 104, 7752-7757.

Ndebele-Murisa, M., E. Mashonjowa, and T. Hill, 2011: The Implications of a changing climate on the Kapenta fish stocks of Lake Kariba, Zimbabwe. Transactions of the Royal Society of South Africa, 66(2), 105-119.

Nelson, G.C., M.W. Rosegrant, J. Koo, R. Robertson, T. Sulser, T. Zhu, C. Ringler, S. Msangi, A. Palazzo, M. Batka, M. Magalhaes, R. Valmonte-Santos, M. Ewing, and D. Lee, 2009: Climate Change: Impact on Agriculture and Costs of Adaptation. Food Policy Report, International Food Policy Research Institute (IFPRI), Washington DC, USA, 19 pp.

Nelson, G. C., H. Valin, R. D. Sands, P. Havlík, H. Ahammad, D. Deryng, J. Elliott, S. Fujimori, T. Hasegawa, E. Heyhoe, P. Kyle, M. Von Lampe, H. Lotze-Campen, D. Mason d'Croz, H. van Meijl, D. van der Mensbrugghe, C. Müller, A. Popp, R. Robertson, S. Robinson, E. Schmid, C. Schmitz, A. Tabeau and D. Willenbockel, 2013: Climate Change Effects on Agriculture: Economic Responses to Biophysical Shocks. Proceedings of the National Academy of Sciences of the United States of America. doi: 10.1073/pnas.1222465110. 
Nelson, G.C., D. van der Mensbrugghe, T. Hasegawa, K. Takahashi, R.D. Sands, P. Kyle, H. Lotze-Campen, M. von Lampe, D.M. d'Croz, H. van Meijl, C. Müller, J. Reilly, R. Robertson, R.D. Sands, C. Schmitz, A. Tabeau, K. Takahashi, H. Valin, and D. Willenbockel, 2014: Agriculture and climate change in global scenarios: why don't the models agree? Agricultural Economics, 45 (1), 85-101.

Nelson, R., M. Howden, and M. Stafford Smith, 2008: Using adaptive governance to rethink the way science supports Australian drought policy. Environmental Science \& Policy, 11(17), 588-601.

Newsham, A. J. and D. Thomas, 2011: Knowing, farming and climate change adaptation in North-Central Namibia. Global Environmental Change, 21(2), 761-770.

Nesamvuni, E., R. Lekalakala, D. Norris, and J.W. Ngambi, 2012: Effects of climate change on dairy cattle, South Africa. African Journal of Agricultural Research, 7(26), 3867-3872.

Nidumolu, U.B., P.T. Hayman, S.M. Howden, and B.M. Alexander, 2012: Re-evaluating the margin of the South Australian grain belt in a changing climate. Climate Research, 51, 249-260.

Nidumolu, U., S. Crimp, D. Gobbett, A. Laing, S.M. Howden, and S. Little, 2013: Spatio-temporal modelling of heat stress and climate change implications for the Murray dairy region, Australia. International Journal of Biometeorology, DOI 10.1007/s00484-013-0703-6.

Nyong, A., F. Adesina, and B. Elasha, 2007: The value of indigenous knowledge in climate change mitigation and adaptation strategies in the African Sahel. Mitigation and Adaptation Strategies for Global Change, 12, 787-797.

Odgaard, M., P. Bøcher, T. Dalgaard, and J. Svenning, 2011: Climate and non-climatic drivers of spatiotemporal maize-area dynamics across the northern limit for maize production - a case study from Denmark. Agriculture Ecosystems and Environment, 142, 291-302.

Oerke, E.C., 2006: Crop losses to pests. The Journal of Agricultural Science, 144, 31 43.

Okada, M., T. Lizumi, Y. Hayashi, and M. Yokozawa, 2011: Modeling the multiple effects of temperature and radiation on rice quality. Environmental Research Letters, 6(3), 034031, doi:10.1088/1748-9326/6/3/034031.

Olesen, J.E., M. Trnka, K. Kersebaum, A. Skjelvåg, B. Seguin, P. Peltonen-Sainio, F. Rossi, J. Kozyra, and F. Micale, 2011: Impacts and adaptation of European crop production systems to climate change. European Journal of Agronomy, 34(2), 96-112.

Olesen, J.E., T.R. Carter, C.H. Diaz-Ambrona, S. Fronzek, T. Heidmann, T. Hickler, T. Holt, M.I. Minguez, P. Morales, J.P. Palutikof, M. Quemada, M. Ruiz-Ramos, G.H. Rubaek, F. Sao, B. Smith, and M.T. Sykes, 2007: Uncertainties in projected impacts of climate change on European agriculture and terrestrial ecosystems based on scenarios from regional climate models. Climatic Change, 81(2), 123143.

O'Reilly, C.M., S.R. Alin, P.D. Plisnier, A.S. Cohen, and B.A. McKee, 2003: Climate change decreases aquatic ecosystem productivity of Lake Tanganyika, Africa. Nature, 424, 766-768.

Orlandini, S., M. Bindi, and S. Howden, 2008: Plant biometeorology and adaptation. In: Biometeorology for Adaptation to Climate Variability and Change: Research Frontiers and Perspectives [Ebi, K., I. Burton, and G. McGregor (eds.)]. Springer, Dordrecht, Netherlands, pp. 107-129.

Ortiz, R., K.D. Sayre, B. Govaerts, R. Gupta, G.V. Subbarao, T. Ban, D. Hodson, J.M. Dixon, J. Iván Ortiz-Monasterio, and M. Reynolds, 2008: Climate change: can wheat beat the heat? Agriculture, Ecosystems \& Environment, 126, 46-58.

Osborne, T.M., D.M. Lawrence, A.J. Challinor, J.M. Slingo, and T.R. Wheeler, 2007: Development and assessment of a coupled crop-climate model. Global Change Biology, 13, 169-183.

Osborne, T.M., G. Rose, and T. Wheeler, 2013: Variation in the global-scale impacts of climate change on crop productivity due to climate model uncertainty and adaptation. Agricultural and Forest Meteorology, 170, 183-194.

Paavola, J., 2008: Livelihoods, vulnerability and adaptation to climate change in Morogoro, Tanzania. Environmental Science \& Policy, 11, 642-654.

Palmer, M.A., C.A. Reidy Liermann, C. Nilsson, M. Florke, J. Alcamo, P.S. Lake, and N. Bond, 2008: Climate change and the world's river basins: anticipating management options. Frontiers in Ecology and the Environment, 6, 81-89.

Palosuo, T., K.C. Kersebaum, C. Angulo, P. Hlavinka, M. Moriondo, J.E. Olesen, R.H. Patil, F. Ruget, C. Rumbaur, J. Takáč, M. Trnka, M. Bindi, B. Çaldağ, F. Ewert, R. Ferrise, W. Mirschel, L. Saylan, B. Šiška, and R. Rötter, 2011: Simulation of winter wheat yields and yield variability in different climates of Europe. A comparison of eight crop growth models. European Journal of Agronomy, 35, 103-114.
Pareek, A. and P. Trivedi, 2011: Cultural values and indigenous knowledge of climate change and disaster prediction in Rajasthan India. Indian Journal of Traditional Knowledge, 10, 183-189.

Park, S., N. Marshall, E. Jakku, A. Dowd, S. Howden M., E. Mendham, and A. Fleming, 2012: Informing adaptation responses to climate change through theories of transformation. Global Environmental Change, 22, 115-126.

Parry, M., A. Evans, M.W. Rosegrant, and T. Wheeler, 2009: Climate Change and Hunger: Responding to the Challenge. World Food Programme (WFP), Rome, Italy, $104 \mathrm{pp}$.

Passioura, J. and J. Angus, 2010: Chapter 2: Improving productivity of crops in waterlimited environments. In: Advances in Agronomy, Vol. 106 [Sparks, D.L. (ed.)]. Elsevier Science and Technology/Academic Press, Waltham, MA, USA, pp. 37-75.

Pathak, H., J.K. Ladha, P.K. Aggarwal, S. Peng, S. Das, Y. Singh, B. Singh, S.K. Kamra, B. Mishra, A. Sastri, H.P. Aggarwal, D.K. Das, and R.K. Gupta, 2003: Trends of climatic potential and on-farm yields of rice and wheat in the Indo-Gangetic Plains. Field Crops Research, 80, 223-234.

Paulson, M.D., A.I. Houston, J.M. McNamara, and R.J.H. Payne, 2009: Seasonal dispersal of pests: one surge or two? Journal of Evolutionary Biology, 22, 11931202.

Pautasso, M., K. Dehnen-Schmutz, O. Holdenrieder, S. Pietravalle, N. Salama, M.J. Jeger, E. Lange, and S. Hehl-Lange, 2010: Plant health and global change some implications for landscape management. Biological Reviews of the Cambridge Philosophical Society, 85, 729-755.

Peltonen-Sainio, P., L. Jauhiainen, and K. Hakala, 2011: Crop responses to temperature and precipitation according to long-term multi-location trials at high-latitude conditions. The Journal of Agricultural Science, 149(1), 49-62.

Peng, S., J. Huang, J. Sheehy, R. Laza, R. Visperas, X. Zhong, G. Centeno, G. Khush, and K. Cassman, 2004: Rice yields decline with higher night temperature from global warming. Proceedings of the National Academy of Sciences of the United States of America, 101, 9971-9975.

Perring, M.P., B.R. Cullen, I.R. Johnson, and M.J. Hovenden, 2010: Modelled effects of rising $\mathrm{CO}_{2}$ concentration and climate change on native perennial grass and sown grass-legume pastures. Climate Research, 42, 65-78.

Perry, A.L., P.J. Low, J.R. Ellis, and J.D. Reynolds, 2005: climate change and distribution shifts in marine fishes. Science, 308, 1912-1915.

Pfeffer, M. and G. Dobler, 2010: Emergence of zoonotic arboviruses by animal trade and migration. Parasites \& Vectors, 3(35), doi:10.1186/1756-3305-3-35.

Piao, S., P. Ciais, Y. Huang, Z. Shen, S. Peng, J. Li, L. Zhou, H. Liu, Y. Ma, Y. Ding, P. Friedlingstein, C. Liu, K. Tan, Y. Yu, T. Zhang, and J. Fang, 2010: The impacts of climate change on water resources and agriculture in China. Nature, 467, 43-51.

Pickering, T.D., B. Ponia, C.A. Hair, P.C. Southgate, and E.S. Poloczanska, 2011: Vulnerability of aquaculture in the tropical Pacific to climate change. In: Vulnerability of Tropical Pacific Fisheries and Aquaculture to Climate Change [Bell, J.D., J.E. Johnson, and A.J. Hobday (eds.)]. Secretariat of the Pacific Community, Noumea, New Caledonia, pp. 647-731.

Pikki, K., V. Vorne, K. Ojanpera, and H. Pleijel, 2007: Impact of elevated $\mathrm{O}_{3}$ and $\mathrm{CO}_{2}$ exposure on potato (Solanum tuberosum L. cv. Bintje) tuber macronutrients ( $\mathrm{N}_{\text {, }}$ $\mathrm{P}, \mathrm{K}, \mathrm{Mg}, \mathrm{Ca}$ ). Agriculture, Ecosystems and Environment, 118(1-4), 55-64.

Pinstrup-Andersen, P., 2009: Food security: definition and measurement. Food Security, 1, 5-7.

Pinto, H.S., J. Zullo Jr., E.D.Assad, and B.A. Evangelista, 2007: 0 aquecimento global e a cafeicultura brasileira. Boletim da Sociedade Brasileira de Meteorologia, 31, 65-72.

Pinto, H.S., E.D. Assad, J.Z. Junior, S. Evangelista, A. Otavian, A. Ávila, B. Evangelista, F. Marin, C. Junior, G.Q. Pellegrino, P. Coltri, and G. Coral, 2008: Global Warming and the New Geography of Agricultural Production in Brazil. Centro de Pesquisas Meteorológicas e Climáticas Aplicadas à Agricultura (CEPAGRI) and Brazilian Agricultural Research Corporation (EMBRAPA), Sao Paulo, Brazil, 83 pp.

Pleijel, H. and J. Uddling, 2012: Yield vs. quality trade-offs for wheat in response to carbon dioxide and ozone. Global Change Biology, 18, 596-605.

Porter, J.R. and M. Gawith, 1999: Temperatures and the growth and development of wheat: a review. European Journal of Agronomy, 10, 23-36.

Porter, J.R. and M.A. Semenov, 2005: Crop responses to climatic variation. Philosophical Transactions of the Royal Society B, 360(1463), 2021-2035.

Prakash, A., 2011: Why volatility matters. In: Safeguarding Food Security in Volatile Global Markets [Prakash, A. (ed.)]. Food and Agriculture Organization of the United Nations (FAO), Rome, Italy, pp. 3-26.

Pratchett, M.S., P.L. Munday, N.A.J. Graham, M. Kronen, S. Pinca, K. Friedman, T.D. Brewer, J.D. Bell, S.K. Wilson, J.E. Cinner, J.P. Kinch, R.J. Lawton, A.J. Williams, L. 
Chapman, F. Magron, and A. Webb, 2011: Vulnerability of coastal fisheries in the tropical Pacific to climate change. In: Vulnerability of Tropical Pacific Fisheries and Aquaculture to Climate Change [Bell, J.D., J.E. Johnson, and A.J. Hobday (eds.)]. Secretariat of the Pacific Community, Noumea, New Caledonia, pp. 493-573.

Prato, T., Q. Zeyuan, G. Pederson, D. Fagre, L. Bengtson, and J. Williams, 2010: Potential economic benefits of adapting agricultural production systems to future climate change. Environmental Management, 45, 577-589.

Pritchard, S.G., 2011: Soil organisms and global climate change. Plant Pathology, 60, 82-99.

Rai, R., M. Aggarwal, and S.B. Aggarwal, 2010: Threat to food security under current levels of ground level ozone: a case study for Indian cultivars of rice. Atmospheric Environment, 44, 4272-4282.

Ramirez-Villegas, J.M., A. Salazar, C. Jarvis, and E. Navarro-Racines, 2012: A way forward on adaptation to climate change in Colombian agriculture: perspectives towards 2050. Climatic Change, 115, 611-628.

Ramirez-Villegas, J., A.J. Challinor, P.K. Thornton, and A. Jarvis, 2013: Implications of regional improvement in global climate models for agricultural impact research. Environmental Research Letters, 8(2), 024018, doi:10.1088/17489326/8/2/024018.

Ravallion, M. and C. Shaohua, 2007: China's (uneven) progress against poverty. Journal of Development Economics, 82, 1-42.

Rayne, S., K. Forest, and K. Friesen, 2009: Projected climate change impacts on grape growing in the Okanagan Valley, British Columbia, Canada. Nature Precedings, doi: 10.1038/npre.2011.3162.2.

Reidsma, P. and F. Ewert, 2008: Regional farm diversity can reduce vulnerability of food production to climate change. Ecology and Society, 13(1), 38.

Reidsma, P., F. Ewert, L. Oude A., and R. Leemans, 2009: Vulnerability and adaptation of European farmers: a multi-level analysis of yield and income responses to climate variability. Regional Environmental Change, 9(1), 25-40.

Renard, D., J. Iriarte, J. Birk, S. Rostain, B. Glaser, and D. McKey, 2011: Ecological engineers ahead of their time: the functioning of pre-Columbian raised-field agriculture and its potential contributions to sustainability today. Ecological Engineering, 45, 30-44.

Renaudeau, D., J. Gourdine, and N. St-Pierre, 2011: A meta-analysis of the effects of high ambient temperature on growth performance of growing-finishing pigs. Journal of Animal Science, 89, 2220-2230.

Rengalakshmi, R., 2007: Localized climate forecasting system: seasonal climate and weather prediction for farm-level decision-making. In: Climate Predictions and Agriculture: Advances and Challenges [Sivakumar, M. and J. Hansen (eds.)] World Meteorological Organization (WMO), Springer-Verlag, Berlin, Heidelberg, Germany, pp. 129-134.

Reyenga, P.J., S.M. Howden, H. Meinke, and G.M. McKeon, 1999: Modelling global change impacts on wheat cropping in south-east Queensland, Australia, Environmental Modeling and Software, 14, 297-306.

Rickards, L. and S.M. Howden, 2012: Transformational adaptation: agriculture and climate change. Crop and Pasture Science, 63, 240-250.

Ringler, C., T. Zhu, X. Cai, J. Koo, and D. Wang, 2010: Climate Change Impacts on Food Security in Sub-Saharan Africa. IFPRI Discussion Paper No. 01042 International Food Policy Research Institute (IFPRI), Washington DC, USA $17 \mathrm{pp}$.

Roberts, M.J. and W. Schlenker, 2010: Identifying Supply and Demand Elasticities of Agricultural Commodities: Implications for the US Ethanol Mandate. NBER Working Paper No. 15921, The National Bureau of Economic Research (NBER) Cambridge, MA, USA, $46 \mathrm{pp}$.

Rocque, S.D.L., J.A. Rioux, and J. Singenbergh, 2008: Climate change: effects on animal disease systems and implications for surveillance and control. Revue Scientifique et Technique (Office International des Epizooties), 27, 339-354.

Roe, T. and T. Graham-Tomasi, 1986: Yield risk in a dynamic model of the agricultural household. In: Agricultural Household Models: Extension, Applications and Policy [Singh, I., L. Squire, and J. Strauss (eds.)]. A World Bank Research Publication, Johns Hopkins University Press, Baltimore, MD, USA, pp. 255-276.

Rosenberg, A. and K. Macleod, 2005: Implementing ecosystem-based approaches to management for the conservation of ecosystem services. Marine Ecology Progress Series, 300, 270-274.

Rosenthal, D. and D.R. Ort, 2012: Examining cassava's potential to enhance food security under climate change. Tropical Plant Biology, 5, 30-38.

Rosenthal, J., 2009: Climate change and the geographic distribution of infectious diseases. Ecohealth, 6, 489-495.
Rosenzweig, C. and M.L. Parry, 1994: Potential impact of climate change on world food supply. Nature, 367, 133-138.

Rosenzweig, C., F.N. Tubiello, R. Goldberg, E. Mills, and J. Bloomfield, 2002: Increased crop damage in the US from excess precipitation under climate change. Global Environmental Change: Human and Policy Dimensions, 12, 197-202.

Rosenzweig, C., J. Elliott, D. Deryng, A.C. Ruane, C. Müller, A. Arneth, and J.W. Jones, 2014: Assessing agricultural risks of climate change in the 21st century in a global gridded crop model intercomparison. Proceedings of the National Academy of Sciences, 201222463.

Rosenzweig, C., J.W. Jones, J.L. Hatfield, A.C. Ruane, K.J. Boote, P. Thorburn, J.M. Antle, G.C. Nelson, C. Porter, S. Janssen, S. Asseng, B. Basso, F. Ewert, D. Wallach, G. Baigorria, and J.M. Winter, 2013: The Agricultural Model Intercomparison and Improvement Project (AgMIP): protocols and pilot studies. Agricultural and Forest Meteorology, 170, 166-182.

Rosenzweig, M.R. and H.P. Binswanger, 1993: Wealth, weather risk and the composition and profitability of agricultural investments. Economic Journal, 103, 56-78.

Rötter, R.P., T. Palosuo, N.K. Pirttioja, M. Dubrovsky, T. Salo, S. Fronsek, R. Aikasalo, M. Trnka, A. Ristolainen, and T. Carter, 2011: What would happen to barley production in Finland if global warming exceeded $4^{\circ} \mathrm{C}$ ? A model-based assessment. European Journal of Agronomy, 35, 205-214.

Rowhanji, P., D. Lobell, M. Lindermann, and N. Ramankutty, 2011: Climate variability and crop production in Tanzania. Agriculture and Forest Meteorology, 151, 449-460.

Roy, S., G. Beig, and S. Ghude, 2009: Exposure-plant response of ambient ozone over the tropical Indian region. Atmospheric Chemistry and Physics, 9, 5253-5260.

Royal Society, 2008: Ground Level Ozone in the $21^{\text {st }}$ Century: Future Trends, Impacts and Policy Implications. Science Policy Document 15/08, The Royal Society, London, UK, $131 \mathrm{pp}$.

Ruane, A.C., L.D. Cecil, R.M. Horton, R. Gordón, R. McCollum, B. Brown, B. Killough, R. Goldberg, A.P. Greeley, and C. Rosenzweig, 2013: Climate change impact uncertainties for maize in Panama: farm information, climate projections, and yield sensitivities. Agricultural and Forest Meteorology, 170, 132-145.

Sadras, V.O. and P.R. Petrie, 2011: Climate shifts in south-eastern Australia: early maturity of Chardonnay, Shiraz and Cabernet Sauvignon is associated with early onset rather than faster ripening. Australian Journal of Grape and Wine Research, 17, 199-205.

Sakurai, G., T. Lizumi, and M. Yokozawa, 2012: Varying temporal and spatial effects of climate on maize and soybean affect yield prediction. Climate Research, 49, 143-154.3

Salick, J. and N. Ross, 2009: Introduction.Traditional peoples and climate change. Global Environmental Change, 19, 137-139.

Sánchez, B., A. Rasmussen, and J.R. Porter, 2014: Temperatures and the growth and development of maize and rice: a review. Global Change Biology, 20, 408-417.

Sands, R.D. and J.A. Edmonds, 2005: Climate change impacts for the conterminous USA: an integrated assessment. Part 7. Economic analysis of field crops and land use with climate change. Climatic Change, 69, 127-150.

Santos, J.A., A.C. Malheiro, M.K. Karremann, and J.G. Pinto, 2011: Statistical modelling of grapevine yield in the Port Wine region under present and future climate conditions. International Journal of Biometeorology, 55, 119-131.

Sari, M., S. de Pee, M.W. Bloem, K. Sun, A. Thorne-Lymean, R. Moench-Pfanner, N. Akhter, K. Kraemer, and R.D. Semba, 2010: Higher household expenditure on animal source and nongrain foods lowers the risk of stunting among children 0-59 months old in Indonesia: implications of rising food prices. The Journal of Nutrition, 140(Suppl. 1), 195S-200S.

Sarkar, A. and S.B. Agrawal, 2010: Elevated ozone and two modern wheat cultivars: an assessment of dose dependent sensitivity with respect to growth, reproductive and yield parameters. Environmental and Experimental Botany, 69, 328-337.

Sarvala, J., V.T. Langenberg, K. Salonen, D. Chitamwebwa, G.W. Coulter, T. Huttula, R. Kanyaru, P. Kotilainen, S. Makasa, N. Mulimbwa, and H. Molsa, 2006: Fish catches from Lake Tanganyika mainly reflect changes in fishery practices, not climate. Verhandlungen Internationale Vereinigung für Theoretische und Angewandte Limnologie, 29, 1182-1188.

Savary, S., N.P. Castilla, F.A. Elazegui, and P.S. Teng, 2005: Multiple effects of two drivers of agricultural change, labour shortage and water scarcity, on rice pest profiles in tropical Asia. Field Crops Research, 91, 263-271.

Savary, S., A. Mila, L. Willocquet, P.D. Esker, O. Carisse, and N. McRoberts, 2011: Risk factors for crop health under global change and agricultural shifts: a framework of analyses using rice in tropical and subtropical Asia as a model. Phytopathology, $101,696-709$. 
Schaefleitner, R., J. Ramirez, A. Jarvis, D. Evers, R. Gutierrez, and M. Scurrah, 2011: Adaptation of the potato crop to changing climates. In: Crop Adaptation to Climate Change [Yadav, S., B. Redden, J.L. Hattfield, and H. Lotze-Campen (eds.)]. Wiley-Blackwell, Oxford, UK, pp. 287-297.

Scherm, H. and X.B. Yang, 1995: Interannual variations in wheat rust development in China and the United States in relation to the El Niño/Southern Oscillation. Phytopathology, 85, 970-976.

Schlenker, W. and D. Lobell, 2010: Robust negative impacts of climate change on African agriculture. Environmental Research Letters, 5(1), 014010, doi:10.1088/ 1748-9326/5/1/014010.

Schlenker, W. and M.J. Roberts, 2009: Nonlinear temperature effects indicate severe damages to U.S. crop yields under climate change. Proceedings of the National Academy of Sciences of the United States of America, 106(37), 15594-15598.

Schroth, G., P. Laderach, J. Dempewolf, S. Philpott, J. Haggar, H. Eakin, T. Castillejos, M. Garcia, L. Soto Pinto, R. Hernandez, A. Eitzinger, and J. Ramirez-Villegas, 2009: Towards a climate change adaptation strategy for coffee communities and ecosystems in the Sierra Madre de Chiapas, Mexico. Mitigation and Adaptation Strategies for Global Change, 14, 605-626.

Semenov, M., R. Mitchell, A. Whitmore, M. Hawkesford, M. Parry, and P. Shewry, 2012: Shortcoming in wheat yield productions. Nature Climate Change, 2, 380382.

Seo, S., 2010: Is an integrated farm more resilient against climate change? A microeconometric analysis of portfolo diversification in African agriculture. Food Policy, 35, 32-40.

Seo, S. and R. Mendelsohn, 2008: Measuring impacts and adaptations to climate change: a structural Ricardian model of African livestock management-super-1. Agricultural Economics, 38, 151-165.

Seo, S., B.A. McCarl, and R. Mendelsohn, 2010: From beef cattle to sheep under global warming? An analysis of adaptation by livestock species choice in South America. Ecological Economics, 69, 2486-2494.

Shaw, M.W., S.J. Bearchell, B.D.L. Fitt, and B.A. Fraaije, 2008: Long-term relationships between environment and abundance in wheat of Phaeosphaeria nodorum and Mycosphaerella graminicola. New Phytologist, 177(1), 229-238.

Shen, S.-H., S.-B. Yang, Y.-X. Zhao, Y.-L. Xu, X.-Y. Zhao, Z.-Y. Wang, J. Liu, and W.-W. Zhang, 2011: Simulating the rice yield change in the middle and lower reaches of the Yangtze River under SRES B2 scenario. Acta Ecologica Sinica, 31(1), 4048.

Shimono, H., M. Okada, Y. Yamakawa, H. Nakamura, K. Kobayashi, and T. Hasegawa, 2008: Rice yield enhancement by elevated $\mathrm{CO}_{2}$ is reduced in cool weather. Global Change Biology, 14, 276-284.

Shimono, H., H. Kanno, and S. Sawano, 2010: Can the cropping schedule of rice be adapted to changing climate? A case study in cool areas of northern Japan. Field Crops Research, 118, 126-134.

Shuang-He, S., Y. Shen-Bin, Z. Yan-Xia, X. Yin-Long, Z. Xiao-Yan, W. Zhu-Yu, L. Juan, and Z. Wei-Wei, 2011: Simulating the rice yield change in the middle and lower reaches of the Yangtze River under SRES B2 scenario. Acta Ecologica Sinica, 31, 40-48.

Silva, T.G.F., M.S.B. Moura, I.I.S. Sá, S. Zolnier, S.H.N. Turco, F. Justino, J.F.A. Carmo, and L.S.B. Souza, 2009: Impactos das mudanças climáticas na produção leiteira do estado de Pernambuco: análise para os cenários B2 e A2 do IPCC: (Impacts of climate change on regional milk production in the Pernambuco State, Brazil: analysis for the A2 and B2 IPCC scenarios). Revista Brasileira de Metreologia, 24, 4, 489-501

Silvestri, S., E. Bryan, C. Ringler, M. Herrero, and B. Okoba, 2012: Climate change perception and adaptation of agro-pastoral communities in Kenya. Regional Environmental Change, 12(4), 791-802.

Skees, J., P. Hazell, and M. Miranda, 1999: New Approaches to Crop Yield Insurance in Developing Countries. Environmental and Production Technology Division (EPTD) Discussion Paper No. 55, International Food Policy Research Institute (IFPRI), Washington, DC, USA, $40 \mathrm{pp}$.

Skoufias, E. and A.R. Quisumbing, 2005: Consumption insurance and vulnerability to poverty: a synthesis of the evidence from Bangladesh, Ethiopia, Mali, Mexico and Russia. European Journal of Development Research, 17, 24-58.

Smit, B. and J.Wandel, 2006: Adaptation, adaptive capacity and vulnerability. Global Environmental Change, 16, 282-292.

Smith, L., H. Alderman, and D. Aduayom, 2006: Food Insecurity in Sub-Saharan Africa: New Estimates from Household Expenditure Survey. IFPRI Research Report No. 146, International Food Policy Research Institute (IFPRI), Washington DC, USA, $122 \mathrm{pp}$.
Smith, P. and J. Olesen, 2010: Synergies between the mitigation of, and adaptation to, climate change in agriculture. Journal of Agricultural Science, 148(5), 543552.

Smith, P., P.J. Gregory, D. van Vuren, M. Obersteiner, P. Havlik, M. Rounsevell, J. Woods, E. Stehfest, and J. Bellarby, 2010: Competition for land. Philosophical Transactions of the Royal Society B, 365, 2941-2957.

Soltani, A. and G. Hoogenboom, 2007: Assessing crop management options with crop simulation models based on generated weather data. Field Crops Research, 103, 198-207.

Soussana, J., A. Graux, and F.N. Tubiello, 2010: Improving the use of modelling for projections of climate change impacts on crops and pastures. Journal of Experimental Botany, 61, 2217-2228.

Southworth, J., J.C. Randolph, M. Habeck, O.C. Doering, R.A. Pfeifer, D.G. Rao, and J.J. Johnston, 2000: Consequences of future climate change and changing climate variability on maize yields in the midwestern United States. Agriculture, Ecosystems \& Environment, 82, 139-158.

Speranza, C.I., B. Kiteme, P. Ambenje, U. Wiesmann, and S. Makali, 2010: Indigenous knowledge related to climate change variability and change: insights from droughts in semi-arid areas of former Makueni Distict, Kenya. Climatic Change, 100, 295-315.

Srivastava, A., S. Naresh Kumar, and P.K. Aggarwal, 2010: Assessment on vulnerability of sorghum to climate change in India. Agriculture, Ecosystems and Environment, 138(3-4), 160-169.

St. Clair, S.B. and J.P. Lynch, 2010: The opening of Pandora's Box: climate change impacts on soil fertility and crop nutrition in developing countries. Plant and Soil, 335, 101-115.

Stathers, T., R. Lamboll, and B.M. Mvumi, 2013: Postharvest agriculture in changing climates: its importance to African smallholder farmers. Food Security, 5, 361392.

Stöckle, C.O., R.L. Nelson, S. Higgins, J. Brunner, G. Grove, R. Boydston, M. Whiting, and C. Kruger, 2010: Assessment of climate change impact on Eastern Washington agriculture. Climatic Change, 102, 77-102.

Sultana, H., N. Ali, M.M. Iqbal, and A.M. Khan, 2009: Vulnerability and adaptability of wheat production in different climatic zones of Pakistan under climate change scenarios. Climatic Change, 94, 123-142.

Sun, C., H. Cao, H. Shao, X. Lei, and Y. Xiao, 2011: Growth and physiological responses to water and nutrient stress in oil palm. Journal of Biotechnology, 10, 1046510471.

Supit, I., C.A. van Diepen, A.J.W. de Wit, P. Kabat, B. Baruth, and F. Ludwig, 2010: Recent changes in the climate yield potential of various crops in Europe. Agricultural Systems, 103, 683-694.

Tabachnick, W.J., 2010: Challenges in predicting climate and environmental effects on vector-borne disease episystems in a changing world. Journal of Experimental Biology, 213, 946-954.

Tan, Z., L.L. Tieszen, S. Liu, and E. Tachie-Obeng, 2010: Modeling to evaluate the response of savanna-derived cropland to warming-drying stress and nitrogen fertilizers. Climatic Change, 100, 703-715.

Tao, F. and Z. Zhang, 2010: Adaptation of maize production to climate change in North China Plain: quantify the relative contributions of adaptation options. European Journal of Agronomy, 33(3), 103-116.

Tao, F. and Z. Zhang, 2011a: Climate change, wheat productivity and water use in the North China Plain: a new super-ensemble-based probabilistic projection. Agricultural and Forest Meteorology, 170, 146-165.

Tao, F. and Z. Zhang, $2011 \mathrm{~b}$ : Impacts of climate change as a function of global mean temperature: maize productivity and water use in China. Climatic Change, 105 409-432.

Tao, F. and Z. Zhang, 2013: Climate change, high-temperature stress, rice productivity, and water use in Eastern China: a new superensemble-based probabilistic projection. Journal of Applied Meteorology and Climatology, 52(3), 531 551.

Tao, F., M. Yokozawa, Y. Xu, Y. Hayashi, and Z. Zhang, 2006: Climate changes and trends in phenology and yields of field crops in China, 1981-2000. Agriculture and Forest Meteorology, 138, 82-92.

Tao, F., M. Yokozawa, J. Liu, and Z. Zhang, 2008a: Climate-crop yield relationships at provincial scales in China and the impacts of recent climate trends. Climate Research, 38, 83-94.

Tao, F., Y. Hayashi, Z. Zhang, T. Sakamoto, and M. Yokozawa, 2008b: Global warming rice production, and water use in China: developing a probabilistic assessment. Agricultural and Forest Meteorology, 148(1), 94-110. 
Tao, F., Z. Zhang, J. Liu, and M. Yokozawa, 2009a: Modelling the impacts of weather and climate variability on crop productivity over a large area: a new processbased model development, optimization, and uncertainties analysis. Agriculture and Forest Meteorology, 149, 831-850.

Tao, F., Z. Zhang, J. Liu, and M. Yokozawa, 2009b: Modelling the impacts of weather and climate variability on crop productivity over a large area: a new superensemble-based probabilistic projection. Agricultural and Forest Meteorology, 149, 1266-1278.

Tao, F., Z. Zhang, and M. Yokozawa, 2011: Dangerous levels of climate change for agricultural production in China. Regional Environmental Change, 11(Suppl. 1), S41-S48, doi:10.1007/s10113-010-0159-8.

Tao, F., Z. Zhang, S. Zhang, Z. Zhu, and W. Shi, 2012: Response of crop yields to climate trends since 1980 in China. Climate Research, 54, 233-247.

Taub, D.R., B. Miller, and H. Allen, 2008: Effect of elevated $\mathrm{CO}_{2}$ on the protein concentration of food crops: a meta-analysis. Global Change Biology, 14, 565-575.

Tausz, M., S. Tausz-Posch, R.M. Norton, G.J. Fitzgerald, M.E. Nicolas, and S. Seneweera, 2011: Understanding crop physiology to select breeding targets and improve crop management under increasing atmospheric $\mathrm{CO}_{2}$ concentrations. Environmental and Experimental Botany, 88, 71-80.

Tchebakova, N., E. Parfenova, G. Lysanova, and A. Soja, 2011: Agroclimatic potential across Central Siberia in an altered twenty-first century. Environmental Research Letters, 6(4), 045207, doi:10.1088/1748-9326/6/4/045207.

Teixeira, E., G. Fischer, H. van Velthuizen, R. van Dingenen, F. Dentener, G. Mills, C. Walter, and F. Ewert, 2011: Limited potential of crop management for mitigating surface ozone impacts on global food supply. Atmospheric Environment, 45 2569-2576.

Teixeira, E., G. Fischer, H. van Velthuizen, C. Walter, and F. Ewert, 2013: Global hot-spots of heat stress on agricultural crops due to climate change. Agricultural and Forest Meteorology, 170, 206-215.

Thenkabail, P., J.G. Lyon, H. Turral, and C. Biradar (eds.), 2009: Remote Sensing of Global Croplands for Food Security. CRC Press, Boca Raton, FL, USA, 476 pp.

Thomas, R.J., 2008: Opportunities to reduce the vulnerability of dryland farmers in Central and West Asia and North Africa to climate change. Agriculture, Ecosystems \& Environment, 126, 36-45.

Thomson, A.M., N.J. Rosenberg, R.C. Izaurralde, and R.A. Brown, 2005: Climate change impacts for the conterminous USA: an integrated assessment. Part 5. Irrigated agriculture and national grain crop production. Climatic Change, 69 , 89-105.

Thornton, P.K., J. van de Steeg, A. Notenbaert, and M.K. Herrero, 2009a: Impact of climate change on livestock and livestock systems in developing countries: a review of what we know and what we need to know. Agricultural Systems, 101, 113-127.

Thornton, P.K., P.G. Jones, G. Alagarswamy, and J. Andresen, 2009b: Spatial variation of crop yield response to climate change in East Africa. Global Environmental Change, 19, 54-65.

Thornton, P.K., P.G. Jones, G. Alagarswamy, J. Andresen, and M. Herrero, 2010: Adapting to climate change: agricultural system and household impacts in East Africa. Agricultural Systems, 103, 73-82.

Thornton, P.K., P.G. Jones, P.J. Ericksen, and A.J. Challinor, 2011: Agriculture and food systems in sub-Saharan Africa in a $4^{\circ} \mathrm{C}+$ world. Philosophical Transactions of the Royal Society A, 369, 1934, 117-136, doi:10.1098/rsta.2010.0246.

Tianhong, Z., S. Yi, H. Guohong, W. Yan, and S. Bei, 2005: Respective and interactive effects of doubled $\mathrm{CO}_{2}$ and $\mathrm{O}_{3}$ concentration on membrane lipid peroxidation and anti-oxidative ability of soybean. Science in China Series C: Life Sciences, 48(1), 136-141.

Tingem, M., M. Rivington, G. Bellocchi, S. Azam-Ali, and J. Colls, 2008: Effects of climate change on crop production in Cameroon. Climate Research, 36, 65-77.

Tingem, M. and M. Rivington, 2009: Adaptation for crop agriculture to climate change in Cameroon: turning on the heat. Mitigation and Adaptation Strategies for Global Change, 14, 153-168.

Travasso, M., G. Magrin, G. Rodríguez, S. Solman, and M. Núñez, 2009: Climate change impacts on regional maize yields and possible adaptation measures in Argentina. International Journal of Global Warming, 1, 201-213.

Trnka, M., J.E. Olesen, K.C. Kersebaum, A.O. Skjelvåg, J. Eitzinger, B. Seguin, P. PeltonenSainio, R. Rötter, A. Iglesias, S. Orlandini, M. Dubrovsky, P. Hlavinka, J. Balek, H. Eckersten, E. Cloppet, P. Calanca, A. Gobin, V. Vucetic, P. Nejedlik, S. Kumar, B. Lalic, A. Mestrea, F. Rossi, J. Kozyra, V. Alexandrov, D. Semerádová, and Z. Zalud, 2011: Agroclimatic conditions in Europe under climate change. Global Change Biology, 17, 2298-2318.
Tubiello, F.N., M. Donatelli, C. Rosenzweig, and C.0. Stockle, 2000: Effects of climate change and elevated $\mathrm{CO}_{2}$ on cropping systems: model predictions at two Italian locations. European Journal of Agronomy, 13(2-3), 179-189.

Turner, N. and H. Clifton, 2009: 'It's so different today': climate change and indigenous lifeways in British Colombia, Canada. Global Environmental Change, 19, 180-190.

Twomlow, S., F. Mugabe, M. Mwale, R. Delve, D. Nanja, P. Carberry, and M. Howden, 2008: Building adaptive capacity to cope with increasing vulnerability due to climatic change in Africa - a new approach. Physics and Chemistry of the Earth, 33, 780-787.

UN ECLAC, 2010: Economics of Climate Change in Latin America and the Caribbean: Summary 2010. United Nations, Economic Commission for Latin America and the Caribbean (UN ECLAC), Santiago, Chile, $107 \mathrm{pp}$.

Urban, D., M.J. Roberts, W. Schlenker, and D. Lobell, 2012: Projected temperature changes indicate significant increase in interannual variability of U.S. maize yields. Climatic Change, 112, 525-533.

Van de Geisen, N., J. Liebe, and G. Jung, 2010: Adapting to climate change in the Volta Basin, West Africa. Current Science, 98, 1033-1037.

Van Dingenen, R., F.J. Dentener, F. Raes, M.C. Krol, L. Emberson, and J. Cofala, 2009: The global impact of ozone on agricultural crop yields under current and future air quality legislation. Atmospheric Environment, 43, 604-618.

Vandermeiren, K., H. Harmens, G. Mills, and L. De Temmerman, 2009: Impacts of ground-level ozone on crop production in changing climate. In: Climate Change and Crops [Singh, S.N. (ed.)]. Environmental Science and Engineering, Subseries: Environmental Science, Springer-Verlag Berlin Heidelberg, Germany, pp. 213-243.

Van Oort, P.A.J., B. G. H. Timmermans and A.C.P.M. van Swaaij, 2012: Why farmers' sowing dates hardly change when temperature rises. European Journal of Agronomy, 40, 102-111.

Vass, K.K., M.K. Das, P.K. Srivastava, and S. Dey, 2009: Assessing the impact of climate change on inland fisheries in River Ganga and its plains in India. Aquatic Ecosystem Health \& Management, 12, 138-151.

Verchot, L.V., M.V. Noordwijk, S. Kandji, T. Tomich, C. Ong, A. Albrecht, J. Mackensen, C. Bantilan, K.V. Anupama, and C. Palm, 2007: Climate change: linking adaptation and mitigation through agroforestry. Mitigation and Adaptation Strategies for Global Change, 12, 901-918.

Vermeulen, S.J., B. Campbell, and J. Ingram, 2012: Climate change and food systems. Annual Review of Environment and Resources, 37, 195-222.

Vitali, A., M. Segnalini, L. Bertocchi, U. Bernabucci, A. Nardone, and N. Lacetera, 2009: Seasonal pattern of mortality and relationships between mortality and temperature-humidity index in dairy cows. Journal of Dairy Science, 92(8), 3781-3790.

von Braun, J. and M. Torero, 2009: Exploring the price spike. Choices, 24, 16-21.

Walker, N.J. and R.E. Schulze, 2008: Climate change impacts on agro-ecosystem sustainability across three climate regions in the maize belt of South Africa. Agriculture, Ecosystems, and Environment, 124, 114-124.

Wall E, A. Wreford, K. Topp, and D. Moran, 2010: Biological and economic consequences heat stress due to a changing climate on UK livestock. Advances in Animal Biosciences, 1(1), 53.

Walter, L., T. Streck, H. Rosa, and C. Kruger, 2010: Climate change and its effects on rice. Ciencia Rural, 40, 2411-2418.

Wang, H.L., Y.T. Gan, R.Y. Wang, J.Y. Niu, H. Zhao, Q.G. Yang, and G.C. Li, 2008: Phenological trends in winter wheat and spring cotton in response to climate changes in northwest China. Agricultural and Forest Meteorology, 148, 12421251.

Wang, M., Y. Li, W. Ye, J. Bornman, and X. Yan, 2011: Effects of climate change on maize production, and potential adaptation measures: a case study in Jilin Province, China. Climate Research, 46, 223-242.

Wang, X., W. Manning, Z. Feng, and Y. Zhu, 2007: Ground-level ozone in China: distribution and effects on crop yields. Environmental Pollution, 147, 394-400.

Wassmann, R., S.V.K. Jagadish, S. Heur, A. Ismail, E. Redona, R. Serraj, R.K. Singh, G. Howell, H. Pathak, and K. Sumfleth, 2009: Climate change affecting rice production: the physiological and agronomic basis for possible adaptation strategies. In:Advances in Agronomy, Vol. 101 [Sparks, D.L. (ed.)]. Elsevier Science and Technology/Academic Press, Waltham, MA, USA, pp. 59-122.

Watson, J. and A. Challinor, 2013: The relative importance of rainfall, temperature and yield data for a regional-scale crop model. Agricultural and Forest Meteorology, 170, 47-57.

Weatherhead, E., S. Gearheard, and R. Barry, 2010: Changes in weather persistence: Insight from Inuit knowledge. Global Environmental Change, 20(3), 523-528. 
Webb, L.B., P.H. Whetton, and E.W.R. Barlow, 2011: Observed trends in winegrape maturity in Australia. Global Change Biology, 17, 2707-2719.

Welch, J.R., J.R. Vincent, M. Auffhammer, P.F. Moya, A. Dobermann, and D. Dawe, 2010: Rice yields in tropical/subtropical Asia exhibit large but opposing sensitivities to minimum and maximum temperatures. Proceedings of the National Academy of Sciences of the United States of America, 107(33), 1456214567, doi:10.1073/pnas.1001222107.

White, A., P. Whalen, and G.V. Jones, 2009: Land and wine. Nature Geoscience, 2(2), 82-84.

Wijeratne, M.A., A. Anandacoomaraswamy, M.K.S.L.D. Amarathunga, J. Ratnasiri, B.R.S.B. Basnayake, and N. Kalra, 2007: Assessment of impact of climate change on productivity of tea (Camellia sinensis L.) plantations in Sri Lanka. Journal of the National Science Foundation of Sri Lanka, 35(2), 119-126.

Wilson, S.K., N.J. Graham, M.S. Pratchett, G.P. Jones, and V.C. Polunin, 2006: Multiple disturbances and the global degradation of coral reefs: are reef fishes at risk or resilient? Global Change Biology, 12, 2220-2234.

Winters P., R. Murgai, E. Sadoulet, A.D. Janvry, and G. Frisvold, 1998: Economic and welfare impacts of climate change on developing countries. Environmental and Resource Economics, 12, 1-24.

Wolfe, D.W., L. Ziska, C. Petzoldt, A. Seaman, L. Chase, and K. Hayhoe, 2008: Projected change in climate thresholds in the Northeastern U.S.: implications for crops, pests, livestock, and farmers. Mitigation and Adaptation Strategies for Global Change, 13, 555-575.

World Bank, 2012: Global Monitoring Report 2012: Food Prices, Nutrition, and the Millenium Development Goals. Global Monitoring Report (GMR) 68171, The World Bank and the International Monetary Fund, The World Bank, Washington, DC, USA, $169 \mathrm{pp}$.

Wratt, D., A.B. Mullan, A. Tait, R. Woods, T. Baisden, D. Giltrap, K. Lock, J. Hendy, Suzi Kerr, A. Stroombergen, and A. Stojanovik, 2008: Costs and Benefits of Climate Change and Adaptation to Climate Change in New Zealand Agriculture: What Do We Know So Far? Contract Report by Integrated Research on the Economics of climate Change Impacts, Adaptation and Mitigation (Ecoclimate Consortium) for the Ministry of Agriculture and Forestry, Wellington, New Zealand, $121 \mathrm{pp}$.

Wright, B.D., 2011: The economics of grain price volatility. Applied Economic Perspectives and Policy, 33(1), 32-58.

Xenopoulus, M.A., D.M. Lodge, J. Alcamo, M. Märker, K. Schulze, and D.P. Van Vuuren, 2005: Scenarios of freshwater fish extinctions from climate change and water withdrawal. Global Change Biology, 11, 1557-1564.

Xiao, G., W. Liu, Q. Xu, Z. Sun, and J. Wang, 2005: Effects of temperature increase and elevated $\mathrm{CO}_{2}$ concentration, with supplemental irrigation, on the yield of rain-fed spring wheat in a semiarid region of China. Agricultural Water Management, 74, 243-255.

Xiong, W., E. Lin, H. Ju, and Y. Xu, 2007: Climate change and critical thresholds in China's food security. Climatic Change, 81, 205-221.

Xiong, W., D. Conway, E. Lin, and I. Holman, 2009: Potential impacts of climate change and climate variability on China's rice yield and production. Climate Research, 40, 23-35.

Yang, L., Y. Wang, G. Dong, H. Gu, J. Huang, J. Zhu, H. Yang, G. Liu, and Y. Han, 2007: The impact of Free-Air $\mathrm{CO}_{2}$ Enrichment (FACE) and nitrogen supply on grain quality of rice. Field Crops Research, 102, 128-140.

Yang, P., W. Wu, Z. Li, Q. Yu, M. Inatsu, Z. Liu, P. Tang, Y. Zha, M. Kimoto, and H. Tang, 2013. Simulated impact of elevated $\mathrm{CO}_{2}$, temperature, and precipitation on the winter wheat yield in the North China Plain. Regional Environmental Change, $14(1), 61-74$.

Yang, X., Z. Liu, and F. Chen, 2013: The possible effect of climate warming on northern limits of cropping system and crop yield in China. Agricultural Sciences in China, 10(4), 585-594.
Yates, D.N. and K.M. Strzepek, 1998: An assessment of integrated climate change impacts on the agricultural economy of Egypt. Climatic Change, 38(3), 261-287.

You, L., M. Rosegrant, S. Wood, and D. Sun, 2009: Impact of growing season temperature on wheat productivity in China. Agricultural and Forest Meteorology, 149, 1009-1014.

Zezza, A., B. Davis, C. Azzarri, K. Covarrubias, L. Tasciotti, and G. Angriquez, 2008: The Impact of Rising Food Prices on the Poor. ESA Working Paper 08-07, Agricultural Development Economics Division (ESA) of the Food and Agricultural Organization of the United Nations (FAO), Rome, Italy, $37 \mathrm{pp}$.

Zhang, X. and X. Cai, 2011: Climate change impacts on global agricultural land availability. Environmental Research Letters, 6, 014014, doi:10.1088/17489326/6/1/014014.

Zhang, X.-C. and W.Z. Liu, 2005: Simulating potential response of hydrology, soil erosion, and crop productivity to climate change in Changwu tableland region on the Loess Plateau of China. Agricultural and Forest Meteorology, 131(3-4), 127-142.

Zhang, T., J. Zhu, X. Yang, and X. Zhang, 2008: Correlation changes between rice yields in North and Northwest China and ENSO from 1960 to 2004. Agricultural and Forest Meteorology, 148, 1021-1033.

Zhang, T., J. Zhu, and R. Wassmann, 2010: Responses of rice yields to recent climate change in China: an empirical assessment based on long-term observations at different spatial scales (1981-2005). Agricultural and Forest Meteorology, 150, 1128-1137.

Zhao, Y., C. Wang, S. Wang, and L.V. Tibig, 2005: Impacts of present and future climate variability on agriculture and forestry in the humid and sub-humid tropics. Climatic Change, 70, 73-116.

Zhu, T., C. Ringler, M.M. Iqbal, T.B. Sulser, and M.A. Goheer, 2013: Climate change impacts and adaptation options for water and food in Pakistan: scenario analysis using integrated global water and food production model. Water International, 38(5), 651-669.

Ziska, L.H., 2010: Global climate change and carbon dioxide: assessing weed biology and management. In: Handbook of Climate Change and Agro-Ecosystems: Impacts, Adaptation and Mitigation [Rosenzweig, C. and D. Hillel (eds.)]. World Scientific Publishing, Hackensack, NJ, USA, pp. 191-208.

Ziska, L.H. and E.W. Goins, 2006: Elevated atmospheric carbon dioxide and weed populations in glyphosate treated soybean. Crop Science, 46, 1354-1359.

Ziska, L.H., D. Blumenthal, G. Runion, E. Hunt, and H. Diaz-Soltero, 2011: Invasive species and climate change: an agronomic perspective. Climatic Change, 105(1-2), 13-42.

Ziska, L.H., J.A. Bunce, H. Shimono, D.R. Gealy, J.T. Baker, P.C.D. Newton, M.P. Reynolds, K.S.V. Jagadish, C. Zhu, M. Howden, and L.T. Wilson, 2012: Food security and climate change: on the potential to adapt global crop production by active selection to rising atmospheric carbon dioxide. Proceedings of the Royal Society B, 279, 4097-4105.

Zougmoré, R., A. Mando, and L. Stroosnijder, 2010: Benefits of integrated soil fertility and water management in semi-arid West Africa: an example study in Burkina Faso. Nutrient Cycling in Agroecosystems, 18, 17-27.

Zumbach, B., I. Misztal, S. Tsuruta, J.P. Sanchez, M. Azain, W. Herring, J. Holl, T. Long, and M. Culbertson, 2008: Genetic components of heat stress in finishing pigs: Development of a heat load function. Journal of Animal Science, 86(9), 20822088.

Zwiers, F.W., X. Zhang, and Y. Feng, 2011: Anthropogenic influence on long return period daily temperature extremes at regional scales. Journal of Climate, 24(3), 881-892. 